Federal Reserve Bank of Minneapolis

Research Department Staff Report 498

May 2014

\title{
Intergenerational Redistribution in the Great Recession*
}

\author{
Andrew Glover \\ University of Texas, Austin \\ Jonathan Heathcote \\ Federal Reserve Bank of Minneapolis and CEPR \\ Dirk Krueger \\ University of Pennsylvania, NBER, and CEPR \\ José-Víctor Ríos-Rull \\ University of Minnesota, \\ Federal Reserve Bank of Minneapolis, \\ NBER, CEPR, and CAERP
}

\begin{abstract}
We construct a stochastic overlapping-generations general equilibrium model in which households are subject to aggregate shocks that affect both wages and asset prices. We use a calibrated version of the model to quantify how the welfare costs of big recessions are distributed across different household age groups. The model predicts that younger cohorts fare better than older cohorts when the equilibrium decline in asset prices is large relative to the decline in wages. Asset price declines hurt the old, who rely on asset sales to finance consumption, but benefit the young, who purchase assets at depressed prices. In our preferred calibration, asset prices decline 2.4 times as much as wages, consistent with the experience of the US economy in the Great Recession. A model recession is close to welfare neutral for households in the 20-29 age group, but translates into a large welfare loss of more than $8 \%$ of lifetime consumption for households aged 70 and over.
\end{abstract}

Keywords: Great Recession; Overlapping generations; Asset prices; Aggregate risk JEL classification: E21, D31, D58, D91

\footnotetext{
*Glover: andrew.glover@austin.utexas.edu; Heathcote: heathcote@minneapolisfed.org; Krueger: dkrueger@econ.upenn. edu; Rios-Rull: vr0j@umn.edu. We thank participants at the Wharton Macro Lunch, the AEA Meetings in Atlanta and Denver, the 2011 EFG Meetings in New York, the Progressive Economics Conference at the Federal Reserve Bank of Richmond, the NBER Summer Institute, the Nordic Summer Symposium in Macroeconomics, German Economics Christmas Meeting, 32 ${ }^{\circ}$ Encontro Brasileiro de Econometria, ASU, Autonoma de Barcelona, Banco de Portugal, Duke, ECB, Sveriges Riksbank, Banca d’Italia, CEMFI, Chicago, Columbia, UC Davis, Hannover, LBS, Miami, NYU, UCL and LSE, and our discussants David Andolfatto, Larry Jones, Gianluca Violante, and Martin Schneider for helpful comments, as well as the National Science Foundation for financial support. The views expressed herein are those of the authors and not necessarily those of the Federal Reserve Bank of Minneapolis or the Federal Reserve System.
} 


\section{Introduction}

The Great Recession was the largest contraction in the United States since the Great Depression. Aggregate output and household incomes fell (and remain) significantly below trend, and the prices of real estate and stocks plummeted. The goal of this paper is to explore the welfare consequences of a severe and long-lasting recession that features a sharp decline in labor earnings and a collapse in asset prices. Our main objective is to study how the welfare costs of such recessions vary across different age groups.

There are good reasons to believe that the welfare effects of large aggregate shocks are unevenly distributed across different generations. Young households have little financial wealth, relative to their labor income, while older households are asset rich but have little human wealth, measured as the present discounted value of future labor income. In addition, young households who buy assets at depressed prices gain from future asset price appreciation, while older households close to the end of the life cycle cannot wait for prices to recover. Thus, a steep fall in asset prices likely has more serious welfare implications for older households.

In the next section, we use data from the Survey of Consumer Finances to document how labor income and net worth vary over the life cycle. We will confirm that older households indeed hold the vast majority of real and financial assets, whereas the young are financial wealth poor but human wealth rich. The same SCF data are then used to estimate the net worth losses associated with the decline in asset prices during the Great Recession, again focusing on how these losses vary with household age. To do so, we decompose net worth into different asset and liability classes, and impute losses by applying asset-class-specific price deflators to age-group-specific portfolios. We find that the average household experienced a decline in net worth of $\$ 140,000$ between the middle of 2007 and the middle of 2010 . These losses were heavily concentrated among older age groups: households aged 60-69 lost $\$ 245,000$ on average.

These empirical facts suggest that the welfare losses from large economic downturns are unevenly distributed across different age groups in the population. However, a more complete welfare analysis requires forecasts for the future evolution of labor income and asset prices, and an understanding of how agents will optimally adjust savings and portfolio choice behavior in response to expected future wage and price changes. In the remainder of the paper, we therefore construct a stochastic general equilibrium model with overlapping generations and large aggregate shocks that affect both wages and endogenous asset prices. We use a version of the model calibrated to aggregate and micro data in 2007 to assess the distributional consequences of severe recessions. 
One question of particular interest that we can ask within the context of this model is whether young people are conceivably better off by becoming economically active in the midst of a large recession rather than in normal times.

The answers to these distributional questions crucially depend on the size of the decline in equilibrium asset prices, relative to the decline in income, in response to a negative aggregate shock. In the model, if middle-aged households have a strong incentive to sell their assets in the downturn (e.g., because they strongly value smooth consumption profiles), then asset prices decline more strongly than income in equilibrium. This in turn benefits younger generations who buy these assets at low prices, potentially compensating them for the fall in earnings they experience. At the same time, we will present empirical evidence that younger households experience disproportionately large earnings losses in recessions, an observation that will ensure holds true in our quantitative model as well. Thus, the overall allocation of welfare losses from a recession depends crucially on the quantitative importance of age differences in exposure to asset price risk, relative to age differences in the direct effect of recessions on labor income.

In our preferred calibration, we find that for the age distribution of welfare losses, the asset price effect dominates, in that deep recessions like the Great Recession are associated with massive welfare losses for older households and much smaller losses (less that $2 \%$ of lifetime consumption) for the young. In alternative versions of the model that either abstract from age variation in earnings losses or feature larger equilibrium asset price movements (induced by a lower intertemporal elasticity of substitution), the youngest age group actually enjoys higher lifetime utility if it becomes economically active during a severe recession. Another finding of interest is that the model rationalizes the age variation in portfolio composition observed in the SCF: older households endogenously hold relatively safe portfolios precisely because they are relatively rich and thus relatively exposed to asset price fluctuations.

Our paper builds on and contributes to three broad strands of the literature. First, we use a large-scale overlapping generations (OLG) model with endogenous portfolio choice to study the implications of aggregate shocks for asset pricing and intergenerational redistribution. The literature that analyzes asset prices and portfolio choice in stochastic OLG economies includes Labadie (1986), Huffman (1987), Ríos-Rull (1994), Storesletten, Telmer, and Yaron (2004, 2007), Constantinides, Donaldson, and Mehra (2002), and Kubler and Schmedders (2013). Ríos-Rull (1996) investigates the properties of business cycles in this class of models, while Ball and Mankiw (2007), Smetters (2006), Krueger and Kubler (2004, 2006), Miyazaki, Saito, and Yamada (2009), and Campbell and Nosbusch (2007) analyze the allocation of aggregate consumption risk across 
different generations.

Second, while we focus on the impact of shocks to aggregate output, a number of related papers study the distributional consequences across age cohorts of other types of large economywide shocks. ${ }^{1}$ Our analysis is similar in spirit to the study of Doepke and Schneider $(2006 a, b)$ that focuses on the inflationary episode of the 1970s and, to a lesser extent, to the study of Meh, Ríos-Rull, and Terajima (2010). A number of studies employ OLG models to investigate the impact of large swings in the demographic structure of the population on factor and asset prices, as well as on the welfare of different age cohorts. Examples include Attanasio, Kitao, and Violante (2007), Krueger and Ludwig (2007), and Ríos-Rull (2001).

Finally, a recent literature estimates empirical models of aggregate consumption that allow for large declines in aggregate consumption (so-called disasters) and uses these estimates in consumption based asset pricing models. See, for example, Barro $(2006,2009)$, and Nakamura, Steinsson, Barro, and Ursua (2013). ${ }^{2}$

The remainder of this paper is organized as follows. In Section 2 we present life-cycle facts on labor income, net worth, and portfolio allocations that motivate our quantitative analysis and are used later to calibrate the model. In Section 3 we set up our model and define a recursive competitive equilibrium. In Section 4 we analyze a sequence of simple examples that can be characterized analytically and that provide important insights into the key mechanism of the model. Section 5 is devoted to the calibration of the model, and Section 6 reports the results from our thought experiment. In Section 7 we discuss the robustness of our findings to alternative parameterizations and modeling assumptions. Section 8 concludes. Details about the computational approach, proofs, and additional theoretical results are relegated to the Appendix.

\section{Data}

In this section we document the life-cycle profiles for labor income, net worth, and portfolio composition that motivate our focus on heterogeneity along the age dimension and will serve as inputs for the calibration of the model. The need for detailed data on household portfolios leads us to use

\footnotetext{
${ }^{1}$ Hur (2013) and Peterman and Sommer (2014) follow our paper and also study the distributional consequences of the Great Recession in life-cycle models, but focus, respectively, on the roles of borrowing constraints and social security for the distribution of welfare losses.

2 The latter paper finds that (on average) disasters are significantly mean reverting, last for six years, and entail long-run consumption declines of $15 \%$. Our calibration will imply a consumption process broadly consistent with these findings, although our disaster lasts slightly longer and is less severe.
} 
the Survey of Consumer Finances (SCF). The SCF is the best source of micro data on the assets and debts of US households. ${ }^{3}$ The survey is conducted every three years, with the two most recent regular surveys conducted in 2007 and 2010. The 2007 survey captures the pre-recession peak in asset prices, while the 2010 survey offers a snapshot of the economy in the aftermath of the Great Recession.

We use the 2007 SCF survey to construct life-cycle profiles for labor income, total income, assets, debts, and net worth in the pre-recession state (see Table 1). These profiles are constructed by averaging (using sample weights) across households partitioned into 10-year age groups. We divide total income into an asset-type income component and a residual non-asset-income component that we call labor income. ${ }^{4}$ We measure net worth as the value of all financial and nonfinancial assets, less the value of all liabilities. Our SCF-based measure of net worth excludes the present value of future pensions associated with defined benefit private pension plans and social security.

In 2007 average household income in the SCF was $\$ 83,430$, while average household net worth was $\$ 555,660$, for a net worth to income ratio of $6.66 .{ }^{5}$ Average household assets amounted to $\$ 659,000$, with an average rate of return of $3.1 \%$. Average household debts came to $\$ 103,300$, with an average interest rate on debts of $6.4 \%$. The share of net asset income in total income was 0.16. Young households had negative net asset income, despite having positive net worth, reflecting the higher average interest rate paid on debts relative to the rate earned on assets.

Income follows the familiar hump shape over the life cycle, while net worth peaks somewhat later. ${ }^{6}$ For 20 - to 29 -year-olds, average net worth is 1.9 times average labor income, while for households aged 70 and older, the corresponding ratio is 21.1. Thus, the old are much more exposed to fluctuations in asset prices than the young. We will ensure, by force of calibration, that

\footnotetext{
${ }^{3}$ One advantage of the survey is that it oversamples wealthy households, using a list based on IRS data. Because the SCF weighting scheme adjusts for higher nonresponse rates among wealthier households, it delivers higher estimates for average income than other household surveys, such as the Current Population Survey (CPS) or the Panel Study of Income Dynamics (PSID).

${ }^{4}$ Asset income is defined as interest or dividend income (minus interest payment on debts), income from capital gains and asset sales, one-third of business, farm, or self-employment income, private retirement income, and an imputation for rents from owner-occupied housing. We set these imputed rents equal to the value of primary residence times the rate of return on all other assets. This rate of return is computed as asset income (excluding imputed rents) divided by aggregate assets (excluding the value of primary residences and the value of vehicles).

Non-asset income is all other income, which includes wage and salary income, two-thirds of business, farm, or self-employment income, social security income, and a variety of public and private transfers.

${ }^{5}$ Since income questions refer to the previous calendar year, while questions about wealth are contemporaneous, we adjust income measures for CPI inflation between 2006 and 2007.

${ }^{6}$ Figure 3 in Section 5 plots the life-cycle profiles for labor income and net worth, alongside the implied profile for consumption.
} 
Table 1: Income and Wealth Over the Life Cycle $(2007$ SCF, \$1,000)

\begin{tabular}{crrrrrr}
\hline \hline Age of Head & $\begin{array}{r}\text { Total } \\
\text { Income }\end{array}$ & $\begin{array}{r}\text { Labor } \\
\text { Income }\end{array}$ & $\begin{array}{r}\text { Asset } \\
\text { Income }\end{array}$ & Assets & Debts & Net Worth \\
\hline All & 83.43 & 70.07 & 13.36 & 659.00 & 103.34 & 555.66 \\
& & & & & & \\
$20-29$ & 38.83 & 39.68 & -0.85 & 130.66 & 53.30 & 77.36 \\
$30-39$ & 69.83 & 68.68 & 1.15 & 335.87 & 136.12 & 199.75 \\
$40-49$ & 93.40 & 84.97 & 8.43 & 598.21 & 132.62 & 465.59 \\
$50-59$ & 117.97 & 99.56 & 18.41 & 959.77 & 133.24 & 826.53 \\
$60-69$ & 109.06 & 76.15 & 32.90 & 1156.96 & 104.10 & 1052.86 \\
$70+$ & 57.56 & 34.46 & 23.11 & 756.76 & 28.48 & 728.28 \\
\hline \hline
\end{tabular}

the life-cycle patterns of labor income and net worth in our structural OLG model are identical to the empirical profiles documented here.

While Table 1 suggests large losses for older households from a slump in asset prices, the risk composition of net worth also varies quite substantially with age. To accurately estimate losses by age group, we therefore further decompose portfolios by age group and examine the patterns for relative price changes across different asset classes. In Table 2 we decompose total net worth into risky net worth and safe net worth, where we define risky net worth as the value of stocks, residential real estate, noncorporate business, and nonresidential property. We define safe net worth as the value of all other assets, less all debts. ${ }^{7}$ In aggregate, risky net worth is 93.9 of aggregate net worth. However, among 30- to 39-year-olds, the corresponding ratio is $140.4 \%$, while among those aged 70 or older, it is only $79.2 \%$. These three ratios reflect three facts: (i) in aggregate, net household holdings of safe assets are very small, (ii) younger households are short in safe assets, because they tend to have substantial mortgage debt (which we classify as a riskless liability) and only small holdings of financial assets, and (iii) older households tend to have little debt and lots of assets, including a significant position in riskless financial assets.

The distributions of net worth (Table 1 ) and its risky versus safe components (Table 2) jointly determine the direct allocation of capital losses across age groups when asset prices fell sharply during the Great Recession. We now estimate these capital losses using aggregate asset-class-

\footnotetext{
${ }^{7}$ For our purposes, stocks include stocks held directly or indirectly through mutual funds and retirement accounts and also includes closely held equity. The category "Bonds + CDs" includes bonds (directly or indirectly held), cash, transaction accounts, CDs, and the cash value of life insurance.
} 
Table 2: Portfolio Shares as a Percentage of Net Worth (2007 SCF)

\begin{tabular}{ccccccccccc}
\hline \hline $\begin{array}{c}\text { Age of } \\
\text { Head }\end{array}$ & $\begin{array}{c}(1) \\
\text { Stocks }\end{array}$ & $\begin{array}{c}(2) \\
\text { Res. real } \\
\text { estate }\end{array}$ & $\begin{array}{c}\text { Noncorp. } \\
\text { bus. }\end{array}$ & $\begin{array}{c}\text { Nonres. } \\
\text { prop. }\end{array}$ & $\begin{array}{c}(5) \\
\text { Risky } \\
\text { NW }\end{array}$ & $\begin{array}{c}(6) \\
\text { Bonds } \\
+ \text { CDs }\end{array}$ & $\begin{array}{c}(7) \\
\text { Cars }\end{array}$ & $\begin{array}{c}(8) \\
\text { Other } \\
\text { assets }\end{array}$ & $\begin{array}{c}(9) \\
\text { Debts }\end{array}$ & $\begin{array}{c}(10) \\
\text { Safe } \\
\text { NW }\end{array}$ \\
\hline All & 30.28 & 46.99 & 12.87 & 3.80 & 93.95 & 16.98 & 3.45 & 4.23 & -18.60 & 6.05 \\
$30-39$ & 13.20 & 77.67 & 43.31 & 1.28 & 135.46 & 13.66 & 15.26 & 4.51 & -68.90 & -35.46 \\
$40-49$ & 26.27 & 96.47 & 12.73 & 4.97 & 140.44 & 13.80 & 9.73 & 4.19 & -68.15 & -40.44 \\
$50-59$ & 32.41 & 57.62 & 12.55 & 3.81 & 104.38 & 15.17 & 4.44 & 4.49 & -28.48 & -4.38 \\
$60-69$ & 32.17 & 32.40 & 13.53 & 3.72 & 92.35 & 17.02 & 2.79 & 3.96 & -16.12 & 7.65 \\
$70+$ & 27.12 & 39.76 & 13.41 & 4.12 & 85.31 & 17.45 & 2.40 & 4.73 & -9.89 & 14.69 \\
\hline \hline
\end{tabular}

Risky Net Worth (5) is equal to the sum of columns $(1)+(2)+(3)+(4)$. Safe Net Worth (10) is the sum of columns $(6)+(7)+(8)+(9)$. Total Net Worth is the sum of columns $(5)+(10)$.

specific price series to revalue age-group-specific portfolios. ${ }^{8}$

We assume that 2007 SCF portfolios reflect the distribution of household net worth in the second quarter of 2007. We then revalue portfolios for each age group, and for each successive quarter, as follows. For all the components of safe net worth (bonds, vehicles, other assets, and debts), we assume no price changes. We price stock wealth using the Wilshire 5000 price index, as of the last trading day in the quarter. We price residential real estate using the Case-Shiller National Home Price Index, which is a quarterly repeat-sales-based index. We price nonresidential property using the Moody's/REAL Commercial Property Price Index, which is a monthly repeat-sales-based index for the prices of apartments, industrial property, commercial property, and retail property. We price non-corporate business wealth using Flow of Funds data. ${ }^{9}$ For stocks and residential property, values reached a low point in the first quarter of 2009 , with prices respectively $46.9 \%$ and $29.5 \%$ below their 2007:2 values. The values of noncorporate business and nonresidential property, by contrast, continued to decline through 2009 and were flat through $2010 .^{10}$

\footnotetext{
${ }^{8}$ We have also investigated the age distribution for net worth in the 2010 SCF. As expected, given the differences in the shares of risky assets described above, the share of net worth held by households aged 20-39 declined, while the share held by households aged 60 and older increased. However, when we compare households in cross section, it is impossible to disentangle the direct effect of asset price declines from the endogenous effects of changes in saving rates in response to those capital losses. Our revaluation exercise allows us to isolate the first effect. When we later simulate our structural model, endogenous behavioral responses to the shock will play an important role in shaping the distribution of welfare losses.

${ }^{9}$ In particular, the Flow of Funds reports changes in market values for a variety of asset types by sector. We focus on the asset type "proprietors' investment in unincorporated business" for the household and nonprofit sector.

${ }^{10}$ Time series for price changes by asset type relative to 2007:2 are reported in Table A-4 in Appendix G.
} 
We apply these price changes to the life-cycle profiles for aggregate net worth and its decomposition as outlined in Tables 1 and 2. We focus on a comparison between 2007:2 and 2010:2 for two reasons. First, Hall (2014) argues that 2010 is a natural recession end date with respect to the dynamics of labor markets. Second, focusing on a mid-2010 end date means that we emphasize the impact of persistent asset price declines, rather than the impact of sharp but relatively transitory declines in stock prices in late 2008 and early 2009. Our calibration exercise in Section 5 will also revolve around thinking of 2007 as the normal pre-recession state and 2010 as the post-recession state. In the first set of columns in Table 3, we report nominal dollar losses across our risky asset types. We then report total dollar losses and total losses as fractions of 2007 age-group-specific net worth and total income.

The average household saw a price-change-induced decline in net worth of $\$ 140,000$ between $2007: 2$ and $2010: 2$, which amounted to $25.3 \%$ of $2007: 2$ average net worth or $168 \%$ of 2007 average annual income. Almost half of this total decline was driven by a decline in house prices and a slightly smaller amount by a decline in stock prices. ${ }^{11}$

Losses varied widely by age. Younger households lost much less, while those in the 60-69 age group lost the most: $\$ 245,000$ on average, or more than twice the average annual income for this age group. At the same time, differences in portfolio composition were large enough to generate substantial age variation in returns. In particular, because younger households were more leveraged, they lost more as a percentage of their net worth: 30- to 39-year-olds lost 37\% of net worth, while households older than 70 lost only $21 \%$. In other words, absent age variation in portfolios, the losses experienced by younger households would have been smaller, and those experienced by older households would have been even larger.

\section{The Model}

The facts documented above guide our modeling choices. First, the substantial heterogeneity by household age in labor income and net worth translates into age-varying exposure to aggregate wage and asset price risk. Thus, a satisfactory quantitative analysis requires an overlapping-generations life-cycle model with aggregate shocks. Our general equilibrium approach in which asset prices respond endogenously to aggregate output fluctuations provides a theoretical link between the dynamics of income, consumption, and savings on the one hand and asset prices on the other.

\footnotetext{
${ }^{11}$ Portfolio-weighted asset values reached a trough in 2009:Q1, 31.7\% below their 2007:Q2 value. Since 2010, asset prices and net worth have further recovered, though real estate prices remain far below their 2007 values.
} 
Table 3: Estimated Losses by Age Group from 2007:2 to 2010:2

\begin{tabular}{|c|c|c|c|c|c|c|c|}
\hline \multirow[b]{2}{*}{$\begin{array}{l}\text { Age of } \\
\text { Head }\end{array}$} & \multicolumn{5}{|c|}{ Dollar Losses $(\$ 1,000)$} & \multicolumn{2}{|c|}{ Losses as $\%$ of } \\
\hline & Stocks & $\begin{array}{c}\text { Res. real } \\
\text { estate }\end{array}$ & $\begin{array}{c}\text { Noncorp. } \\
\text { bus. }\end{array}$ & $\begin{array}{c}\text { Nonres. } \\
\text { prop. }\end{array}$ & $\begin{array}{l}\text { Total } \\
\text { Losses }\end{array}$ & $\begin{array}{c}\text { Net } \\
\text { Worth }\end{array}$ & Income \\
\hline All & 50.03 & 64.07 & 17.90 & 8.42 & 140.41 & 25.3 & 168.3 \\
\hline $20-29$ & 3.04 & 14.74 & 8.38 & 0.40 & 26.55 & 34.3 & 68.4 \\
\hline 30-39 & 15.60 & 47.28 & 6.36 & 3.96 & 73.20 & 36.6 & 104.8 \\
\hline $40-49$ & 42.10 & 65.82 & 14.61 & 7.08 & 129.61 & 27.8 & 138.8 \\
\hline $50-59$ & 80.37 & 85.98 & 27.97 & 12.27 & 206.59 & 25.0 & 175.1 \\
\hline $60-69$ & 100.69 & 92.00 & 35.31 & 17.32 & 245.32 & 23.3 & 224.9 \\
\hline $70+$ & 58.72 & 71.04 & 16.36 & 9.67 & 155.79 & 21.4 & 270.6 \\
\hline
\end{tabular}

Second, empirical portfolio allocations between risky and riskless assets display significant age heterogeneity, which translates into age variation in the sensitivity of net worth to aggregate shocks. This motivates us to consider models with both risky and safe assets.

Third, the direct effect of recessions on labor income varies across age groups, largely reflecting the fact that younger workers are disproportionately likely to become unemployed. ${ }^{12}$ This fact leads us to explore a model specification in which recessions change not only the level of the age-earnings profile, but its shape as well (see Section 6.1.2).

\subsection{Stochastic Structure}

Aggregate fluctuations in the model are driven by shocks to aggregate productivity $z$, where $z$ has finite support $Z$ and evolves over time according to a Markov chain with transition matrix $\Gamma_{z, z^{\prime}}$.

\subsection{Technology}

A representative firm operates a Cobb-Douglas technology that takes as inputs a fixed factor $K$ and labor $L$, and produces as output a nonstorable consumption good $Y$. The firm's total factor productivity (TFP) varies with the aggregate productivity shock. Thus,

$$
Y=z K^{\theta} L^{1-\theta}
$$

where $\theta \in(0,1)$ is capital's share of output. We normalize $K=1$.

\footnotetext{
${ }^{12}$ In Section 6.1.2 we will document the extent of age variation in labor income declines in the Great Recession.
} 
One interpretation of our assumption that capital $K$ is in fixed supply is that $K$ stands in for nonreproducible land or intangible capital. By making the stock of capital fixed, any changes in the demand for assets (i.e., claims to the returns to capital) must translate into movements in asset prices rather than changes in the quantity of capital. This property is important given our focus on the welfare effects of great recessions that are accompanied by large asset price declines. In the standard frictionless business cycle model, by contrast, capital and consumption are the same good, and thus this model cannot generate any movements in the relative price of capital.

\subsection{Endowments}

Households live for I periods and then die with certainty. Thus, the economy is populated by I distinct age cohorts at any point in time. Each age cohort is composed of identical households. In each period of their lives, households are endowed with one unit of time, which they supply to the market inelastically. Their age- and aggregate-shock-dependent labor productivity profile is given by $\left\{\varepsilon_{i}(z)\right\}_{i=1}^{\prime}$. Indexing the productivity profile to the aggregate shock will allow us to capture heterogeneity across age groups in the impact of economic downturns on labor income. We normalize units so that $\sum_{i=1}^{l} \varepsilon_{i}(z)=1$ for all $z \in Z$. Thus, the aggregate supply of labor is constant and equal to $L=1$ at all times. This normalization also implies that aggregate output is given by $Y(z)=z$ for all $z \in Z$.

Labor markets are competitive, and therefore the economy-wide wage per labor efficiency unit supplied is equal to the marginal product of labor from the production technology:

$$
w(z)=(1-\theta) z
$$

Note that because the aggregate supplies of capital and labor are exogenous, and the labor share of income is constant, fluctuations in $z$ need not be interpreted simply as neutral shocks to multifactor productivity: they could equally well capture fluctuations in capital or labor productivity, or capital or labor utilization rates. Thus, our model is consistent with a range of alternative theories regarding the fundamental sources of business cycles. 


\subsection{Preferences}

Households have standard time-separable preferences over stochastic consumption streams $\left\{c_{i}\right\}_{i=1}^{l}$ that can be represented by

$$
E\left[\sum_{i=1}^{I} \prod_{j=1}^{i} \beta_{j} u\left(c_{i}\right)\right],
$$

where $\beta_{i}$ is the time discount factor between age $i-1$ and $i$ (we normalize $\beta_{1}=1$ ). Age variation in the discount factor stands in for unmodeled changes in family size and composition, age-specific mortality risk, and any other factors that generate age variation in the marginal utility of consumption. We will calibrate the profile $\left\{\beta_{i}\right\}_{i=1}^{\prime}$ so that our economy replicates the life-cycle profile for net worth documented in SCF data in Section 2.

Expectations $E($.$) are taken with respect to the underlying stochastic process governing aggre-$ gate risk. Finally, the period utility function is of the constant relative risk aversion form

$$
u(c)=\frac{c^{1-\sigma}-1}{1-\sigma},
$$

where the parameter $\sigma$ is the inverse of the intertemporal elasticity of substitution, and $\sigma=1$ corresponds to log-utility.

\subsection{Financial Markets}

Agents trade financial assets to transfer resources over time. We consider two alternative market structures that differ in the set of assets that can be traded. In the first market structure, which we will treat as our benchmark economy, households can trade both a risk-free bond and leveraged risky equity, and portfolio choice is endogenous. Denote by $\lambda_{i}$ the share of savings allocated by a household of age $i$ to the stock. We will first investigate whether the model can rationalize observed portfolio choices over the life cycle, and then document how the ability of different generations to trade risk affects equilibrium prices and the distribution of welfare losses from an adverse aggregate shock. Note that if the aggregate shock $z$ can only take two values (the case we will consider in our quantitative experiments below), then the economy with endogenous portfolio choice is equivalent to an economy in which a full set of Arrow securities is traded. We define an equilibrium for such an economy in Appendix A, and in Appendix B we describe how we exploit this equivalence in the numerical methods we use to characterize equilibrium allocations. 
The second market structure also features two assets and an endogenous consumption-savings choice. However, the allocations $\left\{\lambda_{i}\right\}$ of household savings across the two assets are treated as exogenous parameters and calibrated to replicate the portfolio composition across risky and riskless assets by age, as observed in the SCF. Thus, households in this model can effectively save in one mutual fund at each age, where the stock versus bond mix in the fund is age varying. We will use this version of our model as a tool for calibrating all model parameters, and as a vehicle for assessing the quantitative importance of getting the age variation in portfolio shares right (relative to the data) for our asset pricing and welfare results.

The two economies with exogenous and endogenous portfolios differ only with respect to whether the division of household savings between stocks and bonds is specified exogenously or chosen optimally. We will therefore define a recursive competitive equilibrium only once, focusing on the most general model: the economy with endogenous portfolios. Finally, note that while agents can insure against life-cycle shocks in the endogenous portfolios economy, they cannot buy insurance ex ante against the date and state in which they become economically active. Thus, aggregate shocks will redistribute between existing and newly active households.

We will now present a recursive definition of competitive equilibrium. The aggregate state of the economy is described by the current aggregate shock $z$ and the cross-sectional distribution $A=\left(A_{1}, \ldots, A_{l}\right)$ of shares of beginning of the period total wealth, where $\sum_{i=1}^{l} A_{i}=1$. Newborn households enter the economy with zero initial wealth, so that $A_{1}=0$. Individual state variables include a household's age $i$ and its individual share of wealth, denoted by $a$.

The representative firm issues a constant quantity $B$ of risk-free real bonds at a price $q(z, A)$ per unit. Each bond is a promise to pay one unit of the consumption good in the next period. We treat the supply of debt $B$ as an exogenous time- and state-invariant parameter of the model. Dividends for the representative firm $d(z, A)$ are then given by aggregate capital income $\theta z$ plus revenue from debt issuance $q(z, A) B$ less debt repayment $B$ :

$$
d(z, A)=\theta z-[1-q(z, A)] B .
$$

Note that returns to equity are risky, while the return to debt is safe and given by the reciprocal of the bond price. The supply of debt $B$ determines the level of leverage in the economy: the higher is $B$, the more leveraged and risky are stocks. Let $p(z, A)$ denote the ex-dividend price of equity. The aggregate value of start of period wealth is the value of aggregate payments to asset 
holders in the period, plus the ex-dividend value of equity:

$$
\begin{aligned}
W(z, A) & =p(z, A)+d(z, A)+B \\
& =p(z, A)+\theta z+q(z, A) B
\end{aligned}
$$

where the second equality follows from the expression for dividends in equation (1).

\subsection{Household Problem}

Let $y_{i}(z, A, a)$ and $\lambda_{i}(z, A, a)$ denote the optimal household policy functions for total savings and for the fraction of savings invested in leveraged equity. Let $c_{i}(z, A, a)$ and $a_{i}^{\prime}\left(z, A, a, z^{\prime}\right)$ denote the associated policy functions for consumption and for shares of next period wealth. The dynamic programming problem of the household reads as

$$
\begin{aligned}
v_{i}(z, A, a)=\max _{c, y, \lambda, a^{\prime}}\left\{u(c)+\beta_{i+1} \sum_{z^{\prime} \in Z} \Gamma_{z, z^{\prime}} v_{i+1}\left(z^{\prime}, A^{\prime}\left(z^{\prime}\right), a^{\prime}\left(z^{\prime}\right)\right)\right\} \quad \text { s.t. } \\
c+y=\varepsilon_{i}(z) w(z)+W(z, A) a \\
a^{\prime}=\frac{\left(\lambda \frac{\left[p\left(z^{\prime}, A^{\prime}\right)+d\left(z^{\prime}, A^{\prime}\right)\right]}{p(z, A)}+(1-\lambda) \frac{1}{q(z, A)}\right) y}{W\left(z^{\prime}, A^{\prime}\right)} \\
A^{\prime}=G\left(z, A, z^{\prime}\right) .
\end{aligned}
$$

The first constraint (3) is the household's budget constraint: consumption plus savings must equal labor earnings plus the household's share of start of period wealth. ${ }^{13}$ The second constraint (4) is the law of motion for the household's share of individual wealth. This constraint merits some additional explanation. Savings in equity are given by $\lambda y$, and the gross return on these savings is given by $\left[p\left(z^{\prime}, A^{\prime}\right)+d\left(z^{\prime}, A^{\prime}\right)\right] / p(z, A)$. Savings in bonds are given by $(1-\lambda) y$, and the gross return on these savings is $1 / q(z, A)$. Thus, the numerator on the right-hand side of equation (4) is the gross value of the household portfolio at the beginning of next period. The household's share of next period wealth is this value divided by aggregate next period wealth, the denominator on the right-hand side of (4). The third constraint is the law of motion for the wealth distribution, which allows agents to forecast future prices, contingent on the sequence for future productivity.

\footnotetext{
${ }^{13}$ Households face the additional constraints that consumption must be nonnegative, and savings at age $I$ must be non-negative.
} 
Let $G_{i}\left(z, A, z^{\prime}\right)$ denote the forecast for the share of next period wealth owned by age group $i$.

Definition 1. A recursive competitive equilibrium is a value function and policy functions for each age, $v_{i}(z, A, a), c_{i}(z, A, a), y_{i}(z, A, a), a_{i}^{\prime}\left(z, A, a, z^{\prime}\right), \lambda_{i}(z, A, a)$, pricing functions $w(z), d(z, A)$, $p(z, A), q(z, A)$, and an aggregate law of motion $G\left(z, A, z^{\prime}\right)$ such that:

1. Given the pricing functions and the aggregate law of motion, the value functions $\left\{v_{i}\right\}$ solve the recursive problem of the households, and $\left\{c_{i}, y_{i}, a_{i}^{\prime}, \lambda_{i}\right\}$ are the associated policy functions.

2. Wages and dividends satisfy

$$
w(z)=(1-\theta) z \quad \text { and } \quad d(z, A)=\theta z-[1-q(z, A)] B .
$$

3. Markets clear

$$
\begin{aligned}
\sum_{i=1}^{I} c_{i}\left(z, A, A_{i}\right) & =z \\
\sum_{i=1}^{I} \lambda_{i}\left(z, A, A_{i}\right) y_{i}\left(z, A, A_{i}\right) & =p(z, A) \\
\sum_{i=1}^{I}\left[1-\lambda_{i}\left(z, A, A_{i}\right)\right] y_{i}\left(z, A, A_{i}\right) & =B q(z, A) .
\end{aligned}
$$

4. The law of motion for the distribution of wealth is consistent with equilibrium decision rules

$$
\begin{aligned}
G_{1}\left(z, A, z^{\prime}\right) & =0 \quad \forall z^{\prime} \\
G_{i+1}\left(z, A, z^{\prime}\right) & =a_{i}^{\prime}\left(z, A, A_{i}, z^{\prime}\right), \quad \forall z^{\prime}, i=1, \ldots, l-1 .
\end{aligned}
$$

\section{Developing Intuition: Four Simple Example Economies}

In order to develop intuition for the key mechanisms at work in our model, we now study four simple example economies: a representative agent version of our environment and three special cases of our general OLG economy. These examples are designed to highlight (i) what determines the magnitude of equilibrium asset price movements, relative to movements in output, and (ii) what determines how price movements translate into welfare effects that vary across different generations. 
From now on, we will assume that the aggregate shock takes only two values: $Z=\left\{z_{l}, z_{h}\right\}$, where $z_{l}$ stands for a severe recession. We will measure the magnitude of the decline in asset prices, relative to output $z$, by the statistic

$$
\xi=\frac{\ln \left(p_{l} / p_{h}\right)}{\ln \left(z_{l} / z_{h}\right)},
$$

where it is understood that, in general, prices and thus the elasticity $\xi$, are functions of the distribution of wealth in the economy prior to the recession. An elasticity of $\xi=2.5$, for example, indicates that the percentage decline in stock prices when the economy enters the recession is two and a half times as large as the fall in output.

\subsection{Example I: Representative Agent Model}

Our first simple economy is the standard infinitely lived representative agent Lucas asset pricing model (translated into our physical environment). ${ }^{14}$ Given the existence of a representative agent, the distribution of wealth is degenerate. With Markov shocks, the only state variable is current productivity $z$. Furthermore, if aggregate shocks are iid, then

$$
\left(\frac{p_{l}}{p_{h}}\right)=\left(\frac{z_{l}}{z_{h}}\right)^{\sigma}
$$

and thus $\xi^{R A}=\sigma$. When aggregate shocks are not iid, the same result still obtains in the special case of log-utility $(\sigma=1)$.

Why do prices become more sensitive to output as the intertemporal elasticity of substitution $1 / \sigma$ falls? For the stock market to clear, stock prices (and expected returns) must adjust to output fluctuations such that the representative household wants to neither buy nor sell stocks. The less willing are households to substitute consumption over time, the more prices must fall (and expected returns increase) in order to induce households to maintain constant stock holdings in response to a decline in output and thus consumption.

In the recent Great Recession in the United States, asset prices fell roughly 2.5 times as much as output, a decline we will target in our quantitative exercise. The representative agent economy generates $\xi^{R A}=2.5$ exactly when $\sigma=2.5$. Of course, although this economy is a useful benchmark, it has nothing to say about the differential welfare effects across age groups, our main

\footnotetext{
${ }^{14}$ The detailed analysis is contained in Appendix C.
} 
object of interest in this paper.

\subsection{Example II: Log-Utility}

With logarithmic utility and an age-income profile that is independent of the aggregate shock, it is possible to fully characterize a recursive competitive equilibrium analytically. The following proposition is proved in Appendix $D$ and does not hinge on $z$ being drawn from a two-point distribution, or on $z$ being independently distributed over time. ${ }^{15}$ We view the main value of this proposition as establishing a benchmark against which to compare our quantitative results, as well as a useful test case for the quality of our computational algorithm.

Proposition 1. Assume (i) the period utility function is logarithmic $(\sigma=1)$, and (ii) relative earnings across age groups are independent of the aggregate state, $\varepsilon_{i}(z)=\varepsilon_{i} \forall z$. Then there exists a recursive competitive equilibrium in the economy with endogenous portfolio choice with the following properties:

1. The distribution of wealth $A$ is constant over time. Denote this distribution $\bar{A}=\left(\bar{A}_{1}, \ldots, \bar{A}_{l}\right)$. Then

$$
G_{i+1}\left(z, \bar{A}, z^{\prime}\right)=a_{i}^{\prime}\left(z, \bar{A}, \bar{A}_{i}, z^{\prime}\right)=\bar{A}_{i+1} \quad \forall z, z^{\prime}, \forall i=1, \ldots, l-1 .
$$

2. Aggregate wealth is proportional to the aggregate shock:

$$
p(z, \bar{A})+q(z, \bar{A}) B=\Psi_{z} \quad \forall z
$$

where $\Psi$ is a constant that does not depend on the value for $B$.

3. Stock and bond prices are given by

$$
\begin{aligned}
& p(z, \bar{A})=p(z)=\Psi z-B \frac{z}{R} \sum_{z^{\prime} \in Z} \Gamma_{z, z^{\prime}} \frac{1}{z^{\prime}} \\
& q(z, \bar{A})=q(z)=\frac{z}{R} \sum_{z^{\prime} \in Z} \Gamma_{z, z^{\prime}} \frac{1}{z^{\prime}} \quad \forall z,
\end{aligned}
$$

where $R=(\Psi+\theta) / \Psi$ is the nonstochastic steady state gross interest rate.

\footnotetext{
${ }^{15} \mathrm{~A}$ similar result is established by Kubler and Schmedders (2013) in a slightly different version of the stochastic OLG model.
} 
4. Asset portfolios are identical across age groups:

$$
\lambda_{i}\left(z, \bar{A}, \bar{A}_{i}\right)=\lambda(z)=\frac{p(z)}{\Psi_{z}} \quad \forall z, \forall i=1, \ldots, l-1 .
$$

5. Consumption and savings at each age are proportional to the aggregate shock:

$$
\begin{aligned}
& c_{i}\left(z, \bar{A}, \bar{A}_{i}\right)=\left[(1-\theta) \varepsilon_{i}+\theta \bar{A}_{i}+\left(\bar{A}_{i}-\bar{A}_{i+1}\right) \Psi\right] z, \\
& y_{i}\left(z, \bar{A}, \bar{A}_{i}\right)=\bar{A}_{i+1} \Psi z \quad \forall z, \forall i=1, \ldots, I-1 .
\end{aligned}
$$

6. The equity premium is given by

$$
\sum_{z} \Pi_{z}\left\{\sum_{z^{\prime}} \Gamma_{z, z^{\prime}} \frac{\left[p\left(z^{\prime}\right)+d\left(z^{\prime}\right)\right]}{p(z)}-\frac{1}{q(z)}\right\}=R \sum_{z} \frac{\Pi_{z}}{z}\left\{\frac{\sum_{z^{\prime} \in Z} \Gamma_{z, z^{\prime}} z^{\prime}-\left(\sum_{z^{\prime} \in Z} \Gamma_{z, z^{\prime}} \frac{1}{z^{\prime}}\right)^{-1}}{1-\frac{B}{R \Psi} \sum_{z^{\prime} \in Z} \Gamma_{z, z^{\prime}} \frac{1}{z^{\prime}}}\right\}
$$

where $\Pi_{z}$ denotes the unconditional probability distribution over $z$.

Proof. See Appendix D.

Corollary 1. If $z$ is iid over time, then stock and bond prices are proportional to the aggregate shock and the average equity premium is given by $R\left(\sum_{z} \frac{\Pi_{z}}{z} \sum_{z} \Pi_{z} z-1\right) /\left(1-\frac{B}{R \psi} \sum_{z} \frac{\Pi_{z}}{z}\right)$.

Corollary 2. In the limit as $\Gamma_{z, z} \rightarrow 1 \forall z$ (perfectly persistent shocks), $q(z) \rightarrow R^{-1}$ and $p(z) \rightarrow$ $\Psi_{z}-B R^{-1}$.

This proposition has various implications. First, for this particular parameterization with logutility, the model predicts that aggregate asset prices fall by exactly as much as output in the recession, $\xi=1$. Second, portfolio allocations are counterfactual since the share invested in stocks is age invariant in the model, but declining with age in the data. Third, since consumption of all age cohorts varies one-for-one with the aggregate shock, all households must necessarily suffer welfare losses from a recession, including specifically the youngest generation. Fourth, with iid shocks the equity premium is positive (since $\sum_{z} \frac{\Pi_{z}}{z} \geq\left(\sum_{z} \Pi_{z} z\right)^{-1}=1$ ) and is increasing in the 
supply of debt $B$. Fifth, the more persistent are the shocks, the less sensitive are bond prices to output, and the more sensitive are stock prices.

Although the log-utility specification delivers clean closed-form solutions, it is of limited interest from the applied perspective of assessing the welfare effects of the Great Recession, primarily because it cannot generate a sufficiently large decline in asset prices, relative to the decline of output, as observed in the data. ${ }^{16}$ In the remainder of the paper, we therefore explore preference specifications that do not suffer from this shortcoming.

\subsection{Example III: Two-Period OLG Economy}

Outside the log-case, closed-form solutions for OLG economies with aggregate risk are not available. To build intuition for the $\sigma \neq 1$ case, we now study the simplest OLG framework in which households live for only two periods: $I=2$. We use this example to discuss how the curvature parameter $\sigma$ affects the elasticity $\xi$ of price changes to output changes in OLG economies. To make that discussion most transparent, we focus on an economy with only the risky stock $(B=0$ and $\left.\lambda_{i} \equiv 0\right)$ and assume that households only earn labor income in the first period of life: $\varepsilon_{1}=1$ and $\varepsilon_{2}=0$. Since young households start with zero assets, all wealth is therefore held by old agents. As a consequence, the wealth distribution is degenerate (and time invariant) in this economy. As in the representative agent model, the only state variable is the exogenous shock $z \in\left\{z_{l}, z_{h}\right\}$.

Consumption of young and old households is given by

$$
\begin{aligned}
& c_{1}(z)=(1-\theta) z-p(z) \\
& c_{2}(z)=\theta z+p(z)
\end{aligned}
$$

and the stock market price is determined by the intertemporal Euler equation

$$
p(z)[(1-\theta) z-p(z)]^{-\sigma}=\beta \sum_{z^{\prime} \in\left\{z_{L}, z_{h}\right\}} \Gamma_{z, z^{\prime}}\left[\theta z^{\prime}+p\left(z^{\prime}\right)\right]^{-\sigma}\left[\theta z^{\prime}+p\left(z^{\prime}\right)\right] .
$$

No closed-form solution is available for the functional equation $p(z)$ that solves equation (8) outside of the special cases $\sigma=0$ and $\sigma=1$. However, in Appendix $\mathrm{E}$ we derive an approximate expression

\footnotetext{
${ }^{16}$ However, this parameterization is useful as a test case for assessing the accuracy of our computational algorithm.
} 
for the elasticity $\xi^{2 p}$ for this two-period (2p) OLG model, again assuming iid shocks: ${ }^{17}$

$$
\begin{aligned}
\xi^{2 p} & \approx \frac{\sigma(1-\theta)}{1-\theta \frac{(R-\sigma)}{(R-1)}} \\
& =\xi^{R A} \times \frac{1-\theta}{1-\theta \frac{(R-\sigma)}{(R-1)}^{R A}}
\end{aligned}
$$

where $R=\frac{\theta+p}{p}>1$ is the steady state gross return on the stock. ${ }^{18}$

Note first that for $\sigma=1$, this formula is exact (as shown in the previous section) and delivers $\xi^{2 p}=\xi^{R A}=1$ : prices fall by exactly as much as output in a downturn. Second, $\xi^{2 p}$ is increasing in $\sigma$, and thus for $\sigma>1$ we have $\xi^{2 p}>1$. Third, $\xi^{2 p}<\xi^{R A}$. Thus, as long as the intertemporal elasticity of substitution $1 / \sigma$ is smaller than one, asset prices fall by more than output in a recession, but by less than in the corresponding representative agent economy with infinitely lived households.

For example, suppose we use the following values from our baseline quantitative six-period model (Section 5): $\sigma=2.5, \theta=0.3017$, and an annual interest rate of $4.47 \%$. Then, using the expression above and assuming a 30 -year period length (so $R=1.0447^{30}$ ), $\xi^{2 p}=2.02$ in the OLG economy, compared with $\xi^{R A}=2.5$ in the representative agent economy. The finding that stock prices are less volatile, relative to output, in OLG economies compared with the infinitely lived representative agent economy will reappear consistently in the various economies we study. The reason is as follows. Consumption of the current old generation must decline in the recession since the price of the asset, the only source for old-age consumption, is lower in the bad than in the good aggregate state of the world. Moreover, for $\sigma>1$, consumption of the old is more sensitive to aggregate shocks than consumption of the young:

$$
\frac{c_{1}\left(z_{h}\right)}{c_{1}\left(z_{l}\right)}<\frac{z_{h}}{z_{l}}<\frac{c_{2}\left(z_{h}\right)}{c_{2}\left(z_{l}\right)} \text {. }
$$

The second inequality reflects the fact that $c_{2}\left(z_{h}\right) / c_{2}\left(z_{l}\right)=p_{h} / p_{l}>z_{h} / z_{l}$ (since $\xi^{2 p}>1$ ), while the first inequality follows from market clearing: $\left(c_{1}\left(z_{h}\right)+c_{2}\left(z_{h}\right)\right) /\left(c_{1}\left(z_{l}\right)+c_{2}\left(z_{l}\right)\right)=z_{h} / z_{l}$. The fact that aggregate risk is disproportionately borne by the old explains why stock prices are less volatile in this economy than in the analogous representative agent economy. Recall that stocks are effectively priced by younger agents, because the supply of stocks by the old is inelastic at any positive price. Because the old bear a disproportionate share of aggregate risk, the young's

\footnotetext{
${ }^{17}$ This approximation involves taking a linear approximation to the pricing equations around the point $z_{l} / z_{h}=1$.

${ }^{18}$ For $\theta$ such that $R=\beta^{-1}$, the expression simplifies to $\xi^{2 p} \approx \frac{\sigma(\beta+1)}{\sigma \beta+1}$.
} 
consumption fluctuates less than output. Thus, smaller price changes (relative to the representative agent economy) are required to induce them to purchase the aggregate supply of equity at each date.

One might wonder whether it is possible that $c_{1}\left(z_{h}\right)<c_{1}\left(z_{l}\right)$, so that newborn households would potentially prefer to enter the economy during a recession rather than during a boom. The answer turns out to be no: while stock prices fall by more than output in the event of a recession, they never fall by enough to compensate the young for their decline in labor earnings. The logic for this result is straightforward. In a two-period OLG economy, stock prices are defined by the inter-temporal first-order condition for young households (equation 8). With iid shocks, the righthand side of this condition is independent of the current value for $z$. Taking the ratio of the two pricing equations across states, the ratio of stock prices across states is given by

$$
\frac{p_{h}}{p_{l}}=\left(\frac{c_{1}\left(z_{h}\right)}{c_{1}\left(z_{l}\right)}\right)^{\sigma} \text {. }
$$

The advantage to the young from entering the economy during a recession is that they buy stocks cheaply, $p_{h} / p_{l}>1$. But the optimality restriction above then implies that $c_{1}\left(z_{h}\right) / c_{1}\left(z_{l}\right)>1$, so the young must suffer low consumption if they enter during a recession. Intuitively, low prices are needed to induce the young to buy stocks when the marginal utility of current consumption is high. But a high marginal utility of consumption requires low consumption for these households.

This example reveals that for the young to potentially gain from a recession, we need people to live for at least three periods, while the previous example with logarithmic preferences indicates that we also require $\sigma>1$. We now move to a three-period example to show that the young can indeed benefit from a recession, and provide some intuition for the combination of model elements required to deliver this result.

\subsection{Example IV: Three-Period OLG Economy}

Now suppose households live for three periods, $I=3$, but do not value consumption when young and discount the future at a constant factor $\beta_{2}=\beta_{3}=\beta$ thereafter. They are only productive in the first period of their lives $\left(\varepsilon_{1}=1\right.$ and $\left.\varepsilon_{2}=\varepsilon_{3}=0\right)$ and can only trade stocks $(B=0$ and $\left.\lambda_{i} \equiv 0\right)$. Given this set of assumptions, young households buy as many stocks as they can afford, while the old sell all the stocks they own. Only the middle-aged make an nontrivial intertemporal decision. In a recession, falling stock prices have countervailing effects on the middle-aged's stock trade decision. On the one hand, low current stock prices offer an incentive to reduce stock sales 
to exploit higher expected stock returns (the substitution effect). On the other, consumption smoothing calls for larger stock sales, since stock sales are the only source of income for this group (the income effect).

Given that young households start their lives with zero asset holdings and that the total number of wealth shares has to sum to one, the only endogenous aggregate state variable in this simple economy is the share of assets held by old households, $A_{3}$, which for simplicity we denote here by $A_{3}=A$. Consequently the share of assets owned by middle-aged households is given by $A_{2}=1-A$, and the first-order condition for middle-aged households can be written as

$$
u^{\prime}[(1-A)(p(z, A)+\theta z)-G(z, A) p(z, A)]=\beta \sum_{z^{\prime}} \Gamma_{z, z^{\prime}} \frac{\left[p\left(z^{\prime}, A^{\prime}\right)+\theta z^{\prime}\right]}{p(z, A)} u^{\prime}\left[G(z, A) p\left(z^{\prime}, A^{\prime}\right)\right]
$$

where consistency requires that tomorrow's asset share of the old is equal to the number of shares purchased by the current middle-aged households: $A^{\prime}=G(z, A)$. In equation (9) marginal utility from consumption when middle-aged is equated to discounted expected marginal utility from consumption when old, adjusted by the gross return on assets $\left[p\left(z^{\prime}, A^{\prime}\right)+\theta z^{\prime}\right] / p(z, A)$.

The second functional equation determining the pricing and optimal policy functions states that the equilibrium demand for shares of the young, $1-G(z, A)$, equals the number of shares that can be purchased with their total labor income $w(z) / p(z)=(1-\theta) z / p(z)$. Thus,

$$
[1-G(z, A)] p(z, A)=(1-\theta) z
$$

The pair of functional equations (9) and (10) jointly determines the unknown equilibrium pricing and policy functions $p(z, A)$ and $G(z, A)$. Consumption and welfare at all ages can easily be calculated from these equilibrium functions. ${ }^{19}$

\footnotetext{
${ }^{19}$ These are given explicitly as$$
c_{3}(z, A)=A[p(z, A)+\theta z]
$$$$
c_{2}(z, A)=(1-A)[p(z, S)+\theta z]-G(z, A) p(z, A)
$$$$
v_{3}(z, A)=u\left[c_{3}(z, A)\right]
$$$$
v_{2}(z, A)=u\left[c_{2}(z, A)\right]+\beta \sum_{z^{\prime}} \Gamma_{z, z^{\prime}} u\left[c_{3}\left(z^{\prime}, G(z, A)\right)\right]
$$$$
v_{1}(z, A)=\beta \sum_{z^{\prime}} \Gamma_{z, z^{\prime}} v_{2}\left[z^{\prime}, G(z, A)\right] .
$$ 
For this economy, in the log-case with iid shocks, as shown in Section 4.2, consumption of all households is proportional to the aggregate shock. Consequently middle-aged and old households suffer welfare losses from the economic downturn, whereas newborn households (who do not value current consumption) are exactly indifferent between being born in normal times and being born in a recession. This suggests that if $\sigma>1$, asset prices should move by more than output, which in turn would be sufficient to break the indifference of the young in favor of preferring to be born in a recession.

For $\sigma \neq 1$ the recursive competitive equilibrium has to be solved numerically, but this is straightforward to do with the only continuous state variable being $A$. We choose the same parameter values as in the previous two-period example. The capital share remains at $\theta=0.3017$, and the time discount factor is chosen as $\beta=(0.96)^{20}=0.44$. The aggregate shock takes two values with $z_{l} / z_{h}=0.917$ so that aggregate output falls by $8.3 \%$, a value also used below in the calibrated version of the full model. We assume that aggregate shocks are uncorrelated over time in this model in which a period lasts for 20 years.

Figure 1 plots the elasticity of asset prices to output, $\xi^{3 p}$, as a function of the share of wealth held by the old generation, for various values of the IES $1 / \sigma$. Note that, as demonstrated above, for the logarithmic case $\sigma=1$ we have $\xi^{3 p}=1$, independent of the wealth distribution $A{ }^{20}$

This figure highlights two key findings. First, the lower is the willingness of households to intertemporally substitute consumption (the higher is $\sigma$ ), the larger is the fall in asset prices, relative to output, in the recession. Second, the size of asset price movements depends on the wealth distribution $A$ when preferences are not logarithmic. The larger is the share of wealth held by the middle-aged (the smaller is $A$ ), the larger is $\xi^{3 p}$ (assuming $\sigma>1$ ). The logic for this is as follows. When the intertemporal elasticity of substitution is less than one, the middle-aged sell more stocks in a recession (compared with normal times) in an attempt to smooth consumption. These extra shares must be bought by the young. The larger the share of wealth in the hands of the middle-aged households, the larger is the downward pressure on prices, since the young must buy more extra shares with the same amount of earnings. ${ }^{21}$ For $\sigma=2.5$, the wealth share of the old generation converges to $A=0.3396$ after a long sequence of good shocks, and for that $A$ we find a price elasticity of $\xi^{3 p}=1.2$, compared with the corresponding values for the representative

\footnotetext{
${ }^{20}$ Given that prices move one-for-one with output, equation (10) implies that $G(z, A)$ must be independent of $z$, and thus that the wealth distribution must be constant, which is consistent with Proposition 1.

${ }^{21}$ In the $\sigma \neq 1$ economies, wealth holdings of the old at the start of a recession need not be the same as at the start of an expansion, on average. The figure traces out the price differences between expansions and recessions, conditional on the same wealth distribution in the economy.
} 


\section{Figure 1: Asset Price Decline Relative to Output}

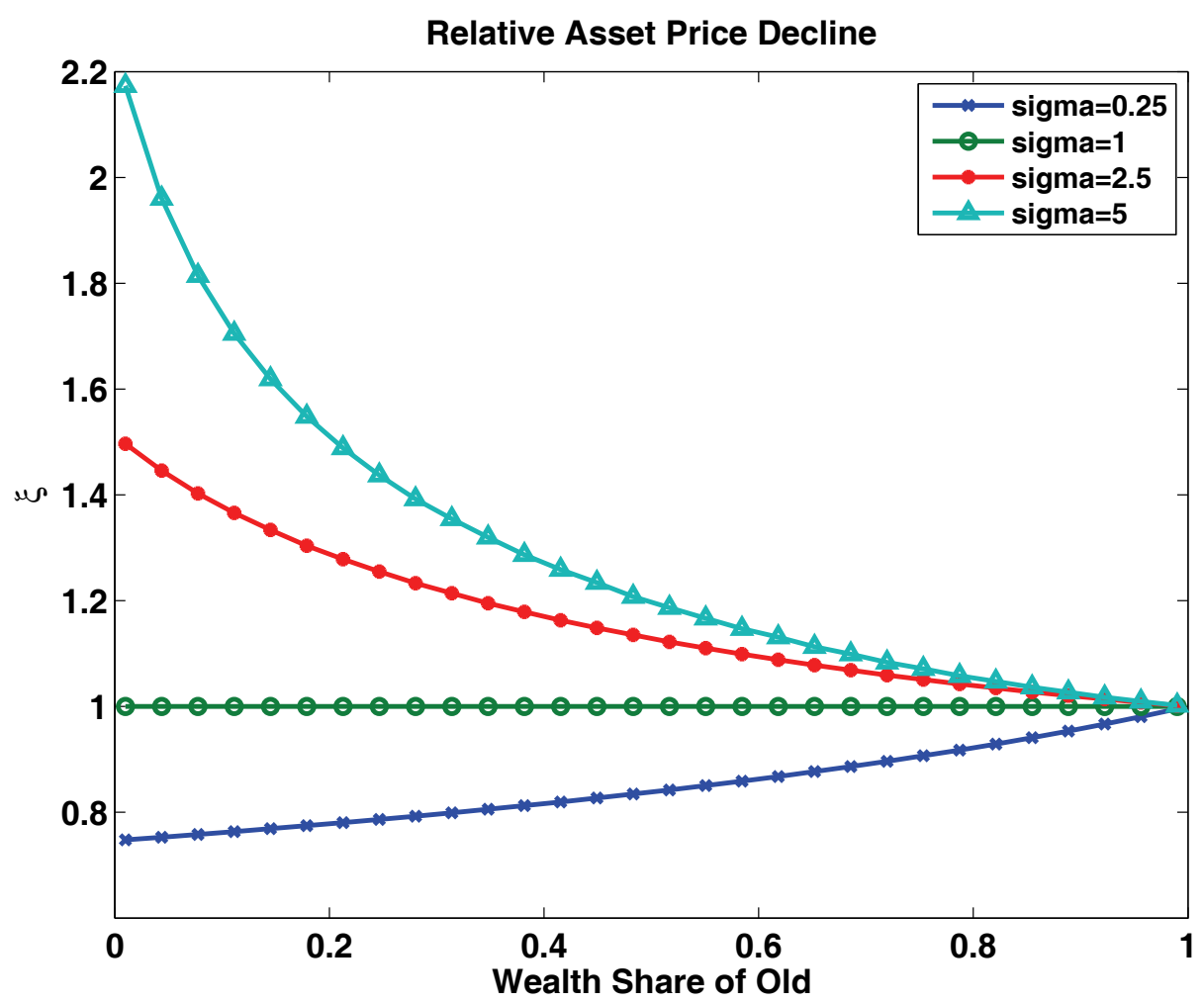

agent and two-period OLG economies of $\xi^{R A}=2.5$ and $\xi^{2 p}=2.06$.

The welfare consequences for young generations of starting their economic lives in a recession, relative to an expansion, are displayed in Figure 2. Welfare is measured as the percentage change in consumption in all periods of a household's life, in all state contingencies, that a household born in an expansion would require to be as well off as being born in a recession, with positive numbers therefore reflecting welfare gains from a recession. Again we plot these numbers as a function of the wealth distribution $A$ and for different values for $\sigma$. We observe that the welfare consequences from recessions for the young mirror the elasticity of asset prices to output (Figure 1), confirming that this elasticity is the crucial determinant of how the welfare costs of recessions are distributed in our class of OLG economies.

The purpose of working through this sequence of simple example economies was to develop intuition for the magnitude of asset price declines relative to output, and the resulting implications for lifetime welfare of different generations. The last example featured welfare gains from a recession for the young as long as $\sigma>1$. Note, however, that here we stacked the deck in favor of obtaining 
Figure 2: Welfare Consequences of Recessions for Young Households

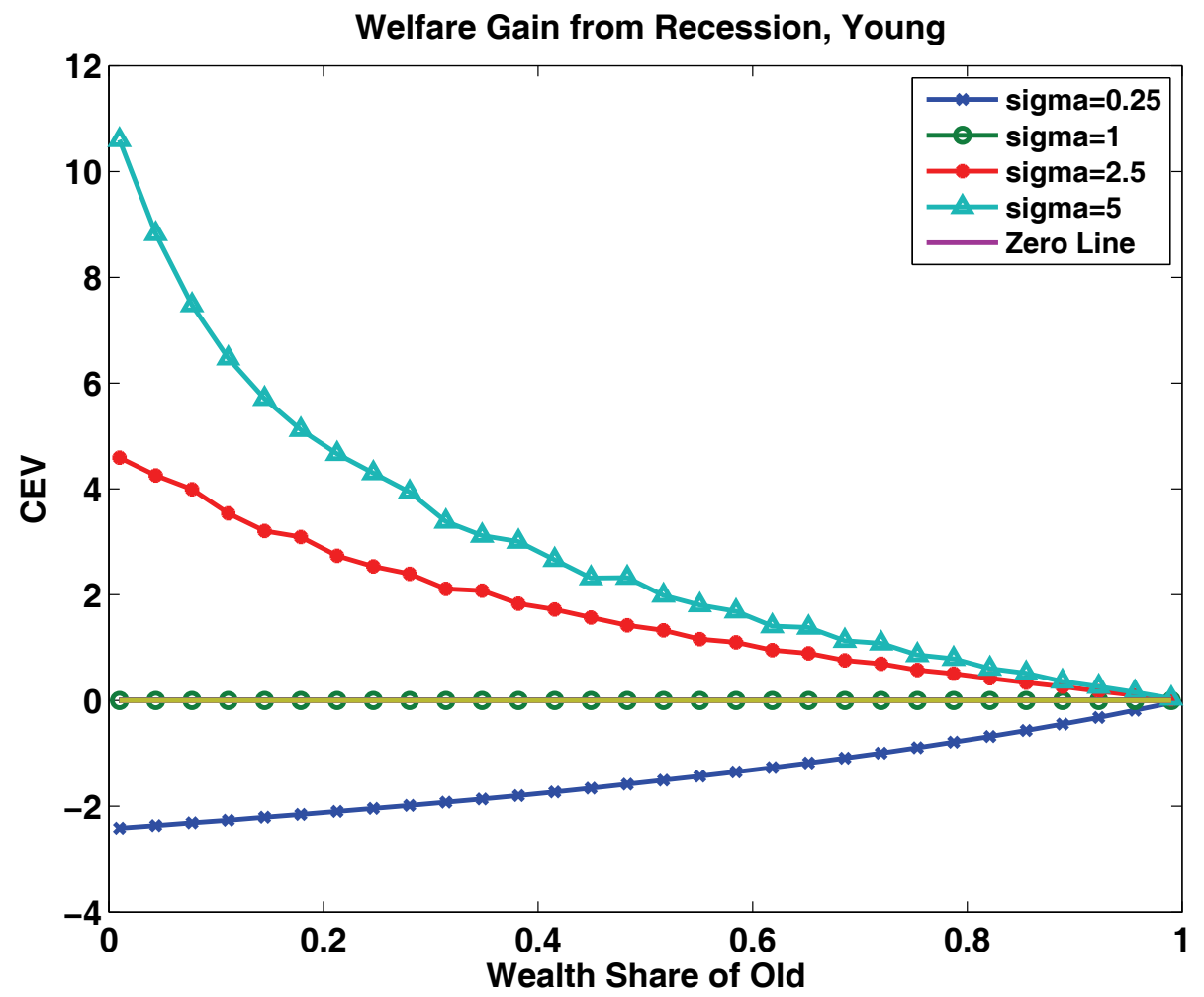

this result. First, young households do not value consumption today and thus are not affected directly by a decline in current aggregate consumption. Second, the middle-aged and the old have no source of income other than selling shares, forcing them to bear a disproportionate share of the burden of recession. The remainder of the paper will now study the size of the asset price decline and the distribution of welfare consequences from a severe and long-lasting recession in a realistically calibrated OLG economy in which life-cycle labor income and wealth profiles match those observed in the 2007 SCF.

\section{Calibration}

We assume agents enter the economy as adults and live for $I=6$ periods, where a period lasts for 10 years. The preference parameters to calibrate are the (inverse of the) intertemporal elasticity of substitution $\sigma$ and the life-cycle profile for discount factors $\left\{\beta_{i}\right\}_{i=2}^{\prime}$. The parameters governing labor endowments over the life-cycle profile are $\left\{\varepsilon_{i}(z)\right\}_{i=1}^{l}$. The parameters defining aggregate income to capital and how this income is partitioned between bond and stockholders are $\theta$ and $B$. 
The technology parameters are the support and transition probability matrix $\Gamma$ for the aggregate productivity shock $z$.

\subsection{Financial Market Parameters}

We use a nonstochastic version of the economy, in which the productivity shock is set to $z_{h}=1$, to calibrate $\theta$ and $B$. Let $\bar{\lambda}$ denote the aggregate share of risky assets (stocks) in total household net worth. Let $\bar{W}$ denote the aggregate wealth to labor income ratio. Thus,

$$
\begin{aligned}
\bar{\lambda} & =\frac{p}{p+q B} \\
\bar{W} & =\frac{p+q B}{1-\theta} .
\end{aligned}
$$

Let $\bar{R}$ denote the gross interest rate. Note that in a nonstochastic version of the model, the same interest rate must apply to both stocks and bonds for agents to be indifferent about an interior portfolio split. ${ }^{22}$ Thus,

$$
\begin{aligned}
& \bar{R}=\frac{1}{q}, \\
& \bar{R}=\frac{p+\theta Y+q B-B}{p} .
\end{aligned}
$$

These are four equations that can be used to solve for $p, q, B$, and $\theta$ as functions of the three empirical moments $\bar{\lambda}, \bar{W}$, and $\bar{R}$. The solution is

$$
\begin{aligned}
p & =\bar{\lambda} \frac{\bar{W}}{1+(\bar{R}-1) \bar{W}} \\
q & =\frac{1}{\bar{R}} \\
B & =\frac{(1-\bar{\lambda}) \bar{R} \bar{W}}{1+(\bar{R}-1) \bar{W}} \\
\theta & =\frac{(\bar{R}-1) \bar{W}}{1+(\bar{R}-1) \bar{W}} .
\end{aligned}
$$

\footnotetext{
${ }^{22}$ The stochastic version of the model will generate a positive but small equity premium.
} 
From the 2007 SCF we measure $\bar{\lambda}$ and $\bar{W}$ by averaging across age groups. ${ }^{23}$

$$
\begin{aligned}
\bar{\lambda} & =500.78 / 545.50=0.918 \\
\bar{W} & =545.50 /(10 \times 69.25)=0.788
\end{aligned}
$$

For the interest rate $\bar{R}$ we target an average weighted return across asset classes. Piazzesi, Schneider, and Tuzel (2007) report real returns on safe and risky assets of $0.75 \%$ and $4.75 \%$ per annum, where the latter is the return on an equally weighted portfolio of stocks returning $6.94 \%$ and housing returning $2.52 \%$. Given that our period length is 10 years, this implies

$$
\bar{R}=\bar{\lambda} \times 1.0475^{10}+(1-\bar{\lambda}) \times 1.0075^{10}=1.5485
$$

Collectively, these values for $\bar{\lambda}, \bar{W}$, and $\bar{R}$ imply that $\theta=0.3017$ and $B=0.0699$.

\subsection{Aggregate Shocks}

We assume that the aggregate shock $z$ takes one of two values: $z \in Z=\left\{z_{l}, z_{h}\right\}$. We normalize $z_{h}=1$ and set $z_{l}=0.917$ so that in a recession, output falls by $8.3 \%$. This corresponds to the size of the gap that opened up between actual real GDP per capita and trend real GDP per capita between the NBER start and end dates for the recession (2007:4 and 2009:2). ${ }^{24}$ We assume that $z$ is iid over time, with the probability of $z=z_{h}$ equal to 0.85 . Given that a period is 10 years, this implies that the expected duration of periods of high productivity is $10 / 0.15=66.7$ years, while the expected duration of periods of low productivity is $10 / 0.85=11.8$ years. Thus, in our calibration, a recession involves a large and long-lasting decline in output, but is a fairly rare event.

\subsection{Intertemporal Elasticity of Substitution}

The simpler versions of the model considered earlier indicated that the intertemporal elasticity parameter $\sigma$ strongly influences the size of equilibrium asset price fluctuations. Informed by that finding, we set the baseline value for $\sigma$ so that a model recession features a realistic decline in

\footnotetext{
${ }^{23}$ In our model, each age group is assumed to be of equal size. Thus, given that we will later seek to replicate earnings and net worth for each age group, the appropriate aggregate targets are unweighted averages across age groups. Because these age groups are not of exactly identical size in the SCF, these aggregate targets do not correspond exactly to SCF population averages, but the differences are small.

${ }^{24}$ We define trend growth to be the average growth rate in GDP per capita between 1969:1 and 2007:4, which was $2.0 \%$ per year. The gap as of $2010: 2$ was essentially unchanged at $8.4 \%$.
} 
household net worth. Between the 2007 and 2010 SCF cross sections, mean real household net worth declined by $19.6 \%$ (relative to a $2 \%$ trend growth rate). Thus, the decline in asset prices associated with the recession was $19.6 / 8.3=2.4$ times as large as the decline in output. The model generates a similar asset price decline given $\sigma=2.5$. We will conduct sensitivity analysis with respect to this parameter in Section $7 .{ }^{25}$

\subsection{Life-Cycle Profiles}

We set the life-cycle labor endowment profile $\left\{(1-\theta) \varepsilon_{i}\left(z_{h}\right)\right\}_{i=1}^{\prime}$ equal to the empirical 2007 SCF life-cycle profile for labor income, as described in Section 2.

We set the life-cycle profile $\left\{\beta_{i}\right\}_{i=2}^{\prime}$ so that the nonstochastic version of the model generates the 2007 SCF life-cycle profile for net worth, given the other determinants of life-cycle saving: the preference elasticity $\sigma$, the profile for earnings, and the interest rate $\bar{R}$. In particular, note that household budget constraints in the deterministic version of the model can be written as

$$
\begin{aligned}
c_{i} & =(1-\theta) \varepsilon_{i}+\bar{R} y_{i-1}-y_{i} \text { for } i=1, \ldots, N-1 \\
c_{N} & =(1-\theta) \varepsilon_{N}+\bar{R} y_{N-1},
\end{aligned}
$$

where $y_{i}$ is total savings for age group $i$ (net worth for age group $i+1$ ). The youngest age group corresponds to households aged 20-29, and the sixth and oldest age group corresponds to households aged 70 and above. We measure $\left\{(1-\theta) \varepsilon_{i}\right\}_{i=2}^{\prime}$ as 10 times average annual labor income of age group $i$, and $\left\{y_{i}\right\}_{i=1}^{I-1}$ as the average net worth of age group $i+1$. Because agents in our model enter the economy with zero initial wealth, we recategorize asset income for the youngest group in the SCF as labor income: thus, we set $\bar{R} y_{0}=0$ and set $(1-\theta) \varepsilon_{1}$ equal to 10 times average annual labor income for the youngest group plus $\bar{R}$ times the data value for $y_{0}$. We also set $y_{I}=0$, since the oldest group does not save in our model.

Given the sequences $\left\{(1-\theta) \varepsilon_{i}\right\},\left\{y_{i}\right\}$, and $\bar{R}$, the budget constraints imply a life-cycle consumption profile, $\left\{c_{i}\right\}$. This consumption profile can be used to back out the sequence of time discount factors that supports the age-varying profile for returns. In particular, in the nonstochastic

\footnotetext{
${ }^{25}$ Estimates for the intertemporal elasticity of substitution $1 / \sigma$ vary significantly, from values close to zero when estimated from macro data (see, e.g., Hall 1988) to values that can be above one when estimated from micro data on specific samples of households that are stockholders (see, e.g., Vissing-Jorgensen and Attanasio 2003). Thus, a value of $1 / \sigma=1 / 2.5$ is consistent with most estimates from macro and micro data with samples representative of the US population.
} 
version of the model, the household's intertemporal first-order condition implies that

$$
\beta_{i+1}=\left(\frac{c_{i+1}}{c_{i}}\right)^{\sigma} \frac{1}{\bar{R}}
$$

Note that the consumption profile is derived directly from household budget constraints and is pinned down by the data on labor income, net worth, and returns. Thus, the consumption profile is independent of preference parameters, including $\sigma$. However, supporting this consumption profile as an equilibrium outcome requires a discount factor profile $\left\{\beta_{i}\right\}$ that does depend on $\sigma$. For example, the larger is $\sigma$, the more sensitive is the implied profile for $\beta_{i}$ to age variation in consumption growth.

\section{Figure 3: Life-Cycle Profiles for Consumption, Net Worth, and Labor Income}

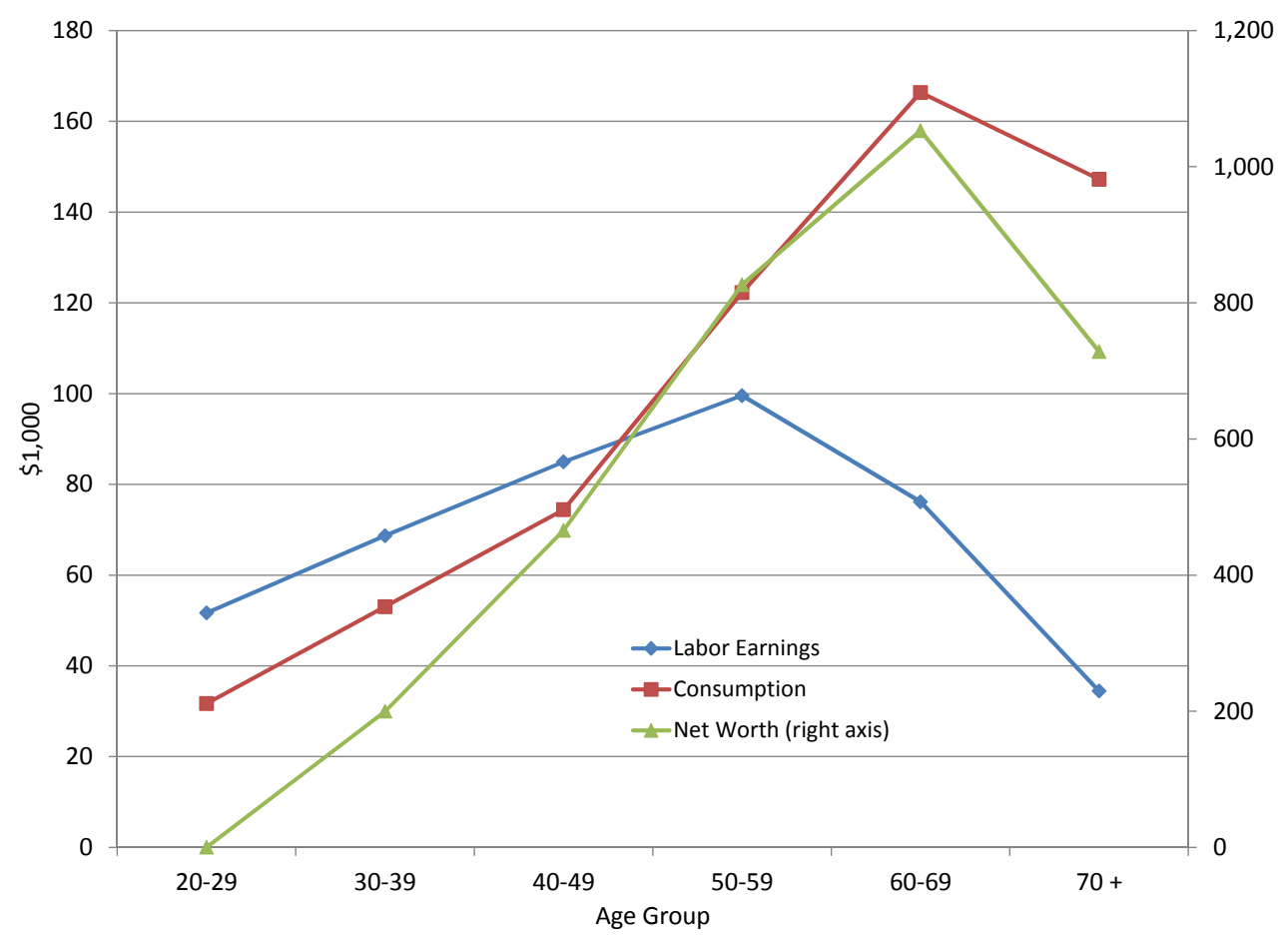

Figure 3 shows life-cycle profiles for consumption, net worth, and labor income from the nonstochastic version of our model, and Figure 4 displays the implied calibrated profile $\left\{\beta_{i}\right\}_{i=1}^{\prime}$, with $\beta_{1}$ normalized to 1 . Note that $\beta_{i}$ is generally larger than one. This reflects the fact that the data indicate strong growth in income and net worth over the life cycle between the 20-29 age group and the 50-59 age group. However, $\beta_{i}$ should not be interpreted solely as capturing pure time 
preference: it also incorporates the effects of age variation in family size and composition on the marginal utility on consumption.

\section{Figure 4: Implied Discount Factors for Various Elasticities of Substitution}

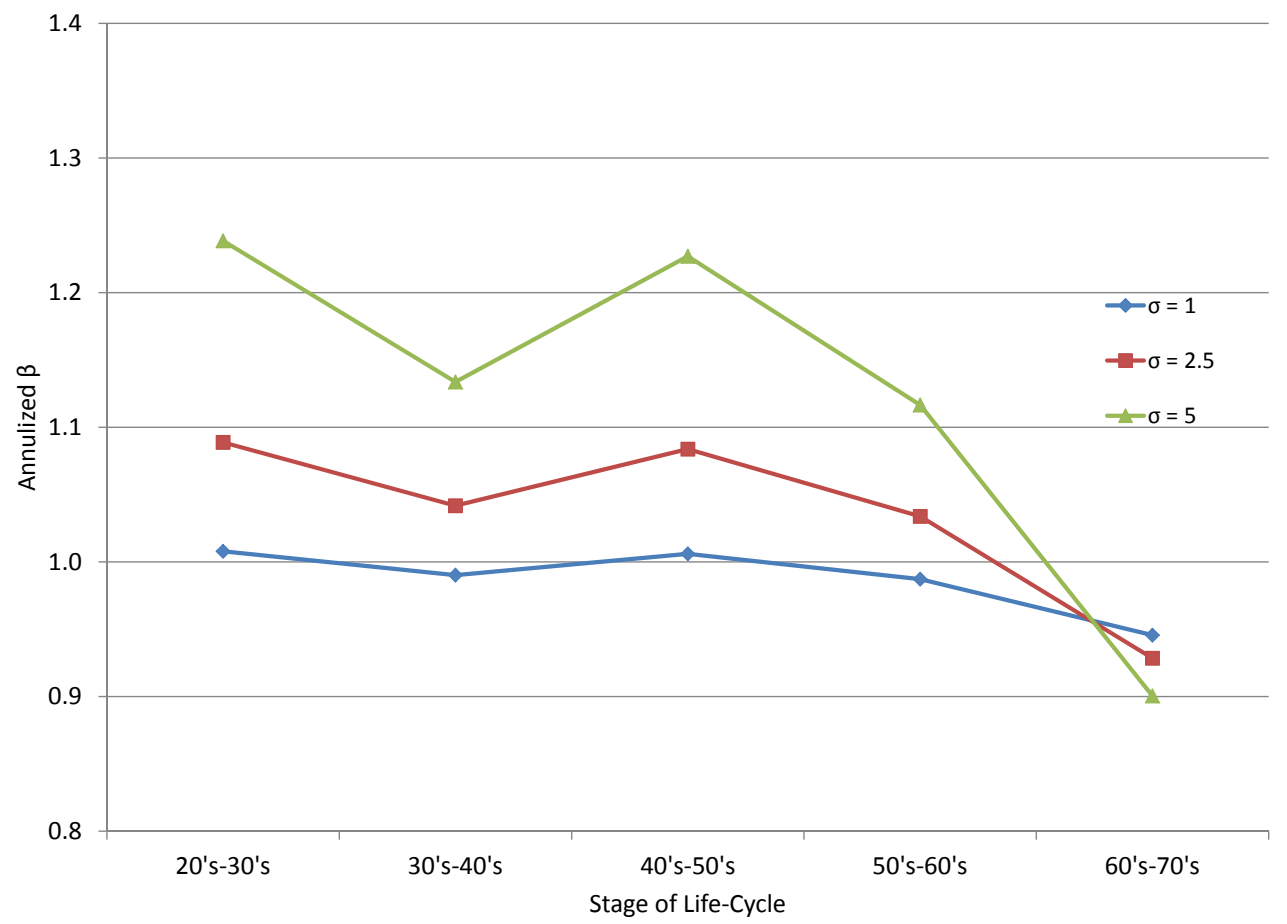

\subsection{Cyclical Declines in Earnings}

We think of the age profile for labor income calibrated to 2007 SCF data (discussed above) as corresponding to the age profile for earnings in normal times $\left\{\varepsilon_{i}\left(z_{h}\right)\right\}_{i=1}^{l}$. We then measure the percentage decline in labor income by age group between 2007 and 2010, in order to estimate how recession-induced earnings losses are distributed across the age distribution. In principle, we could measure these declines directly in the SCF, but the SCF sample size is relatively small, making it difficult to precisely estimate age-group-specific earnings declines. We therefore turn to the much larger March CPS. We use the 2008 and 2011 survey years, containing data for income years 2007 and 2010. Our CPS measure of nonasset income is conceptually close to the SCF measure of labor income we used to calibrate the life-cycle profile for model earnings. This measure includes all CPS income components except for dividends, interest, rents, and one-third of self-employment income. 
The SCF and CPS life-cycle profiles for nonasset income align quite closely.

We construct the life-cycle profile for the recession state $\left\{\varepsilon_{i}\left(z_{l}\right)\right\}_{i=1}^{\prime}$ by multiplying the normal state profile $\left\{\varepsilon_{i}\left(z_{h}\right)\right\}_{i=1}^{\prime}$ by the age-group specific percentage declines observed in the CPS, and then renormalizing so that average efficiency in the recession state is equal to one. The declines in earnings by age group fed into the model $\left(z_{l} \varepsilon_{i}\left(z_{l}\right)-\varepsilon_{i}\left(z_{h}\right)\right) / \varepsilon_{i}\left(z_{h}\right)$ are shown in Table $4 .{ }^{26}$

\begin{tabular}{l} 
Table 4: Recession Decline in Model Ear \\
\hline
\end{tabular}

Thus, as expected, the age-earnings profile shifts in favor of older generations: the decline in earnings in the recession has a disproportionate impact on younger age groups.

\subsection{Calibration with Exogenous Portfolios}

In our baseline model, agents choose both how much to save and how to divide savings between stocks and bonds. We also consider an alternative version of the model in which savings is a choice, but in which the portfolio split is exogenous. In this version, we introduce as new parameters agevarying portfolio splits $\left\{\lambda_{i}\right\}_{i=1}^{\prime}$, which we set equal to age-group-specific shares of risky assets in net worth from the SCF (see Table 2). All other parameter values are identical to the baseline model.

Note that the nonstochastic versions of the models with exogenous and endogenous portfolios are identical. In particular, absent aggregate shocks, agents in the model are indifferent about which portfolio mix to hold, and thus any allocation of stocks and bonds across age groups including the one observed in the data - is an equilibrium. Once aggregate shocks are introduced, the two economies are no longer identical.

The advantage of the exogenous portfolios model, relative to the baseline, is that by forcing

\footnotetext{
${ }^{26}$ The differentials across age groups are similar when considering a much narrower measure of labor income that only includes wage and salary income.
} 
model agents to hold exactly the portfolios that actual households were holding in 2007, we generate a very realistic distribution of capital losses across age groups in a simulated model recession. However, equilibrium portfolios in the baseline endogenous portfolios model will turn out to be quite similar to those observed in the data, which diminishes the relative appeal of the exogenous portfolios model. The disadvantage of the exogenous portfolios approach is that it limits the ways in which agents can hedge aggregate risk ex ante, and the ways they can respond to shocks ex post. ${ }^{27}$

\section{Results for the Benchmark Economy}

The calibration procedure delivers realistic joint life-cycle profiles for earnings, net worth, and (in the exogenous portfolios specification) portfolios. These are the necessary ingredients for our model to serve as a suitable laboratory for exploring the distributional impact of aggregate shocks.

Table 5 displays the asset price declines triggered by a recession with an $8.3 \%$ drop in aggregate income, and Table 6 reports the corresponding welfare effects. These numbers are computed assuming that the recession is preceded by a long period of normal times, with subsequent output realizations drawn from the iid distribution described in Section 5. We display results for four economies, starting in the first (bolded) column of both tables with our benchmark economy with endogenously determined portfolios ("Endog.") and a labor earnings distribution that moves over the cycle and thus results in asymmetric earnings losses ("Asym.").

\section{Table 5: Elasticity $\xi$ of Asset Prices to Output}

\begin{tabular}{l|cccc}
\hline \hline & \multicolumn{4}{|c}{ Portfolio \& Earnings Model } \\
\hline \multirow{3}{*}{ Asset } & Endog. & Endog. & Exog. & Exog. \\
& Asym. & Sym. & Asym. & Sym. \\
\hline Wealth & $\mathbf{2 . 3 5}$ & 2.25 & 2.23 & 2.01 \\
Stock & $\mathbf{2 . 3 4}$ & 2.28 & 2.24 & 1.98 \\
Bond & $\mathbf{2 . 3 6}$ & 1.94 & 2.06 & 2.26 \\
\hline \hline
\end{tabular}

In the remaining columns we report results for three other economies in which portfolios are exogenously fixed ("Exog.") and/or the labor earnings distribution does not depend on the aggregate state of the economy $z$ ("Sym."). These results will be useful in interpreting the sources of the differential welfare consequences of the Great Recession by age.

\footnotetext{
${ }^{27}$ In the exogenous portfolios model, one can generate equity premia of arbitrary size by appropriate choice of portfolio shares $\left\{\lambda_{i}\right\}$ and/or outstanding bonds $B$.
} 
Table 6: Welfare Losses from Recession by Age

\begin{tabular}{l|cccc}
\hline \hline & \multicolumn{4}{|c}{ Portfolio \& Earnings Model } \\
\hline & Endog. & Endog. & Exog. & Exog. \\
Age Group & Asym. & Sym. & Asym. & Sym. \\
\hline $20-29$ & $\mathbf{- 1 . 6 7 \%}$ & $-0.35 \%$ & $-1.64 \%$ & $-0.72 \%$ \\
$30-39$ & $\mathbf{- 2 . 1 1} \%$ & $-2.38 \%$ & $-2.80 \%$ & $-2.20 \%$ \\
$40-49$ & $\mathbf{- 2 . 5 0} \%$ & $-2.70 \%$ & $-1.69 \%$ & $-1.80 \%$ \\
$50-59$ & $\mathbf{- 3 . 6 6} \%$ & $-3.80 \%$ & $-3.41 \%$ & $-2.88 \%$ \\
$60-69$ & $\mathbf{- 5 . 4 5} \%$ & $-5.03 \%$ & $-5.03 \%$ & $-5.74 \%$ \\
$70+$ & $\mathbf{- 8 . 3 0} \%$ & $-8.38 \%$ & $-9.88 \%$ & $-11.07 \%$ \\
\hline \hline
\end{tabular}

First, from Table 5 we observe that the value of aggregate wealth declines 2.35 as much as aggregate income, or $19.6 \%$, relative to the income decline of $8.3 \%$. This (by virtue of our choice of risk aversion $\sigma$ ) exactly matches the decline in net worth observed in the data between 2007 and 2010. The model-implied drops in stock and bond prices are very similar. ${ }^{28}$

Column 1 of Table 6 displays the welfare consequences of a model recession by age group, where the 20- to 29-year-old group becomes economically active in the recession period. ${ }^{29}$ We observe that each age group suffers welfare losses, but that these losses are monotonically increasing in age and differ dramatically in magnitude. Whereas the oldest cohort loses $8.3 \%$ of remaining lifetime consumption, the youngest cohort experiences welfare losses of only $1.67 \%$ of lifetime consumption, even though this group's labor earnings in the recession period declines by more than $11 \%$.

For the oldest generation, the current recession period is the last period of life, and thus welfare losses and current consumption losses coincide. The $8.3 \%$ loss for this group reflects the combined effects of lost labor earnings due to the recession (which is nil, according to the data) and the valuation loss for the risky part of their asset portfolio, due to a near $20 \%$ price decline in the stock market. ${ }^{30} 31$ Young households, instead, suffer from a large decline in their current labor

\footnotetext{
${ }^{28}$ Recall, though, that these price movements have very different effects on ex post returns: the stock price decline reduces ex post returns to stocks in the recession period, while the bond price decline has no effect on the ex post return to one-period bonds: this is what defines the bond as a safe asset.

${ }^{29}$ Welfare is measured as the percentage change in consumption (in all states and over all remaining periods of life) under a no recession scenario needed to make households indifferent between the current aggregate state being $z_{l}$ rather than $z_{h}$.

${ }^{30}$ The portfolio allocation chosen by households (in the period prior to the recession) is depicted in Figure 6 (solid blue line) and will be discussed in greater detail in the next section. The oldest households hold about $60 \%$ of their portfolio in risky assets.

${ }^{31}$ In contrast to the case with $\sigma=1$ and symmetric earnings losses, the consumption loss (relative to the norecession scenario) is not exactly equal to $8.3 \%$ (the size of the output decline), but is instead slightly smaller
} 
earnings, but get to buy assets at temporarily depressed prices, which strongly mitigates their welfare losses. ${ }^{32}$

Given the importance of the asset price channel, in Section 6.2 below we isolate the quantitative importance of this channel by considering a "partial equilibrium" version of our model in which asset prices do not respond to the collapse in real economic activity. Prior to this analysis, in the next section we demonstrate the importance of explicitly modeling endogenous portfolio choice and heterogeneous earnings losses by age for our welfare analysis, in turn providing further intuition for the results documented thus far.

\subsection{Dissecting the Results}

In Section 2 we empirically documented three salient facts distinguishing young and households: (i) their divergent claims to financial and human wealth (current and future labor earnings), (ii) their differential exposure to risky financial assets, and (iii) their asymmetric labor earnings declines during the Great Recession. Our baseline model is consistent with all three features, and we therefore believe that it paints an accurate picture of the welfare impact of the Great Recession for different age cohorts. But to better understand what drives these welfare results, we now consider a sequence of alternative economies in which portfolios are exogenous and identical to those in the data in 2007 and/or the decline in labor earnings in the Great Recession is symmetric across age groups and equal to $8.3 \%$ for all households.

(8.297\%). Because markets are sequentially complete, the consumption drop is equalized across all households who were active in the period prior to the recession (i.e., those aged 30 and older in the recession period), whereas the newborn suffer slightly larger consumption losses of $8.357 \%$. The finding of very similar current consumption declines is specific to the $\sigma=2.5$ case and does not extend to alternative parameterizations (see Section 7).

${ }^{32}$ One may wonder to what extent the differential welfare losses documented so far reflect the fact that the current old will spend the remainder of their lives in the recession state, while younger households, in expectation, will spend the majority of their future lives in normal times. In order to address this issue, in Table A-5 in Appendix $\mathrm{G}$, we report an alternative, wealth-based welfare loss measure that is invariant to the remaining lifetime horizon. More precisely, we ask how much we must reduce wealth for each cohort in the no-recession state for households to be indifferent between life with or without the recession in the current period. To make the magnitude of these numbers easier to interpret, we normalize the wealth numbers by per capita consumption in normal times. From Table A-5 we observe that qualitatively, and to a large extent quantitatively, the same pattern of welfare losses emerges as from our consumption-based measure: welfare losses are broadly monotonic in age in that older generations are made massively worse off by the recession, whereas the welfare losses for the youngest generations are relatively modest. Note that the wealth-based measure shows especially large losses for the 60-69 age cohort. It is at that age that life-cycle consumption peaks, and thus a given percentage of remaining lifetime consumption loss translates into a large absolute current wealth loss for that group. 


\subsubsection{Exogenous Portfolios and Symmetric Earnings Losses}

The results are most transparent when portfolios are fixed and all generations lose a constant share of earnings in the Great Recession. The results for this specification are contained in the last column of Tables 5 and 6 . Furthermore, the right panel of Figure 5, shows the dynamics of aggregate wealth (net worth) leading into and following a recession that lasts for one model period. ${ }^{33}$ Recall that the shock involves an $8.3 \%$ decline in productivity and that agents assign a $15 \%$ probability to a recession occurring in any period. ${ }^{34}$ Finally, Figure 6 displays (dashed red line, labeled "data") the portfolio share in the risky asset households are restricted to hold at each age.

In order to display the dynamics of asset prices, we simulate our model economy, assuming that the sequence for aggregate productivity involves a long period of normal times, a recession in period zero, and a return to normal times in subsequent periods. We see in the right panel of Figure 5 (dashed green line) that in the economy with symmetric earnings losses, aggregate wealth falls by about twice as much as aggregate income, and thus by significantly less than in the benchmark economy. Also note that asset prices overshoot in the first period of recovery after the crisis. This reflects the endogenous dynamics of the wealth distribution in the model. When the shock hits, older households, and especially those in the 60- to 69-year-old age group, sell additional assets to fund consumption. Thus, in the period after the recession, a larger share of aggregate wealth is held by younger cohorts, who are net buyers of assets, while less is held by older cohorts, who are net sellers. This translates into higher net asset demand in the period after the recession and thus the observed overshooting in asset prices.

The welfare losses from the recession are more asymmetric across age groups, relative to the benchmark economy. This is especially noticeable for the oldest generation, who now lose $11 \%$ of remaining lifetime consumption, on account of the fact that, relative to the benchmark, this generation now faces earnings declines of $8.3 \%$ and is forced to hold a more risky portfolio $(80 \%$ as opposed to $60 \%$ in risky assets; see Figure 6 ). The youngest generation, becoming economically active during the recession, still suffers welfare losses. These, however, are very mild at $0.72 \%$ (and milder than in the benchmark economy, since with symmetric earnings declines, their earnings loss is only $8.3 \%$ rather than $11 \%$ as in the benchmark).

\footnotetext{
${ }^{33}$ Given that the number of outstanding bonds and stocks is fixed, total aggregate wealth is a weighted sum (with fixed weights) of stock and bond prices.

${ }^{34}$ That is, this price path for a specific realization of the aggregate stochastic process is based on household decision rules that fully internalize the possibility, in the period prior to the recession, that such a recession might (or might not) occur, and also capture the possibility that the recession may last for more than one model period.
} 
Figure 5: Equilibrium Asset Prices
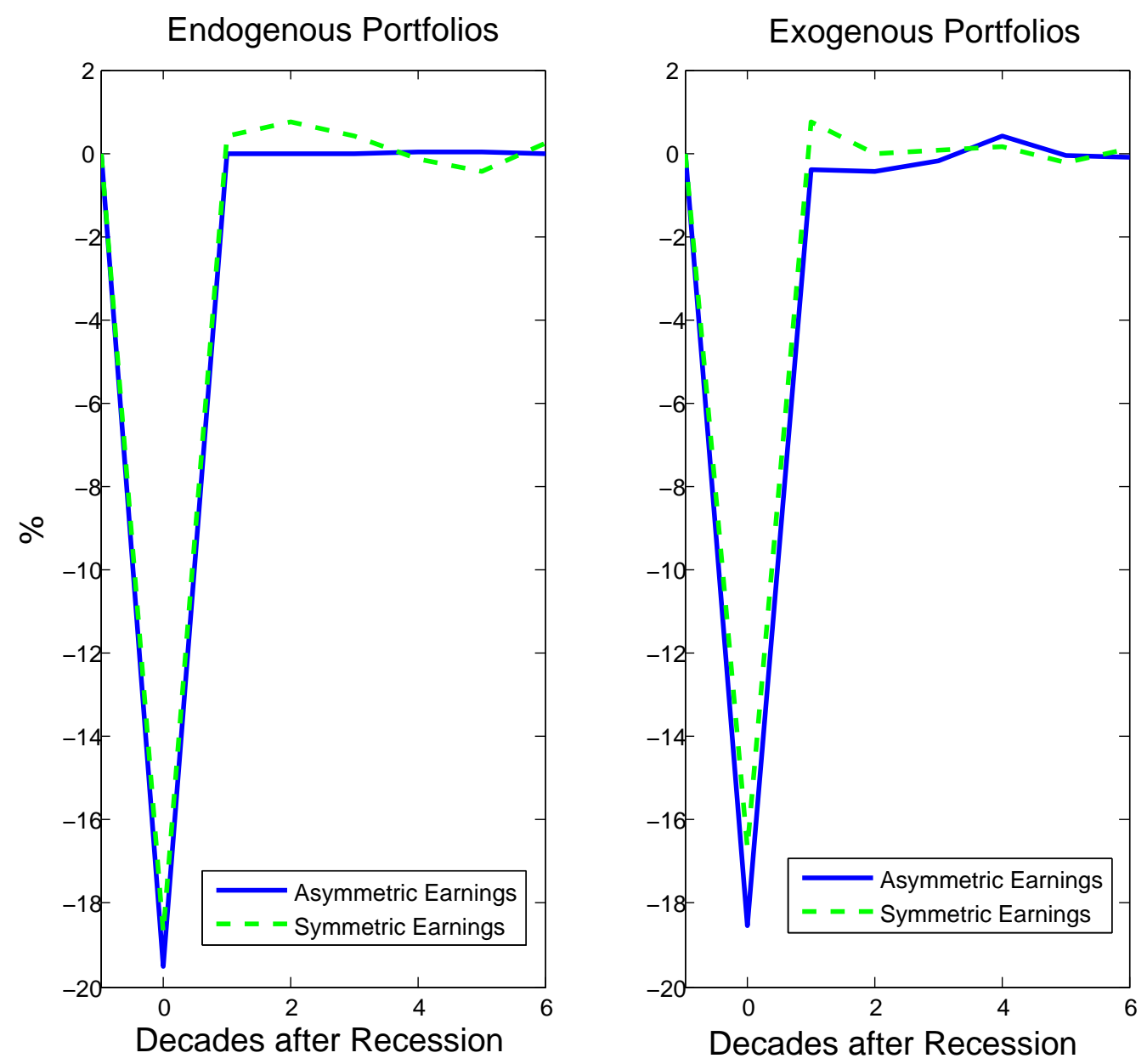

Finally, and most noticeably, the welfare losses of the 30 year-olds now exceed those of the 40 year-olds. The key to understanding this finding is again Figure 6: in the data, the 20 year-olds hold very risky portfolios (recall that real estate is counted as a risky asset). In fact, their portfolios are riskier than what households find optimal in the benchmark economy with endogenous portfolio choice. Once the recession hits, the now 30 year-olds are faced with massive capital losses and start the recession period with very low wealth, relative to the no-recession scenario. The situation is exactly the reverse for the 40 year-olds who (as 30 year-olds) make safer portfolio choices in the data than in the benchmark model and thus suffer smaller losses due to the asset price meltdown in the recession. 
Figure 6: Portfolio Shares in Risky Assets: Models and Data

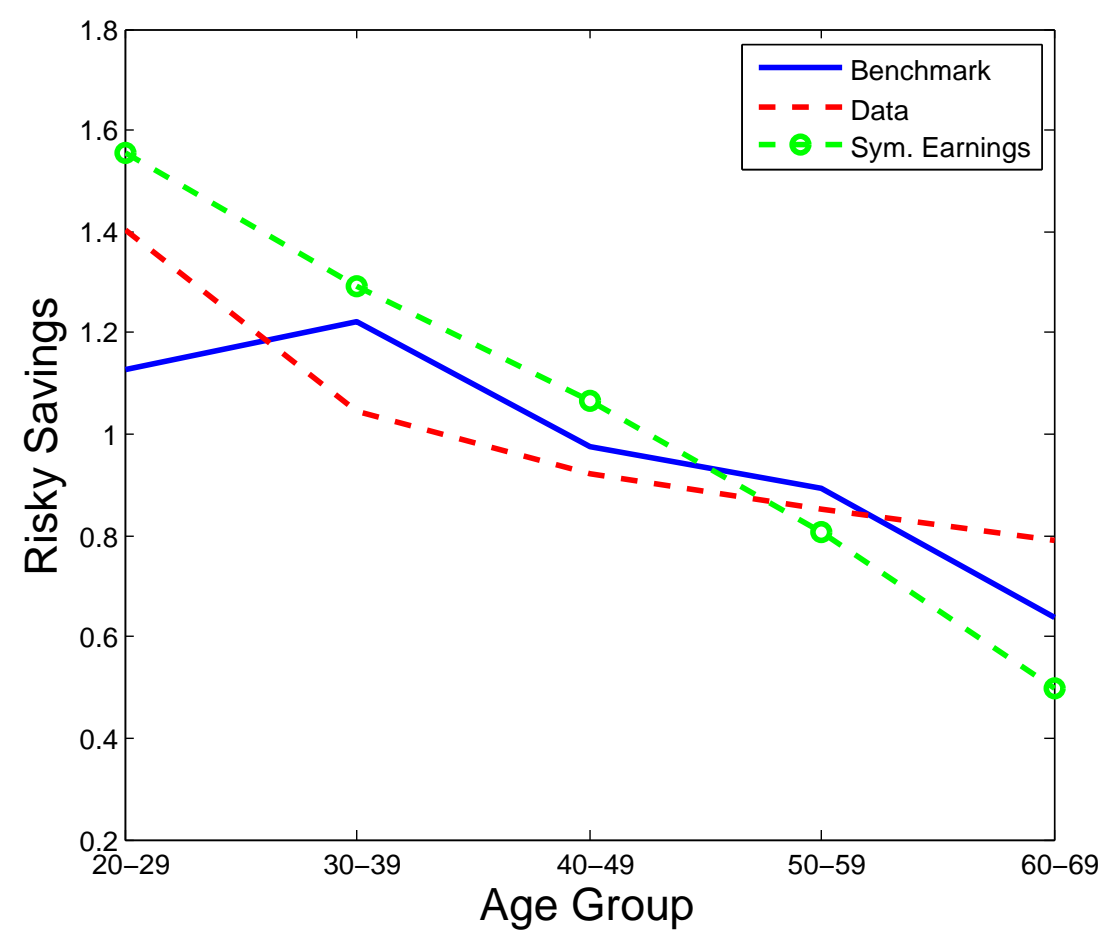

\subsubsection{Asymmetric Earnings Losses}

In the previous subsection we assumed, counterfactually, that each age cohort was subjected to the same $8.3 \%$ decline in labor earnings in the recession. We now isolate the importance of asymmetric earnings losses for our benchmark results. Introducing larger earnings declines for young households and smaller ones for the elderly has two effects. First, it directly and mechanically reduces welfare losses for older generations and raises them for the young. But second, and more subtly, it has an impact on the dynamics of asset prices in general equilibrium. This can be seen by comparing the solid blue line with the dashed green line in the right panel of Figure 5.

With asymmetric earnings losses, young households on the asset demand side of the market are income poorer, and thus prices have to drop more in the recession period to induce these households to buy up the assets: the wealth decline amounts to $18.5 \%$ rather than $16.7 \%$. The asset price overshooting result also disappears, since the 40 year-olds in the post-recession period now have less wealth: their larger earnings losses as 30 year-olds in the recession period induced them to buy fewer assets. Also note that the (a)symmetry of earnings losses also has an impact on which asset prices move more, since the young buy stocks (partially on credit), while middle-aged 
households also buy bonds. Thus, if the earnings losses are concentrated among the young, it is stock prices that must fall more sharply given exogenous and fixed portfolio shares. In contrast, if labor earnings losses are evenly distributed, the price decline is more severe in the bond market (see Table 5, columns 3 and 4).

The more substantial collapse in the price of risky assets (relative to the symmetric earnings case), ceteris paribus, hurts those with risky portfolios most severely. Thus, not surprisingly, as the third column of Table 6 indicates, the 30 year-olds now suffer even more, both because their earnings losses are steeper than in the previous subsection and because of the sharp fall in stock prices. On the other hand, for the other generations the direct earnings effect and the general equilibrium price effects tend to go in opposite directions: the new entrants benefit from steeper price declines but suffer from more severe earnings losses, while the impacts are reversed for older generations. Column 3 of Table 6 summarizes the upshot for welfare of this trade-off. In Section 6.2 below, we further disentangle the importance of each effect.

\subsubsection{Endogenous Portfolio Choice}

In the benchmark economy, households choose their asset portfolios optimally to try to hedge against earnings and asset return risk. Of course, since the underlying risk is aggregate in nature, endogenous portfolio choice simply leads to a reallocation of this risk across different generations, rather than to diversification for the economy as a whole.

Figure 6 shows that, broadly speaking (and with one exception explained below), young households find it optimal to hold riskier asset portfolios than old households, resulting in downwardsloping life-cycle portfolio shares. The age variation in portfolios predicted by the theory is remarkably similar to that observed in the data, indicating that the model offers a compelling theoretical rationale for observed portfolio choice over the life cycle.

Why do households gradually adopt safer portfolios as they age? First, note that with two assets and two possible aggregate shock realizations, markets are sequentially complete in the model with endogenous portfolio choice (a fact we exploit in the computation of this version of the model; see Appendix B). Thus, all households born prior to the recession share consumption risk perfectly in the recession period. ${ }^{35}$ As long as asset prices fluctuate by more than output (that is, as long as $\xi>1$, which is the case in equilibrium as long as $\sigma>1$ ), younger households who have

\footnotetext{
${ }^{35}$ Note that the overlapping-generations structure of the model prevents the cohorts who are alive at a particular point in time from sharing aggregate risk with past or future generations.
} 
little wealth relative to earnings require a more leveraged portfolio (a higher equity-to-debt ratio) to face the same consumption exposure to aggregate risk as older (and wealthier) households. ${ }^{36}$ Thus, the equilibrium share of equity in household portfolios is decreasing with age, consistent with the downward-sloping profile for the share of risky assets in net worth observed in the SCF.

Note that the slope of the life-cycle portfolio profile is steeper when earnings losses are symmetric across generations (the dashed green line with circles in Figure 6), relative to the situation in which the labor earnings of the young are more sensitive to aggregate conditions than those of the old (the solid blue line). The intuition for this result is exactly the same as before: a larger exposure to aggregate risk via the labor market for the young reduces the optimally chosen exposure to this same risk through financial portfolios. In fact, as Figure 6 shows, in the benchmark economy with asymmetric earnings losses, the fact that the 20 year-olds understand that they will suffer severe labor income losses as 30 year-olds should a recession materialize makes them select relatively safe portfolios, relative to the symmetric earnings loss economy and relative to the data. The initial nonmonotonicity of portfolio shares in the benchmark economy (which is absent with symmetric earnings losses and absent in the data) is fully consistent with efficient consumption risk sharing in a world in which the young suffer especially pronounced declines in labor earnings in recessions.

Finally, Figure 5 (left panel) and Table 6 (columns 1 and 2) trace out the equilibrium price dynamics and welfare consequences associated with these portfolio choices. The dynamics of asset prices are broadly similar to the cases with exogenous portfolios, but the price declines are now somewhat more pronounced (in that asset prices now fall in excess of 19\%). The difference between the economies with symmetric and asymmetric earnings losses is smaller now, since while it is still true that with asymmetric earnings losses, the young are less inclined to buy assets in the recession (putting extra downward pressure on prices), at the same time the young now endogenously chose safer portfolios prior to the recession and thus are not as wealth poor when the recession hits. Looking at asset price dynamics in the benchmark economy (the solid blue line in the left panel of Figure 5), we see that asset prices in the first recovery period neither overshoot nor undershoot, relative to their long-run levels associated with the good aggregate state. This reflects the fact that in this particular specification, the wealth distribution is largely insensitive to the cycle: in a recession, lower earnings and cheaper asset prices have nearly perfectly offsetting effects on labor market entrants' desire to purchase assets.

\footnotetext{
${ }^{36}$ Recall from Proposition 1 in Section 4 that with logarithmic preferences and symmetric earnings losses, portfolios are age invariant. This is precisely because in this case, human and financial wealth exhibit exactly the same exposure to aggregate risk, and thus the young are in no better position to bear aggregate asset price risk than are the old.
} 
Column 1 in Table 6 indicates that the age distribution of welfare effects in the endogenous portfolio model is broadly similar to that in the corresponding exogenous portfolio economy (column 3 ). This reflects the fact that the age profile for portfolio composition is similar in the two models, while at the same time the models exhibit similar asset price dynamics. There are, however, some noteworthy differences between the two economies. For example, despite larger price declines in the endogenous portfolio economy, the oldest generation suffers smaller welfare losses because it has endogenously chosen a safer portfolio (relative to the empirical portfolio imposed in the exogenous portfolio model) in the pre-recession period.

Column 2 in Table 6 indicates that economically newborn households would suffer minimal welfare losses in a recession if they were not disproportionately hurt in the labor market: the current earnings loss of $8.3 \%$ would be compensated for by attractively low asset prices. However, since earnings losses are indeed more strongly concentrated among the young ( $11 \%$ instead of $8.3 \%$ for the "newborns"), nontrivial welfare losses of $1.67 \%$ of permanent consumption materialize in the benchmark economy, notwithstanding the effects of favorable asset price movements. Given the central importance of the asset price mechanism, in the next section we conduct a series of counterfactual thought experiments to document its precise quantitative impact on our welfare results.

\subsection{Quantifying the Asset Price Channel}

In this section we present the welfare consequences of a recession when holding asset prices constant. The collapse in asset prices and (in expectation) their subsequent recovery affects households in two ways. First, for all households that were alive and that had purchased risky assets in the previous no-recession period, the asset price collapse presents a negative wealth effect. Second, going forward, relative to the no-recession scenario all households (including the economically newborns) can count on asset price appreciation. Table 7 displays the welfare effects for the baseline model (with endogenous portfolio choice and asymmetric earnings losses across age groups) and for two alternative partial equilibrium paths for asset prices and returns. In the "Constant Returns" column we assume that the recession entails labor income losses, but no changes in asset returns in the recession period or any future periods. In the "No Price Recovery" column, we impose the initial capital losses from the baseline general equilibrium model, but assume that returns are fixed at their pre-recession levels in all future periods.

When we compare across the three columns of Table 7 , it is clear that asset price dynamics are quantitatively very important for the size and age distribution of welfare losses. Welfare losses for 
the youngest generation more than double absent an asset price recovery following the recession. The welfare implications from the downturn also turn more negative for the 30-39 and the 4049 cohorts. For older cohorts, in contrast, the absence of the initial asset devaluation effect in the "Constant Returns" case implies smaller welfare losses than in the baseline model, since for these age groups, capital losses in the recession period matter more than expected future capital gains. For all age groups, welfare costs are largest in the "No Price Recovery" case, since here the recession brings capital losses, but no future expected capital gains. Contrasting the "Constant Returns" and "No Price Recovery" cases isolates the role of capital losses in the recession period for the distribution of welfare effects: these losses have zero impact on the youngest group, but devastating consequences for the 50 and 60 year-olds.

Table 7: Welfare Losses: Alternative Asset Price Paths

\begin{tabular}{l|ccc}
\hline \hline & \multicolumn{3}{|c}{ Economy } \\
\hline Age Group & Baseline & Constant Returns & No Price Recovery \\
\hline $20-29$ & $-1.67 \%$ & $-3.66 \%$ & $-3.66 \%$ \\
$30-39$ & $-2.11 \%$ & $-3.34 \%$ & $-5.95 \%$ \\
$40-49$ & $-2.50 \%$ & $-2.78 \%$ & $-8.43 \%$ \\
$50-59$ & $-3.66 \%$ & $-3.24 \%$ & $-10.50 \%$ \\
$60-69$ & $-5.45 \%$ & $-1.27 \%$ & $-10.72 \%$ \\
$70+$ & $-8.30 \%$ & $0.06 \%$ & $-8.30 \%$ \\
\hline \hline
\end{tabular}

To summarize, the endogenous collapse in asset prices is the quantitatively crucial ingredient in our determination of the welfare losses from the Great Recession. It strongly mitigates the losses for the young induced by massive labor income losses because it affords these households favorable opportunities for asset purchases. Conversely, for older households with substantially positive risky asset positions, the asset price collapse is the main source of welfare losses from the recession, since for these age cohorts, capital losses on their portfolios matter more than declines in labor income.

\section{Robustness of Our Results}

The purpose of this section is to investigate the robustness of our results to alternative parameterizations of the model and alternative modeling assumptions. 


\subsection{Alternative Parameterizations: The Role of the Size of Asset Price Declines}

Given the results in the previous section, one would expect that the magnitude of the welfare losses induced by a recession depends crucially on the magnitude of the asset price decline it implies. We argued in Section 4 that by reducing the intertemporal elasticity of substitution $1 / \sigma$, we can amplify asset price fluctuations. We therefore now display results for our economies for values of $\sigma=1$ and $\sigma=5$. The larger is $\sigma$, the larger will be the fluctuations in asset prices, and thus the more quantitatively potent the asset price channel described in the previous section. ${ }^{37}$ In Table 8 we display the magnitude of asset price declines $\xi$ for $\sigma \in\{1,2.5,5\}$ for the model with endogenous portfolios. Table 9 summarizes the corresponding welfare consequences.

Table 8: Comparison of Elasticities across Parameterizations

\begin{tabular}{l|ccc|ccc}
\hline \hline & \multicolumn{5}{|c}{ Endogenous Portfolio Economies } \\
\hline & \multicolumn{3}{|c}{ Asymmetric Earnings } & \multicolumn{3}{c}{ Symmetric Earnings } \\
\hline Asset & $\sigma=1$ & $\boldsymbol{\sigma}=\mathbf{2 . 5}$ & $\sigma=5$ & $\sigma=1$ & $\sigma=2.5$ & $\sigma=5$ \\
\hline Wealth & 1.05 & $\mathbf{2 . 3 5}$ & 4.04 & 1.00 & 2.25 & 3.89 \\
Stock & 1.03 & $\mathbf{2 . 3 4}$ & 4.11 & 1.00 & 2.28 & 4.01 \\
Bond & 1.19 & $\mathbf{2 . 3 6}$ & 3.30 & 1.00 & 1.94 & 2.56 \\
\hline \hline
\end{tabular}

Table 9: Comparison of Welfare Losses

\begin{tabular}{l|ccc|ccc}
\hline & \multicolumn{6}{|c}{ Endogenous Portfolio Economies } \\
\hline & \multicolumn{4}{|c}{ Asymmetric Earnings } & \multicolumn{3}{c}{ Symmetric Earnings } \\
\hline Age Group & $\sigma=1$ & $\boldsymbol{\sigma}=\mathbf{2 . 5}$ & $\sigma=5$ & $\sigma=1$ & $\sigma=2.5$ & $\sigma=5$ \\
\hline $20-29$ & $-4.38 \%$ & $\mathbf{- 1 . 6 7} \%$ & $0.09 \%$ & $-2.37 \%$ & $-0.35 \%$ & $1.42 \%$ \\
$30-39$ & $-2.36 \%$ & $\mathbf{- 2 . 1 1} \%$ & $-2.58 \%$ & $-2.77 \%$ & $-2.38 \%$ & $-2.81 \%$ \\
$40-49$ & $-2.97 \%$ & $\mathbf{- 2 . 5 0} \%$ & $-2.90 \%$ & $-3.27 \%$ & $-2.70 \%$ & $-3.07 \%$ \\
$50-59$ & $-3.91 \%$ & $\mathbf{- 3 . 6 6} \%$ & $-4.00 \%$ & $-4.09 \%$ & $-3.81 \%$ & $-4.13 \%$ \\
$60-69$ & $-5.25 \%$ & $\mathbf{- 5 . 4 5} \%$ & $-5.72 \%$ & $-5.36 \%$ & $-5.55 \%$ & $-5.82 \%$ \\
$70+$ & $-8.22 \%$ & $\mathbf{- 8 . 3 0} \%$ & $-8.41 \%$ & $-8.30 \%$ & $-8.38 \%$ & $-8.49 \%$ \\
\hline \hline
\end{tabular}

From Table 8 we observe, as expected, that the magnitude of asset price movements increases monotonically with $\sigma$, albeit in a concave fashion. The elasticity of net worth with respect to output $\xi$ is very close to 1 for $\sigma=1$, equal to 2.35 for $\sigma=2.5$ and about 4 for $\sigma=5$, in the

\footnotetext{
${ }^{37}$ Note that for each $\sigma$, we recalibrate the life-cycle profile of time discount factors $\left\{\beta_{i}\right\}$ so that the model continues to be consistent with the 2007 SCF net worth profiles over the life cycle.
} 
benchmark economy with age-dependent earnings losses. ${ }^{38}$ Similar results are obtained if earnings losses are symmetric across cohorts, but now $\xi$ is exactly equal to one when $\sigma=1$, in line with Proposition 1.

The changes in the welfare consequences of a recession, especially for the youngest cohort, follow the magnitude of asset price movements rather closely. If $\sigma=1$, this age group suffers significantly more. If, on the other hand, $\sigma=5$ and thus asset prices fall roughly $33 \%$ rather than $20 \%$ as in the benchmark calibration, then young households in fact register welfare gains from the recession, notwithstanding the sharp labor income losses they suffer. While expected lifetime utility for the youngest age group is slightly higher in the recession state than in normal times, current consumption is $6.32 \%$ lower. This confirms that the source of welfare gains for the youngest group is their ability to increase asset purchases when prices are temporarily low in the recession period, thereby ensuring higher asset income and consumption (relative to the nonrecession scenario) later in the life cycle. ${ }^{39}$

Comparing the welfare losses with $\sigma=5$ to the benchmark $(\sigma=2.5)$, we see that older generations lose more now, due to the larger declines in asset prices. Note, however, that older households choose safer portfolios in the $\sigma=5$ case, precisely because they anticipate sharper asset price declines in the positive probability event that a recession hits. The impact on portfolios can be gauged from Figure 7, which displays portfolio allocations over the life cycle chosen under $\sigma=5$ with those emerging under the benchmark calibration with $\sigma=2.5$. Because of these endogenous portfolio adjustments, welfare losses for older generations are only moderately higher in the former case despite the much more substantial declines in asset prices.

Thus, the sensitivity analysis with respect to the IES $1 / \sigma$ reconfirms the importance of the endogenous asset pricing channel for the age distribution of welfare costs. It also demonstrates that for plausible parameterizations of the model, asset price movements can be so large that agents may prefer to become economically active in a recession rather than in normal times. However, the model-implied asset price declines under $\sigma=5$ are larger than were actually observed in the Great Recession, leading us to prefer $\sigma=2.5$ as our benchmark choice.

\footnotetext{
${ }^{38}$ Given that both assets are in fixed supply, this elasticity is a weighted sum of the stock price and the bond price elasticities.

${ }^{39}$ Welfare gains for the youngest group are even larger in the case of symmetric earnings losses, since the youngest cohort's decline in labor income is then smaller.
} 
Figure 7: Portfolio Shares in Risky Assets, $\sigma=5$

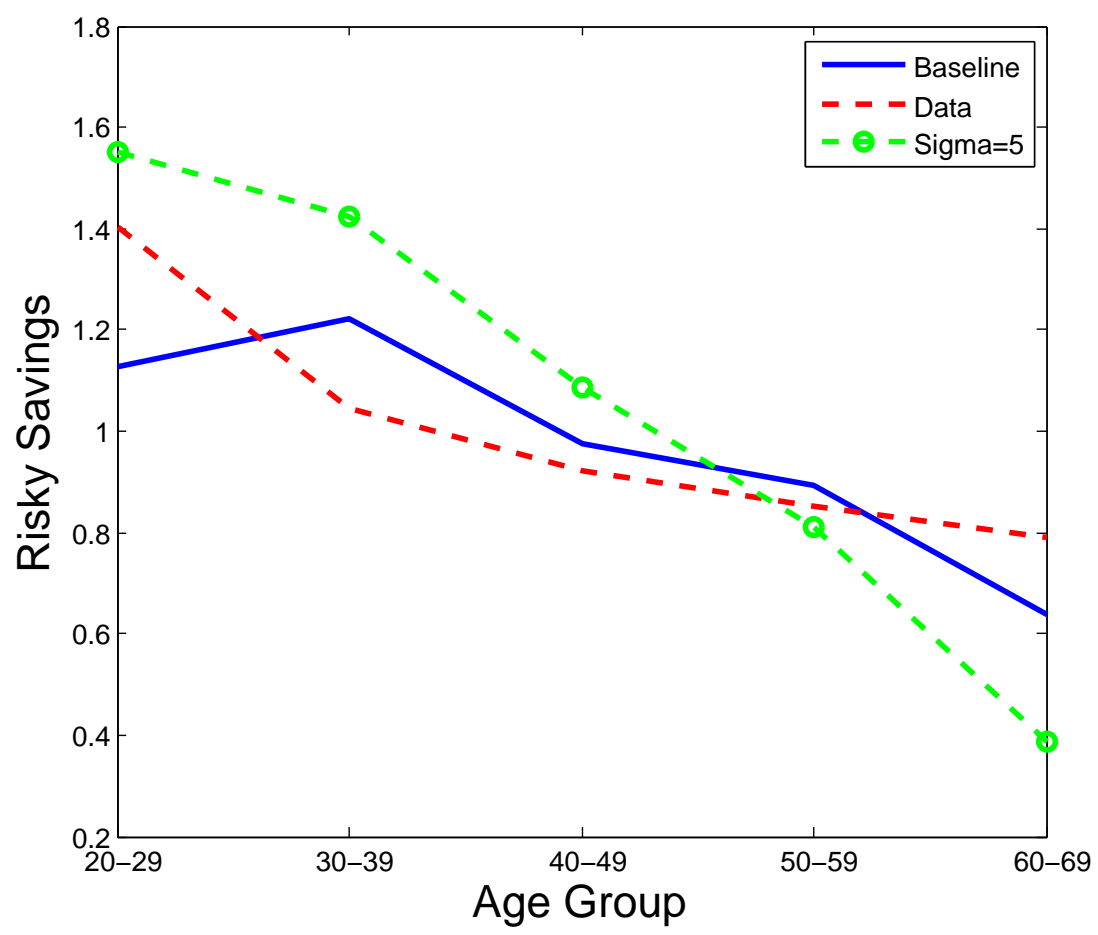

\subsection{Alternative Modeling Choices}

In this section we want to briefly argue that our qualitative and quantitative results are robust to a number of alternative modeling assumptions.

\subsubsection{Explicitly Modeling Housing}

Residential real estate is the single most important component of household net worth. We now extend our baseline model to allow households to invest in three assets: stocks, bonds, and housing. The key finding will be that under a particular rescaling of parameter values, the welfare consequences of recessions in the economies with and without housing are identical. In what follows, the superscript $H$ is used to differentiate parameter values from their counterparts in the original model without housing. 
Preferences are given by

$$
E\left[\sum_{i=1}^{I} \prod_{j=1}^{i} \beta_{j}^{H} \frac{x_{i}^{1-\sigma^{H}}-1}{1-\sigma^{H}}\right]
$$

where $x_{i}$ is a composite consumption bundle comprising nondurable consumption $c$ and housing services $s$, with respective shares $v^{H}$ and $1-v^{H}$ :

$$
x_{i}=c_{i}^{v^{H}} s_{i}^{1-v^{H}}
$$

This Cobb-Douglas specification is consistent with extensive empirical evidence (see, for example, Davis and Ortalo-Magne 2011). We assume that the aggregate supply of housing services is state invariant and normalized to one. Housing is perfectly divisible, and there is a frictionless rental market. Thus, agents can separate the decisions of how much housing to consume versus how much housing to own for investment purposes. The technology for producing the nondurable good $c$ is exactly the same as in the baseline model, and this technology produces $z^{H}$ units of nondurable output. Now corporate debt is a promise to deliver one unit of the composite good $x$ in the next period. The firm issues $B^{H}$ units of this debt each period. We then have the following proposition.

Proposition 2. If

$$
\begin{aligned}
(1-\theta) & =\left(1-\theta^{H}\right) v^{H}, \\
B & =\left(1+\frac{\left(1-v^{H}\right)}{v^{H} \theta^{H}}\right) B^{H}, \\
\{z\} & =\left\{\left(z^{H}\right)^{v^{H}}\right\}, \\
\left\{\beta_{i}\right\} & =\left\{\beta_{i}^{H}\right\}, \\
\left\{\varepsilon_{i}\right\} & =\left\{\varepsilon_{i}^{H}\right\}, \\
\sigma & =\sigma^{H}, \\
\Gamma & =\Gamma^{H},
\end{aligned}
$$

then in the economy without housing, the life-cycle consumption profiles and the law of motion 
for wealth are identical, state by state, to their counterparts in the economy with housing:

$$
\begin{aligned}
c_{i}(z, A, a) & =x_{i}\left(z^{H}, A, a\right) \\
G\left(z, A, z^{\prime}\right) & =G^{H}\left(z^{H}, A,\left(z^{H}\right)^{\prime}\right) .
\end{aligned}
$$

where $G^{H}$ denotes the law of motion for wealth shares in the model with housing. It follows immediately that the welfare consequences of recessions in the two economies are identical for each age, in each aggregate state.

\section{Proof. See Appendix F.}

The key to this result is that, in this model, rents comove perfectly with output, and house prices comove perfectly with the value of nonhousing wealth. Let $p^{h}(z, A)$ denote the ex-rent price of housing, and let rents and the price of non-durable consumption be denoted by $r(z, A)$ and $p^{c}(z, A)$. Then in the model with housing,

$$
\begin{aligned}
p^{h}(z . A) & =\frac{\left(1-v^{H}\right)}{v^{H} \theta^{H}}\left[p(z, A)+q(z, A) B^{H}\right] \\
\frac{r(z, A)}{p^{c}(z, A)} & =\frac{\left(1-v^{H}\right)}{v^{H}} z^{H} .
\end{aligned}
$$

Thus, the housing asset offers the same returns as the market portfolio of corporate equity and debt. It follows that introducing housing does not affect households' ability to share risks across generations. At the same time, given Cobb-Douglas preferences and the implied constant expenditure shares for nondurable consumption and housing, introducing housing does not change the shapes of the life-cycle profiles for consumption or asset holdings.

\subsubsection{Accounting for Intra-Cohort Heterogeneity}

Our baseline calibration replicates average income and wealth by age. However, it is well known that a large fraction of aggregate wealth is held by a relatively small fraction of households. Thus, one might wonder whether less wealthy households are likely to experience similar welfare losses across the life cycle.

To address this question, we now consider an alternative version of the model in which there are two types of households: a wealthy type and a low-wealth type. We assume that the wealthy type 
accounts for a fixed fraction $\kappa_{y}$ of aggregate labor earnings and passively holds a fixed fraction $\kappa_{a}$ of aggregate debt and equity. It follows that the wealthy consume a fixed fraction $(1-\theta) \kappa_{y}+\kappa_{a} \theta$ of aggregate output at each date. Because the wealthy type is assumed to invest passively, assets are priced by the low-wealth type, and prices fluctuate such that this type always demands $\left(1-\kappa_{a}\right)$ shares and $\kappa_{a} B$ bonds.

Since the wealthy type accounts for fixed fractions of earnings, asset holdings, and consumption, we can solve for equilibrium allocations by ignoring the wealthy group altogether and simply recalibrating the baseline model to target a lower wealth to labor income ratio corresponding to $\bar{W}^{P}=\frac{\left(1-\kappa_{a}\right)}{\left(1-\kappa_{y}\right)}$. We identify the wealthy type with households in the top $10 \%$ of the net worth distribution in the $2007 \mathrm{SCF}$, which implies $\kappa_{a}=0.678, \kappa_{y}=0.334$, and $\bar{W}^{P}=0.483 \bar{W}$. Retaining our original targets for $\bar{R}$ and $\bar{\lambda}$, equation 16 implies new values for the supply of bonds and for capital's share of $B^{P}=0.0400$ and $\theta^{P}=0.1729$.

Given the life-cycle profiles for labor income and for net worth for the low-wealth group, we can follow the procedure outlined in Section 5 to reverse engineer the life-cycle profile $\left\{\beta_{i}^{P}\right\}$ that rationalizes the implied life-cycle profile for consumption for the low-wealth group. Because this group does less life-cycle saving, its consumption rises less rapidly over the life cycle, and the implied discount factors are therefore smaller.

We will focus on our baseline model specification, in which agents choose both total savings and the portfolio split between equity and bonds. Earnings losses are distributed asymmetrically across age groups, consistently with the evidence from the CPS discussed earlier. We also assume our baseline value for risk aversion, $\sigma=2.5$.

The equilibrium decline in asset prices in the new low-wealth economy when the recession hits is $2.40 \%$, which is very similar to the $2.35 \%$ decline in the baseline model. Table 10 compares the welfare losses associated with entering a recession in the low-wealth economy with those in the baseline model. The distribution of losses by age is quite similar in the two models. One difference is that welfare costs are generally somewhat larger in the low-wealth economy for younger agents. The reason for this finding is that with a lower aggregate wealth to income ratio, the asset price channel for redistributing between old and young agents is less important. Older households hold less wealth, and thus suffer smaller capital losses, while younger households do less life-cycle saving and benefit less from temporarily depressed asset prices. 


\section{Table 10: Welfare Losses: Low-Wealth Calibration}

\begin{tabular}{l|cc}
\hline \hline & \multicolumn{2}{|c}{ Economy } \\
\hline Age Group & Baseline & Low Wealth \\
\hline $20-29$ & $-1.67 \%$ & $-2.50 \%$ \\
$30-39$ & $-2.11 \%$ & $-2.83 \%$ \\
$40-49$ & $-2.50 \%$ & $-3.24 \%$ \\
$50-59$ & $-3.66 \%$ & $-4.04 \%$ \\
$60-69$ & $-5.45 \%$ & $-5.58 \%$ \\
$70+$ & $-8.30 \%$ & $-8.25 \%$ \\
\hline \hline
\end{tabular}

\section{Conclusion}

In this paper we have analyzed the distributional consequences of a large recession across different age groups. In a quantitative version of our stochastic overlapping-generations economy restricted to match life-cycle income and asset profiles from the SCF, we find that older households suffer large welfare losses from a severe, long-lasting recession. Young households, in contrast, lose less and might even benefit from an economic downturn. The key statistic that determines these welfare consequences is the size of the equilibrium asset price decline, relative to the fall in wages and output. If households have a low intertemporal elasticity of substitution, then middle-aged households are eager to sell their assets in a downturn in order to smooth consumption, thereby putting additional downward pressure on asset prices. This amplifies welfare losses for older households and also implies potential welfare gains for households that become economically active during the recession and buy assets at fire-sale prices.

Knowledge about how the welfare costs of recessions are distributed across the age distribution can help inform the discussion of the appropriate policy response. Many of the policies that have been implemented in response to the Great Recession have obvious distributional consequences. First, financing an increasing share of the government budget through debt rather than taxation shifts the tax burden toward the young and future generations, benefitting older age groups. Second, the Troubled Asset Relief Program (TARP) and large-scale asset purchases by the Federal Reserve were policies that were more or less explicitly designed to support asset prices. To the extent that these policies were successful, these were policies that disproportionately benefitted older and therefore wealthier households. ${ }^{40}$ From the perspective of the age-asymmetric welfare

\footnotetext{
${ }^{40}$ Another important policy response was a dramatic extension of unemployment benefits. On the one hand, this favored younger workers, who bore the brunt of rising unemployment. On the other, older workers are more likely to be eligible to receive benefits. In 2010, the numbers of insured unemployed in the 25-34, 35-44, and 45-54 age
} 
losses documented in this paper, a distributional argument can be made in favor of such policies. We view a full quantitative exploration of this hypothesis as an obvious next step in the analysis, but one beyond the scope of the current paper.

\section{References}

Attanasio, O., S. Kitao, and G. Violante (2007): "Global Demographic Trends and Social Security Reform," Journal of Monetary Economics, 54(1), 144-198.

Ball, L., And N. G. MAnkiw (2007): "Intergenerational Risk Sharing in the Spirit of Arrow, Debreu, and Rawls, with Applications to Social Security Design," Journal of Political Economy, 115(4), 523-547.

BArro, R. (2006): "Rare Disasters and Asset Markets in the Twentieth Century," Quarterly Journal of Economics, 121(3), 823-866.

(2009): "Rare Disasters, Asset Prices, and Welfare Costs," American Economic Review, 99(1), 243-264.

Brumm, J., And F. Kubler (2013): "Applying Negishi's method to Stochastic Models with Overlapping Generations," Working Paper, University of Zurich.

Campbell, J., And Y. Nosbusch (2007): "Intergenerational Risksharing and Equilibrium Asset Prices," Journal of Monetary Economics, 54(8), 2251-2268.

Constantinides, G., J. Donaldson, and R. Mehra (2002): “Junior Can't Borrow: A New Perspective on the Equity Premium Puzzle," Quarterly Journal of Economics, 117(1), 269-296.

Davis, M. A., And F. Ortalo-Magne (2011): "Household Expenditures, Wages, Rents," Review of Economic Dynamics, 14(2), 248-261.

Doepke, M., And M. SchneIder (2006a): "Inflation and the Redistribution of Nominal Wealth," Journal of Political Economy, 114(6), 1069-1097.

- (2006b): "Inflation as a Redistribution Shock: Effects on Aggregates and Welfare," NBER Working Paper 12319.

Hall, R. E. (1988): "Intertemporal Substitution in Consumption," Journal of Political Economy, 96(2), 339-357.

(2014): "Quantifying the Lasting Harm to the U.S. Economy from the Financial Crisis," Unpublished manuscript.

groups were very similar (Department of Labor, Employment and Training Administration). 
Huffman, G. (1987): "A Dynamic Equilibrium Model of Asset Prices and Transaction Volume," Journal of Political Economy, 95(1), 138-159.

HuR, S. (2013): "The Lost Generation of the Great Recession," Working Paper, University of Pittsburgh.

Krueger, D., And F. Kubler (2004): "Computing Equilibrium in OLG Models with Stochastic Production," Journal of Economic Dynamics and Control, 28(7), 1411-1436.

Krueger, D., And F. Kubler (2006): "Pareto-Improving Social Security Reform when Financial Markets Are Incomplete!?," American Economic Review, 96(3), 737-755.

Krueger, D., And A. Ludwig (2007): "On the Consequences of Demographic Change for Rates of Returns to Capital, and the Distribution of Wealth and Welfare," Journal of Monetary Economics, 54(1), 49-87.

Kubler, F., And K. Schmedders (2013): "Life-Cycle, Portfolio Choice, the Wealth Distribution and Asset Prices," Working Paper, University of Zurich.

Labadie, P. (1986): "Comparative Dynamics and Risk Premia in an Overlapping Generations Model," Review of Economic Studies, 53(1), 139-152.

Meh, C., J.-V. Ríos-Rull, and Y. Terajima (2010): “Aggregate and Welfare Effects of Redistribution of Wealth under Inflation and Price-Level Targeting," Journal of Monetary Economics, 57(6), 637-652.

Miyazaki, K., M. Saito, and T. Yamada (2009): "On the Intergenerational Sharing of Cohort-Specific Shocks on Permanent Income," Macroeconomic Dynamics, 14(01), 93-118.

Nakamura, E., J. Steinsson, R. Barro, and J. Ursua (2013): "Crises and Recoveries in an Empirical Model of Consumption Disasters," American Economic Journal: Macroeconomics, 5(3), 35-74.

Peterman, W. B., And K. Sommer (2014): "How Well Did Social Security Mitigate the Effects of the Great Recession?," Finance and Economics Discussion Series 2014-13, Federal Reserve Board.

Piazzesi, M., M. Schneider, and S. Tuzel (2007): "Housing, Consumption and Asset Pricing," Journal of Financial Economics, 83(3), 531-569.

Ríos-Rull, J.-V. (1994): "On the Quantitative Importance of Market Completeness," Journal of Monetary Economics, 34(3), 463-496.

(1996): "Life-Cycle Economies and Aggregate Fluctuations," Review of Economic Studies, 63(3), 465-489.

(2001): "Population Changes and Capital Accumulation: The Aging of the Baby Boom," Advances in Macroeconomics, 1(1), Article 7. 
Smetters, K. (2006): "Risk Sharing across Generations without Publicly Owned Equities," Journal of Monetary Economics, 53(7), 1493-1508.

Storesletten, K., C. Telmer, and A. Yaron (2004): "Cyclical Dynamics in Idiosyncratic Labor Market Risk," Journal of Political Economy, 112(3), 695-717.

Storesletten, K., C. Telmer, and A. Yaron (2007): "Asset Pricing with Idiosyncratic Risk and Overlapping Generations," Review of Economic Dynamics, 10(4), 519-548.

Vissing-Jørgensen, A., And O. P. Attanasio (2003): "Stock-Market Participation, Intertemporal Substitution, and Risk-Aversion," American Economic Review, 93(2), 383-391. 


\section{Appendix (for Review and Online Publication Only)}

\section{A Economy with Endogenous Portfolios and Complete Markets}

Since in our applications the number of values the aggregate state can take is two, markets are sequentially complete when households can freely trade a bond and a stock. We exploit this for the purposes of characterizing equilibrium prices numerically. In particular, after having solved for equilibrium allocations (as described in the next section), we can easily construct prices of statecontingent claims (Arrow securities). We then reconstruct the equilibrium prices of conventional stocks and bonds as additional (effectively redundant) assets. For completeness, we here supply the equilibrium definition for the economy with a full set of Arrow securities.

Let $a_{i}\left(z^{\prime}\right)$ be shares of stock purchased by a household of age $i$. These shares represent a claim to fraction $a_{i}\left(z^{\prime}\right)$ of the capital stock if and only if aggregate state $z^{\prime}$ is realized in the next period. The state of the economy is the distribution of shares of stock $A$, given the current period shock $z$. We denote the state-contingent stock prices $P\left(z, A, z^{\prime}\right)$.

With this asset market structure, the maximization problem of the households now reads as

$$
\begin{aligned}
v_{i}(z, A, a)= & \max _{c \geq 0, a^{\prime}\left(z^{\prime}\right)}\left\{u(c)+\beta_{i+1} \sum_{z^{\prime} \in Z} \Gamma_{z, z^{\prime}} v_{i+1}\left(z^{\prime}, A^{\prime}\left(z^{\prime}\right), a^{\prime}\left(z^{\prime}\right)\right)\right\} \\
\text { s.t. } & c+\sum_{z^{\prime}}\left[a^{\prime}\left(z^{\prime}\right)-a\right] P\left(z, A, z^{\prime}\right)=\varepsilon_{i}(z) w(z)+d(z) a \\
& A^{\prime}\left(z^{\prime}\right)=G\left(z, A, z^{\prime}\right)
\end{aligned}
$$

with solution $c_{i}(z, A, a), a_{i}^{\prime}\left(z, A, a, z^{\prime}\right)$.

Definition 2. A recursive competitive equilibrium with complete markets are value and policy functions $\left\{v_{i}, c_{i}, a_{i}^{\prime}\right\}$, pricing functions $w, d, P$, and an aggregate law of motion $G$ such that:

1. Given the pricing functions and the aggregate law of motion, the value functions $\left\{v_{i}\right\}$ solve the recursive problem of the households and $\left\{c_{i}, a_{i}^{\prime}\right\}$ are the associated policy functions.

2. Wages and dividends satisfy

$$
w(z)=(1-\theta) z \quad \text { and } \quad d(z)=\theta z .
$$




\section{Markets clear}

$$
\begin{aligned}
\sum_{i=1}^{I} c_{i}\left(z, A, A_{i}\right) & =z \\
\sum_{i=1}^{\prime} a_{i}^{\prime}\left(z, A, A_{i}, z^{\prime}\right) & =1 \quad \forall z^{\prime} \in Z .
\end{aligned}
$$

4. The aggregate law of motion is consistent with individual optimization

$$
\begin{aligned}
G_{1}\left(z, A, z^{\prime}\right) & =0 \\
G_{i+1}\left(z, A, z^{\prime}\right) & =a_{i}^{\prime}\left(z, A, A_{i}, z^{\prime}\right) \quad \forall z^{\prime}, i=1, \ldots, I-1 .
\end{aligned}
$$

We now describe how we reconstruct returns and prices for conventional stocks and bonds, given the prices of state-contingent shares, exploiting the equivalence between the two market structures when the aggregate shock takes only two values. Let $W(z, A)$ denote the value of the (unlevered) firm after it has paid out dividends. This is equal to the price of all state-contingent shares:

$$
W(z, A)=\sum_{z^{\prime} \in Z} P\left(z, A, z^{\prime}\right) .
$$

In the presence of state-contingent shares, risk-free bonds and levered stocks are redundant assets, but they can still be priced. We now compute these prices $q(z, A)$ and $p(z, A)$ as functions of the state-contingent prices $P\left(z, A, z^{\prime}\right)$ and $W(z, A)$. There are two ways of securing one unit of the good unconditionally in the next period. One could either buy one unit of the risk-free bond at price $q(z, A)$ or instead buy a bundle of state-contingent shares for each possible $z^{\prime}$, setting the state-specific quantity to $1 /\left[W\left(z^{\prime}, G\left(z, A, z^{\prime}\right)\right)+\theta z^{\prime}\right]$ so as to ensure a gross payout of one in each state. A no-arbitrage argument implies that the cost of the two alternative portfolios must be identical:

$$
q(z, A)=\sum_{z^{\prime}} \frac{P\left(z, A, z^{\prime}\right)}{W\left(z^{\prime}, G\left(z, A, z^{\prime}\right)\right)+\theta z^{\prime}} .
$$

With the bond price in hand, the stock price can immediately be recovered from the condition that the value of the unlevered firm (in the economy with state-contingent shares) must equal the 
value of levered stocks and risk-free bonds:

$$
p(z, A)=W(z, A)-q(z, A) B
$$

\section{B Computational Appendix}

Even for a moderate number of generations, the state space is large: $N-2$ continuous state variables (plus $z$ ). Since we want to deal with large shocks, local methods should be used with caution. We therefore use global approximation on sparse grids, thereby respecting the size of our aggregate shock while avoiding the curse of dimensionality. The baseline model takes advantage of the fact that our two assets span the space of possible shocks, therefore allowing us to solve the model via a planning problem using the Negishi algorithm. The fixed-portfolio economies do not solve such a planning problem, so we must directly solve for the competitive equilibrium.

\section{B.1 Endogenous Portfolio Economy}

In our economy with endogenous trade in stocks and bonds, there are two assets and two values for the aggregate shock. Thus, the set of agents who are active at dates $t-1$ and $t$ select portfolios that pool date $t$ risk perfectly and share the same growth rate for the marginal utility of consumption. But it is impossible for agents active at date $t-1$ to share risk with agents who enter the economy at date $t$, and thus shocks at $t$ reallocate resources between the newborn and existing cohorts.

The computational challenge for characterizing equilibrium allocations is to characterize this reallocation. As Brumm and Kubler (2013) show, the key condition that pins down the share of the newborns is their lifetime budget constraint that must be satisfied. Thus, computing a competitive equilibrium amounts to solving for a law of motion for the consumption share of newborn agents, with the property that the present values of lifetime income and consumption are equal with zero initial wealth. We now formally describe this way of characterizing competitive equilibrium.

Let the aggregate state be $z$ and the vector $\boldsymbol{\lambda}=\boldsymbol{\lambda}_{1}, \ldots, \boldsymbol{\lambda}_{\text {I where }} \lambda_{i} \in[0,1]$ for all $i$. Let $\boldsymbol{\lambda}$ define age group $i$ 's share of aggregate output as follows for $i=1, \ldots, l$ :

$$
c_{i}(z, \lambda)=\lambda_{i} z
$$


Let $\boldsymbol{\lambda}^{\prime}=G\left(z^{\prime}, \lambda\right)$ define a law of motion for $\boldsymbol{\lambda}$ and thus a resource-feasible allocation. We will use the notation $\lambda_{i}^{\prime}=G_{i}\left(z^{\prime}, \lambda\right)$.

Allocations in the competitive equilibrium with endogenous portfolios are defined by one particular specification for $G\left(z^{\prime}, \lambda\right)$.

The numerical challenge is to characterize $G_{1}\left(z^{\prime}, \lambda\right)$ which defines $\lambda_{1}^{\prime}$. Given $G_{1}\left(z^{\prime}, \lambda\right)$, we will see that the remaining $G_{i}\left(z^{\prime}, \lambda\right)$, for $i=2, \ldots, l$, defining consumption shares for agents of ages $i=2, \ldots, l$ in the next period are given by

$$
\boldsymbol{\lambda}_{i}^{\prime}=G_{i}\left(z^{\prime}, \boldsymbol{\lambda}\right)=\beta_{i}^{\frac{1}{\sigma}} \frac{\left(1-G_{1}\left(z^{\prime}, \boldsymbol{\lambda}\right)\right)}{\sum_{i=1}^{l-1} \beta_{i+1}^{\frac{1}{\sigma}} \lambda_{i}} \times \boldsymbol{\lambda}_{i-1} \quad i=2, \ldots, l .
$$

The logic for this specification, as we will see shortly, is that it guarantees that all agents share the same state-contingent inter-temporal marginal rate of substitution. Note that, by construction

$$
\sum_{i=1}^{\prime} \lambda_{i}^{\prime}=1
$$

We now describe how we solve for the function $G_{1}\left(z^{\prime}, \lambda\right)$ corresponding to the competitive equilibrium.

Define, for $i=1, \ldots, I-1$

$$
\begin{aligned}
p_{i}\left(z, z^{\prime}, \boldsymbol{\lambda}\right) & =\pi\left(z^{\prime} \mid z\right) \frac{\prod_{l=1}^{i+1} \beta_{l} c_{i+1}\left(z^{\prime}, \boldsymbol{\lambda}^{\prime}\right)^{-\sigma}}{\prod_{l=1}^{i} \beta_{l} c_{i}(z, \boldsymbol{\lambda})^{-\sigma}} \\
& =\pi\left(z^{\prime} \mid z\right) \frac{\prod_{l=1}^{i+1} \beta_{l}\left(\boldsymbol{\lambda}_{i+1}^{\prime} z^{\prime}\right)^{-\sigma}}{\prod_{l=1}^{i} \beta_{l}\left(\boldsymbol{\lambda}_{i} z\right)^{-\sigma}} \\
& =\pi\left(z^{\prime} \mid z\right) \frac{\left(1-G_{1}\left(z^{\prime}, \boldsymbol{\lambda}\right)\right)}{\sum_{i=1}^{l-1} \beta_{i+1}^{\frac{1}{\sigma}} \boldsymbol{\lambda}_{i}}\left(\frac{z^{\prime}}{z}\right)^{-\sigma} .
\end{aligned}
$$

where the second line substitutes in the consumption sharing rule (A-11), and the third line uses the law of motion (A-12). Note from the third line that $p_{i}\left(z, z^{\prime}, \lambda\right)$ is independent of $i$.

Next define functions $B_{i}(z, \lambda)$ as follows, starting from $i=I$, and moving sequentially down 
to $i=1$ :

$$
\begin{aligned}
B_{l}(z, \lambda) & =c_{l}(z, \lambda)-w_{l}(z) \\
B_{i-1}(z, \lambda) & =c_{i-1}(z, \lambda)-w_{i-1}(z)+\sum_{z^{\prime} \in \mathcal{Z}} p\left(z, z^{\prime}, \lambda\right) B_{i}\left(z^{\prime}, \lambda^{\prime}\right) \\
B_{1}(z, \lambda) & =c_{1}(z, \lambda)-w_{1}(z)+\sum_{z^{\prime} \in \mathcal{Z}} p\left(z, z^{\prime}, \lambda\right) B_{2}\left(z^{\prime}, \lambda^{\prime}\right)
\end{aligned}
$$

where in each case $\lambda^{\prime}=G\left(z^{\prime}, \lambda\right)$.

Claim Given the sharing rule $(\mathrm{A}-11)$ and the law of motion $G_{i}\left(z^{\prime}, \lambda\right)$ for $i \geq 2(\mathrm{~A}-12)$, the allocation defined by a function $G_{1}\left(z^{\prime}, \lambda\right)$ is a competitive equilibrium in the stock economy if and only if the implied $B_{1}(z, \lambda)=0$ for all $z, \boldsymbol{\lambda}$.

Proof First, note that allocations in the stock economy are identical to those in an economy in which agents trade two Arrow securities, each of which pays out if and only if one particular value for the aggregate shock $z$ is realized. In an economy with trade in Arrow securities, the conditions defining a competitive equilibrium are: (i) security prices reflect state-contingent marginal rates of substitution, (ii) the agent's budget constraints are satisfied at each age, where financial wealth at age $i=1$ is zero, and (iii) the aggregate resource constraint is satisfied. These conditions are all satisfied by the allocation described above: condition (i) is equation (A-13), condition (ii) is equations (A-14), and condition (iii) is satisfied by virtue of equation (A-11).

Note finally that for computational purposes it is not necessary to carry around the entire vector $\lambda$ since $\sum_{i=1}^{l} \boldsymbol{\lambda}_{i}=1$. Thus, a sufficient state vector is $\left(z,\left\{\boldsymbol{\lambda}_{i}\right\}_{i=1}^{I-1}\right)$. The law of motion A-12 is still sufficient to define consumption for all age groups in the next period.

We now move to solving for the unknown function $G_{1}$ described above. In order to solve the model we implement the following algorithm:

1. Initiate a grid of $\mathcal{L}=\left\{\boldsymbol{\lambda}^{j}\right\}_{j=1}^{J}$, where each $\boldsymbol{\lambda}^{j}$ is an $I-1$ dimensional vector. These will be the collocation points and are in practice sets on a Smolyak grid.

2. For each $z \in \mathcal{Z}$, and each $j=1, \ldots, J$, guess a value $G_{1}\left(z, \lambda_{j}\right)$. Use these guesses to construct an interpolating function $\hat{G}_{1}(z, \lambda)$ for any vector $\lambda$. In practice, we use Chebyshev polynomials in this step.

3. For the $(\# \mathcal{Z})^{l-1}$ possible histories through which a newborn agent could live, and for each 
$j=1, \ldots, J$, use $\hat{G}_{1}$ to construct consumption allocations, Arrow securities prices, and budget errors as described above. The interpolation is necessary because the vector of weights will typically not lie on the grid after one period passes.

4. Steps [2] and [3] create $\# \mathcal{Z} \times J$ equations (the budget errors for each shock value and each collocation vector) in the same number of unknowns (the values of $G_{1}$ for each shock and collocation vector). We use a nonlinear root finder to solve this system of equations.

\section{B.2 Fixed Portfolio Economy}

Relative to the methods described in Krueger and Kubler $(2004,2006)$, there are two additional complications in the present model. The first is that, while the sparse grids used there are subsets of $(I-1)$-dimensional cubes, wealth shares used in this paper are defined on the $(I-2)$ dimensional simplex. We deal with this issue by defining the state space in levels of wealth rather than in shares, and then we map a generation's level of wealth into a share when evaluating the Euler equations. The second complication is that the prices of the assets cannot be read off the first-order conditions in this model ${ }^{41}$ but must instead adjust so that the excess demand for stocks and bonds is zero in both cases. We now describe our algorithm for solving the model.

1 Solve for the steady state prices and wealth levels: $\bar{p}, \bar{q}, \bar{W}=\left(\bar{W}_{2}, \bar{W}_{3}, \ldots, \bar{W}_{l-1}, \bar{W}_{l}\right)$. As described above, we work with an endogenous state space of dimension $I-1$ rather than $I-2$ and then map wealth levels into wealth shares.

2 Create a sparse grid around the steady state wealth distribution. Call this grid $\mathbb{W}$. We verify ex-post that the wealth distribution stays within this hyper-cube along the simulation path.

3 We start with an outer loop over prices (this loop was unnecessary in Krueger and Kubler (2004)). At an outer loop iteration $n$ we have guesses from the previous iteration for Chebyshev coefficients $\left(\alpha_{z}^{p, n}, \alpha_{z}^{q, n}\right)$ for the prices that are used to compute the values of prices $(p, q)$ for each realization of $z$ and each point $W \in \mathbb{W}$ in the endogenous state space. We denote the vector of price values by $\left(\psi_{z, W}^{p, n}, \psi_{z, W}^{q, n}\right)_{W \in \mathbb{W}}$. The Chebyshev coefficients $\left(\alpha_{z}^{p, n}, \alpha_{z}^{q, n}\right)$ also determine the pricing functions on the entire state space, denoted by $\left(\widehat{\psi}_{z}^{p, n}, \widehat{\psi}_{z}^{q, n}\right)$, somewhat abusing notation. ${ }^{42}$

\footnotetext{
${ }^{41}$ One can do this in production economies where factor prices equal marginal productivities

${ }^{42}$ Note that this notation implies $\widehat{\psi}_{z}^{p, n}(W)=\psi_{z, W}^{p, n}$.
} 
4 Given approximate pricing functions in the inner loop, we iterate over household policies. In this loop we generate both the savings policy function and the law of motion for the wealth distribution consistent with approximate price functions $\left(\widehat{\psi}_{z}^{p, n}, \widehat{\psi}_{z}^{q, n}\right)$. The savings policy is indexed by generation and current state $z$, and so the current guess of the savings policy function at policy iteration $m$ when the price iteration is $n$ is determined by Chebyshev coefficients of the form $\left(\alpha_{z, i}^{y, n, m}\right)$. These can be used to compute the optimal savings level at each grid point $W$ and is denoted by $\left(\psi_{z, i, W}^{y, n}\right)$. As in the previous step, the Chebyshev coefficients also determine the entire approximating savings functions $\left(\widehat{\psi}_{z, i}^{y, n}\right)$. The law of motion for wealth is a function of savings, current prices, and future prices; it must therefore be indexed by current state $z$, generation $i$, and future state $z^{\prime}$. Similarly, the Chebyshev coefficients $\left(\alpha_{z, i, z^{\prime}}^{G, n, m}\right)$ are used to compute the law of motion $\left(\psi_{z, i, z^{\prime}, W}^{G, n}\right)$ for all points $\mathbb{W} \in \mathbb{W}$ and to generate the approximating functions $\widehat{\psi}_{z, i, z^{\prime}}^{G, n}$.

5 At this point we loop over each value of $z$ and each point in $W \in \mathbb{W}$ and solve the $I-1$ Euler equations for the $I-1$ optimal savings levels, $y_{i, z}, W$. The Euler equations that we solve to generate the updated savings levels are:

$$
u^{\prime}\left(c_{i}\left(y_{i, z, W} ; W, z\right)\right)=\beta_{i} \mathbb{E}_{z} \widehat{R}_{i}^{n, m}\left(z^{\prime}\right) u^{\prime}\left(\widehat{c}_{i+1}\left(W_{+}\left(z^{\prime}\right), z^{\prime n, m}\right),\right.
$$

where

$$
\begin{gathered}
\widehat{R}_{i}^{n, m}\left(z^{\prime}\right)=\left(\lambda_{i} \frac{\widehat{\psi}_{z^{\prime}}^{p, n}\left(\psi_{z, z^{\prime}, W}^{G, n}\right)+\theta z^{\prime}+\bar{B} \widehat{\psi}_{z^{\prime}}^{q, n}\left(\psi_{z, z^{\prime}, W}^{G, m}\right)-\bar{B}}{\psi_{z, W}^{p, n}}+\frac{\left(1-\lambda_{i}\right)}{\psi_{z, W}^{q, n}}\right) \\
W_{+}\left(z^{\prime}\right)=\left[\begin{array}{c}
W_{+, 2}\left(z^{\prime}\right) \\
\ldots \\
W_{+, I}
\end{array}\right]=\left[\begin{array}{c}
\left(\lambda_{1} \frac{\widehat{\psi}_{z^{\prime}}^{p, n}\left(\psi_{z, z^{\prime}, W}^{G, n, m}\right)+\theta z^{\prime}+\bar{B} \widehat{\psi}_{z^{\prime}}^{q, n}\left(\psi_{z, z^{\prime}, W}^{G, n}\right)-\bar{B}}{\psi_{z, W}^{p, n}}+\frac{\left(1-\lambda_{1}\right)}{\psi_{z, W}^{q, n}}\right) y_{1, z, W} \\
\ldots \\
\left(\lambda_{I-1} \frac{\widehat{\psi}_{z^{\prime}}^{p, n}\left(\psi_{z, z^{\prime}, W}^{G, n, m}\right)+\theta z^{\prime}+\bar{B} \widehat{\psi}_{z^{\prime}}^{q, n}\left(\psi_{z, z^{\prime}, W}^{G, n, m}\right)-\bar{B}}{\psi_{z, W}^{p, n}}+\frac{\left(1-\lambda_{l-1}\right)}{\psi_{z, W}^{q, n}}\right) y_{I-1, z, W}
\end{array}\right]
\end{gathered}
$$




$$
\begin{aligned}
c_{1}\left(y_{1, z} ; W, z\right)= & (1-\theta) z \epsilon_{1}(z)-y_{1, z, W} \\
& \text { for } i=1, \ldots, I-1: \\
c_{i}\left(y_{i, z} ; W, z\right)= & (1-\theta) z \epsilon_{i}(z)+\left(\widehat{\psi}_{z, W}^{p, n}+\theta z+\bar{B} \widehat{\psi}_{z, W}^{q, n}\right) \frac{W_{i}}{\sum_{l=2}^{l} W_{l}}-y_{i, z, W} \\
& \text { for } i=1, \ldots, I-2: \\
\widehat{c}_{i+1}\left(W_{+}\left(z^{\prime}\right), z^{\prime n, m}\right)= & (1-\theta) z \epsilon_{i+1}\left(z^{\prime}\right)+W_{+, i+1}\left(z^{\prime}\right)-\widehat{\psi}_{z^{\prime}, i+1}^{y, n, m}\left(W_{+}\left(z^{\prime}\right)\right) \\
\widehat{c}_{l}\left(W_{+}\left(z^{\prime}\right), z^{\prime n, m}\right)= & (1-\theta) z \epsilon_{I}\left(z^{\prime}\right)+W_{+, I}\left(z^{\prime}\right) .
\end{aligned}
$$

Note that in the calculation of the $c_{i}$ 's, we switch from using wealth levels to using wealth shares to satisfy the requirement that only the latter are truly minimal state variables. This is another difference relative to the previous use of Smolyak polynomials in Krueger and Kubler (2004).

With the new savings in hand, we update the savings policies as $\psi_{z, i, W}^{y, n, m+1}=y_{i, z, W}$. The law of motion for wealth levels is updated via

$$
\psi_{z, i, z^{\prime}, W}^{G, n+1}=\left(\lambda_{i} \frac{\widehat{\psi}_{z^{\prime}}^{p, n}\left(\psi_{z, z^{\prime}, W}^{G, n, m}\right)+\theta z^{\prime}+\bar{B} \widehat{\psi}_{z^{\prime}}^{q, n}\left(\psi_{z, z^{\prime}, W}^{G, n, m}\right)-\bar{B}}{\psi_{z, W}^{p, n}}+\frac{\left(1-\lambda_{i}\right)}{\psi_{z, W}^{q, n}}\right) \psi_{i, z, W}^{y, n, m+1}
$$

6 If $\max _{W \in \mathbb{W}} \max _{z} \max _{z^{\prime}} \max _{i}\left|\psi_{z, i, W}^{y, n, m+1}-\psi_{z, i, W}^{y, n, m}\right|$ is below an acceptable tolerance level, then we proceed to step [7]. Otherwise we return to [4] with the updated savings functions and aggregate law of motion for wealth, but now indexed by step $m+1$. We now generate new Chebyshev coefficients $\alpha_{z, i}^{y, n, m+1}$ by solving the system $\widehat{\psi}_{z, i}^{y, n+m+1}(W)=\psi_{z, i, W}^{y, n, m+1}$ for each $W \in \mathbb{W}$.

7 For each point in the grid $\mathbb{W}$ and each value $z$, we check the market clearing conditions. If:

$$
\max _{W \in \mathbb{W}} \max _{z}\left|\sum_{i=1}^{I-1} \frac{\psi_{z, i, W}^{y, n, m+1} \lambda_{i}}{\psi_{z, W}^{p, n}}-1\right|+\left|\sum_{i=1}^{I-1} \frac{\psi_{z, i, W}^{y, n, m+1}\left(1-\lambda_{i}\right)}{\psi_{z, W}^{q, n}}-\bar{B}\right|
$$

is below an acceptable tolerance level we stop. Otherwise, we update our guess of prices $\psi_{z, W}^{p, n+1}=\sum_{i=1}^{l-1} \lambda_{i} \psi_{z, i, W}^{y, n, m+1}$ and $\psi_{z, W}^{q, n+1}=\sum_{i=1}^{l-1}\left(1-\lambda_{i}\right) \psi_{z, i, W}^{y, n, m+1} / \bar{B}$ and return to step [3]. We now generate new Chebyshev coefficients $\left(\alpha_{z, i}^{p, n+1}, \alpha_{z, i}^{q, n+1}\right.$ by solving $\widehat{\psi}_{z}^{p, n+1}(W)=\psi_{z, W}^{p, n+1}$ and $\widehat{\psi}_{z}^{q, n+1}(W)=\psi_{z, W}^{q, n+1}$ for each value of $z$ and each $W \in \mathbb{W}$. 


\section{B.3 Numerical Accuracy}

The analytical results available for the endogenous portfolio economy, for the case when $\sigma=1$ and the age profile of earnings does not vary with $z$, provide us with a useful test case to assess the numerical accuracy of our computational results. We now compare our numerical results with the theoretical prediction from Proposition 1 in the main text, item by item. We make the following observations from our simulations:

1 The distribution of wealth shares is constant along the simulation. This is shown for the computed model in Table A-1.

Table A-1: Wealth Shares With $\sigma=1$

\begin{tabular}{l|rrrrr}
\hline \hline & $30-39$ & $40-49$ & $50-59$ & $60-69$ & $70-79$ \\
\hline Expansion & $6.1 \%$ & $14.2 \%$ & $25.3 \%$ & $32.2 \%$ & $22.3 \%$ \\
Recession & $6.0 \%$ & $14.2 \%$ & $25.3 \%$ & $32.2 \%$ & $22.3 \%$ \\
\hline \hline
\end{tabular}

2 The bond and stock prices are proportional to $z$. Specifically, $\bar{p}=p(z, \bar{A}) / z=0.505$ and $\bar{q}=q(z, \bar{A}) / z=0.646$ for all $z \in Z$.

3 According to the proposition, with $\sigma=1$ portfolio shares $\lambda_{i}$ are age invariant and equal to $\frac{\bar{p}}{\bar{p}+\bar{B} \bar{q}}$. From point [2] we can calculate $\frac{\bar{p}}{\bar{p}+\bar{B} \bar{q}}=0.918$. We report the computed model's portfolio shares in Table A-2. There is a slight deviation from the theoretical shares, but the computation is accurate within $0.3 \%$.

Table A-2: Portfolio Shares with $\sigma=1$

\begin{tabular}{lllll}
\hline \hline $20-29$ & $30-39$ & $40-49$ & $50-59$ & $60-69$ \\
\hline 0.915 & 0.916 & 0.917 & 0.919 & 0.920 \\
\hline \hline
\end{tabular}

4 The average consumption profiles, normalized by total output $z$ (that is, the consumption shares) along the simulation path are displayed in the first two columns of Table A-3. Note that they are independent of $z$, as the proposition indicates. They are also equal to the theoretical consumption shares characterized by Proposition 1 and displayed in the last column of Table A-3.

5 Verification of part [5] of the proposition is guaranteed since [2] holds. 


\section{Table A-3: Consumption as Fraction of Output}

\begin{tabular}{l|ccc}
\hline \hline Age Group & Expansion & Recession & Theory \\
\hline $20-29$ & $5.33 \%$ & $5.33 \%$ & $5.33 \%$ \\
$30-39$ & $8.92 \%$ & $8.92 \%$ & $8.92 \%$ \\
$40-49$ & $12.51 \%$ & $12.51 \%$ & $12.51 \%$ \\
$50-59$ & $20.55 \%$ & $20.55 \%$ & $20.55 \%$ \\
$60-69$ & $27.96 \%$ & $27.96 \%$ & $27.96 \%$ \\
$70+$ & $24.74 \%$ & $24.74 \%$ & $24.74 \%$ \\
\hline \hline
\end{tabular}

6 The equity premium in theory is $0.162 \%$, given our calibration. Along the simulation, the average equity premium is $0.154 \%{ }^{43}$

\section{Asset Prices in the Representative Agent Economy}

Suppose the representative agent invests an exogenous fraction $\lambda$ of savings in stocks and fraction $1-\lambda$ in bonds. Let $c(z, a)$ and $y(z, a)$ denote optimal consumption and savings as functions of the aggregate shock $z$ and individual start-of-period wealth $a$, and let $p(z)$ and $q(z)$ be the equilibrium prices for stocks and bonds. Note that there is no need to keep track of aggregate wealth as a state: by assumption, the supply of capital is constant and equal to one. Thus, prices can only depend on $z$.

The dynamic programming problem for a household is

$$
\left.v(z, a)=\max _{c \geq 0, y}\left\{u(c)+\beta \sum_{z^{\prime} \in Z} \Gamma_{z, z^{\prime}} v\left(z^{\prime}, a^{\prime}\right)\right)\right\}
$$

subject to

$$
c+y=(1-\theta) z+(p(z)+d(z)+B) a
$$

and the law of motion

$$
a^{\prime}\left[p\left(z^{\prime}\right)+d\left(z^{\prime}\right)+B\right]=\left(\frac{\lambda\left[p\left(z^{\prime}\right)+d\left(z^{\prime}\right)\right]}{p(z)}+\frac{(1-\lambda)}{q(z)}\right) y .
$$

\footnotetext{
${ }^{43}$ It is natural that our errors are larger for prices and portfolios than for consumption because computing these objects requires a second step of approximating prices using the Arrow prices. In particular, the stock price is recursive and is computed iteratively.
} 
The solution to this problem yields decision rules $c(z, a), y(z, a)$ and $a^{\prime}\left(z^{\prime}, y(z, a)\right)$ is the associated value for next period wealth.

Given the preferences and technology described above, the market clearing conditions are simply

$$
\begin{aligned}
\lambda y(z, 1) & =p(z), \\
(1-\lambda) y(z, 1) & =q(z) B \\
c(z, 1) & =z .
\end{aligned}
$$

The individual and aggregate consistency condition is

$$
a^{\prime}\left(z^{\prime}, y(z, 1)\right)=1
$$

Now suppose the process for $z$ is a two-state Markov chain. There are just two equity prices to solve for: $p(z) \in\left\{p\left(z_{l}\right), p\left(z_{h}\right)\right\}$. The two market clearing conditions for stocks and bonds imply a parametric relationship between $q(z)$ and $p(z)$ :

$$
q(z)=\frac{p(z)(1-\lambda)}{\lambda B}
$$

Thus, stock and bond prices must be equally sensitive to aggregate shocks. The realized gross real return to saving is given by

$$
\lambda \frac{\left[p\left(z^{\prime}\right)+d\left(z^{\prime}\right)\right]}{p(z)}+(1-\lambda) \frac{1}{q(z)}=\frac{p\left(z^{\prime}\right)+\lambda \theta z^{\prime}}{p(z)},
$$

where the second equality follows from substituting in $d\left(z^{\prime}\right)=\theta z^{\prime}+q\left(z^{\prime}\right) B-B$ and the expression for $q(z)$, as a function of $p(z)$. Thus, the equilibrium equity prices are defined by the solutions to the two intertemporal first-order conditions:

$$
\begin{aligned}
p\left(z_{h}\right) u^{\prime}\left(c\left(z_{h}, 1\right)\right) & =\beta \sum_{z^{\prime} \in Z} \Gamma_{z_{h}, z^{\prime}}\left[u^{\prime}\left(c\left(z^{\prime}, 1\right)\right)\left[\lambda \theta z^{\prime}+p\left(z^{\prime}\right)\right]\right] \\
p\left(z_{l}\right) u^{\prime}\left(c\left(z_{l}, 1\right)\right) & =\beta \sum_{z^{\prime} \in Z} \Gamma_{z_{l}, z^{\prime}}\left[u\left(c\left(z^{\prime}, 1\right)\right)\left[\lambda \theta z^{\prime}+p\left(z^{\prime}\right)\right]\right]
\end{aligned}
$$

which, using the market clearing condition for consumption and the CRRA preference specification, 
can be written as

$$
\begin{aligned}
p\left(z_{h}\right) z_{h}^{-\sigma} & =\beta \Gamma_{h} z_{h}^{-\sigma}\left[\lambda \theta z_{h}+p\left(z_{h}\right)\right]+\beta\left(1-\Gamma_{h}\right) z_{l}^{-\sigma}\left[\lambda \theta z_{l}+p\left(z_{l}\right)\right] \\
p\left(z_{l}\right) z_{l}^{-\sigma} & =\beta \Gamma_{I} z_{l}^{-\sigma}\left[\lambda \theta z_{l}+p\left(z_{l}\right)\right]+\beta\left(1-\Gamma_{l}\right) z_{h}^{-\sigma}\left[\lambda \theta z_{h}+p\left(z_{h}\right)\right]
\end{aligned}
$$

where $\Gamma_{h}=\Gamma_{z_{h}, z_{h}}$ and $\Gamma_{l}=\Gamma_{z_{l}, z_{l}}$. From the second pricing equation,

$$
p\left(z_{h}\right)=\frac{\beta \Gamma_{h} \lambda \theta z_{h}+\beta\left(1-\Gamma_{h}\right) \frac{z_{l}^{-\sigma}}{z_{h}^{-\sigma}}\left(\lambda \theta z_{l}+p\left(z_{l}\right)\right)}{\left(1-\beta \Gamma_{h}\right)} .
$$

Substituting this into the first pricing equation,

$$
p\left(z_{l}\right)=\frac{\beta \Gamma_{I} z_{l}^{-\sigma} \lambda \theta z_{l}+\beta\left(1-\Gamma_{I}\right) z_{h}^{-\sigma}\left(\lambda \theta z_{h}+\frac{\beta \Gamma_{h} \lambda \theta z_{h}+\beta\left(1-\Gamma_{h}\right) \frac{z_{l}^{-\sigma}}{z_{h}^{-\sigma}} \lambda \theta z_{l}}{\left(1-\beta \Gamma_{h}\right)}\right)}{z_{l}^{-\sigma}\left(\frac{(1-\beta)\left(1+\beta\left(1-\Gamma_{h}-\Gamma_{l}\right)\right)}{\left(1-\beta \Gamma_{h}\right)}\right)} .
$$

Since the expression for $p\left(z_{h}\right)$ is symmetric, we can take the ratio to express the ratio of prices across states as a function of fundamentals:

$$
\frac{p\left(z_{l}\right)}{p\left(z_{h}\right)}=\frac{z_{l}}{z_{h}}\left(\frac{\left(1-\Gamma_{l}\right) z_{h}^{1-\sigma} z_{l}^{\sigma-1}+\left(\beta+\Gamma_{l}-\beta \Gamma_{h}-\beta \Gamma_{l}\right)}{\left(1-\Gamma_{h}\right) z_{l}^{1-\sigma} z_{h}^{\sigma-1}+\left(\beta+\Gamma_{h}-\beta \Gamma_{h}-\beta \Gamma_{l}\right)}\right) .
$$

Note that $\lambda$ and $\theta$ have dropped out here: the ratio of stock prices across states does not depend on either $\lambda$ or $\theta$, though the levels of prices do. If aggregate shocks are iid, then $1-\Gamma_{l}=\Gamma_{h}$ and the expression above simplifies to

$$
\frac{p\left(z_{l}\right)}{p\left(z_{h}\right)}=\left(\frac{z_{l}}{z_{h}}\right)^{\sigma} \text {. }
$$

It is straightforward to verify that the same result is obtained even without the iid assumption in two special cases: $\sigma=1$ or $\beta=1$.

\section{Proof of Proposition 1: Economy with Log Utility}

We will verify that the conjectured expressions for prices and allocations satisfy households' budget constraints, households' intertemporal first-order conditions, and all the market clearing conditions. 
1. Market Clearing Recall that $\sum_{i=1}^{l} \varepsilon_{i}=1, \bar{A}_{1}=0$ and $\sum_{i=1}^{l} \bar{A}_{i}=1$. It is then straightforward to verify that the expressions in Proposition 1 for $\lambda_{i}(z), c_{i}\left(z, \bar{A}, \bar{A}_{i}\right)$, and $y_{i}\left(z, \bar{A}, \bar{A}_{i}\right)$ satisfy the market clearing conditions for goods, stocks, and bonds.

2. Budget Constraints Given identical portfolios across age groups, all households earn the return to saving. Substituting in the candidate expressions for prices (Property 3) and portfolio shares (Property 4), the gross return to saving conditional on productivity being $z_{-1}$ in the previous period and $z$ in the current period is

$$
\begin{aligned}
\frac{\lambda\left(z_{-1}\right)[p(z)+d(z)]}{p\left(z_{-1}\right)}+\frac{1-\lambda\left(z_{-1}\right)}{q\left(z_{-1}\right)} & =\frac{p(z)+d(z)}{z_{-1} \Psi}+\frac{z_{-1} \Psi-p\left(z_{-1}\right)}{z_{-1} \Psi q\left(z_{-1}\right)} \\
& =\frac{p(z)+d(z)}{z_{-1} \Psi}+\frac{B}{z_{-1} \Psi} \\
& =\frac{z(\Psi+\theta)}{z_{-1} \Psi} .
\end{aligned}
$$

Given this expression for returns, consumption for a household of age $i$ is

$$
c_{i}\left(z, \bar{A}, \bar{A}_{i}\right)=(1-\theta) \varepsilon_{i} z+y_{i-1}\left(z_{-1}, \bar{A}, \bar{A}_{i}\right) \frac{z(\Psi+\theta)}{z_{-1} \Psi}-y_{i}\left(z, \bar{A}, \bar{A}_{i}\right)
$$

Substituting in the candidate expression for $y_{i}\left(z, \bar{A}, \bar{A}_{i}\right)$ gives

$$
c_{i}\left(z, \bar{A}, \bar{A}_{i}\right)=z\left[(1-\theta) \varepsilon_{i}+\theta \bar{A}_{i}+\left(\bar{A}_{i}-\bar{A}_{i+1}\right) \Psi\right]
$$

which is the conjectured expression for equilibrium consumption (Property 5). Thus, the conjectured allocations satisfy households' budget constraints.

3. Optimal Savings and Portfolio Choices It remains to verify that agents' intertemporal first-order conditions with respect to stocks and bonds are satisfied. For bonds we have

$$
\frac{q(z)}{c_{i}\left(z, \bar{A}, \bar{A}_{i}\right)}=\beta_{i+1} \sum_{z^{\prime} \in Z} \Gamma_{z, z^{\prime}} \frac{1}{c_{i+1}\left(z^{\prime}, \bar{A}, \bar{A}_{i+1}\right)} \quad \forall i=1, \ldots, l-1 .
$$

Substituting in the expression for consumption,

$$
q(z)=\kappa_{i+1}(\bar{A}) \sum_{z^{\prime} \in Z} \Gamma_{z, z^{\prime}} \frac{z}{z^{\prime}} \quad \forall i=1, \ldots, l-1
$$


where

$$
\kappa_{i+1}(\bar{A})=\beta_{i+1} \frac{(1-\theta) \varepsilon_{i}+\theta \bar{A}_{i}+\left(\bar{A}_{i}-\bar{A}_{i+1}\right) \Psi}{(1-\theta) \varepsilon_{i+1}+\theta \bar{A}_{i+1}+\left(\bar{A}_{i+1}-\bar{A}_{i+2}\right) \Psi} .
$$

For stocks, we have

$$
\begin{aligned}
p(z) & =\kappa_{i+1}(\bar{A}) \sum_{z^{\prime} \in Z} \Gamma_{z, z^{\prime}} \frac{z}{z^{\prime}}\left(p\left(z^{\prime}\right)+\theta z^{\prime}+q\left(z^{\prime}\right) B-B\right) \\
& =\kappa_{i+1}(\bar{A}) \sum_{z^{\prime} \in Z} \Gamma_{z, z^{\prime}}\left(\Psi+\theta-\frac{B}{z^{\prime}}\right) \quad \forall i=1, \ldots, I-1 .
\end{aligned}
$$

Adding the two first-order conditions for stocks and bonds gives

$$
\begin{aligned}
p(z)+q(z) B & =z \Psi=\kappa_{i+1}(\bar{A}) \sum_{z^{\prime} \in Z} \Gamma_{z, z^{\prime}}\left[z\left(\Psi+\theta-\frac{B}{z^{\prime}}\right)+\frac{z}{z^{\prime}} B\right] \\
& =\kappa_{i+1}(\bar{A}) z(\Psi+\theta) \quad \forall i=1, \ldots, l-1
\end{aligned}
$$

This equation is satisfied as long as

$$
\kappa_{i+1}(\bar{A})=\frac{\Psi}{\Psi+\theta}=\frac{1}{R} \quad \forall i=1, \ldots, l-1
$$

Given this expression for $\kappa_{i+1}(\bar{A})$, it is immediate that the expressions for asset prices (Property 3 ) satisfy the households' first-order conditions for stocks and bonds (equations A-15 and $\mathrm{A}-16)$ :

$$
\begin{aligned}
& p(z, \bar{A})=p(z)=z \Psi-B \frac{z}{R} \sum_{z^{\prime} \in Z} \Gamma_{z, z^{\prime}} \frac{1}{z^{\prime}} \\
& q(z, \bar{A})=q(z)=\frac{z}{R} \sum_{z^{\prime} \in Z} \Gamma_{z, z^{\prime}} \frac{1}{z^{\prime}} \quad \forall z .
\end{aligned}
$$

4. Equity Premium We can derive a near-closed-form expression for the equity premium (up to the endogenous value for wealth $\Psi$ ). Let $\Pi_{z}$ denote the unconditional probability of 
aggregate productivity being $z$. The average equity premium is defined as

$$
\begin{aligned}
& \sum_{z} \Pi_{z}\left\{\sum_{z^{\prime}} \Gamma_{z, z^{\prime}}\left[\frac{p\left(z^{\prime}\right)+d\left(z^{\prime}\right)}{p(z)}\right]-\frac{1}{q(z)}\right\} \\
= & \sum_{z} \Pi_{z}\left\{\sum_{z^{\prime}} \Gamma_{z, z^{\prime}}\left[\frac{p\left(z^{\prime}\right)+\theta z^{\prime}+q\left(z^{\prime}\right) B-B}{p(z)}\right]-\frac{1}{q(z)}\right\} \\
= & \sum_{z} \frac{\Pi_{z}}{p(z)}\left\{\sum_{z^{\prime}} \Gamma_{z, z^{\prime}}\left[z^{\prime}(\Psi+\theta)\right]-B-\frac{\sum_{z^{\prime} \in Z} \Gamma_{z, z^{\prime}}\left(\Psi+\theta-\frac{B}{z^{\prime}}\right)}{\sum_{z^{\prime} \in Z} \Gamma_{z, z^{\prime}} \frac{z}{z^{\prime}}}\right\} \\
= & (\Psi+\theta) \sum_{z} \frac{\Pi_{z}}{p(z)}\left\{\sum_{z^{\prime}} \Gamma_{z, z^{\prime}} z^{\prime}-\frac{1}{\sum_{z^{\prime} \in Z} \Gamma_{z, z^{\prime}} \frac{1}{z^{\prime}}}\right\} \\
= & R \sum_{z} \frac{\Pi_{z}}{z}\left\{\frac{\left(\sum_{z^{\prime} \in Z} \Gamma_{z, z^{\prime}} z^{\prime}-\left(\sum_{z^{\prime} \in Z} \Gamma_{z, z^{\prime}} \frac{1}{z^{\prime}}\right)\right.}{\left(1-\frac{B}{R \Psi} \sum_{z^{\prime} \in Z} \Gamma_{z, z^{\prime}} \frac{1}{z^{\prime}}\right)}\right\}
\end{aligned}
$$

, where $R=\frac{(\psi+\theta)}{\psi}$. If $z$ is iid so that $\Gamma_{z, z^{\prime}}$ is equal to the unconditional probability $\Pi_{z^{\prime}}$, this simplifies to

$$
\sum_{z} \Pi_{z}\left\{\sum_{z^{\prime}} \Pi_{z^{\prime}}\left[\frac{p\left(z^{\prime}\right)+d\left(z^{\prime}\right)}{p(z)}\right]-\frac{1}{q(z)}\right\}=R \frac{\left(\sum_{z} \frac{\Pi_{z}}{z} \sum_{z} \Pi_{z} z-1\right)}{\left(1-\frac{B}{R \Psi} \sum_{z} \frac{\Pi_{z}}{z}\right)}
$$

5. Solving for $\Psi$ and $\bar{A} \quad$ Equations (A-17) are the first-order conditions for pricing claims to capital for a nonstochastic life-cycle economy, in which the constant asset price is $\Psi$ and the constant asset income is $\theta$. The $I-1$ equations $(\mathrm{A}-17)$ combined with $\bar{A}_{1}=0$ and the market clearing condition $\sum_{i=1}^{\prime} \bar{A}_{i}=1$ can be used to solve numerically for $\left\{\bar{A}_{i}\right\}_{i=1}^{\prime}$ and $\Psi$. This system of equations is the one used to calibrate the nonstochastic version of our model economy. There we set $\theta$ to replicate a target interest rate $R=(\Psi+\theta) / \Psi$, and we set the life-cycle profile $\left\{\beta_{i}\right\}_{i=2}^{l}$ to replicate the empirical distribution for wealth by age, which determines both the aggregate start-of-period wealth $(\Psi+\theta)$ and its age distribution $\left\{\bar{A}_{i}\right\}_{i=1}^{l}$. 


\section{E Asset Prices in the Two-Period Overlapping-Generations Economy}

Let $\widetilde{p}=\frac{p\left(z_{h}\right)}{p\left(z_{l}\right)}, \widetilde{z}=\frac{z_{h}}{z_{l}}$, and $\widetilde{x}=\frac{z_{l}}{p_{l}}$. In terms of these variables, the intertemporal first-order conditions, conditional on the current state being $z_{l}$ and $z_{h}$ are, respectively,

$$
\begin{aligned}
((1-\theta) \widetilde{x}-1)^{-\sigma} & =\beta \Gamma_{z_{l}, z_{l}}(\theta \widetilde{x}+1)^{1-\sigma}+\beta \Gamma_{z_{l}, z_{h}}(\theta \widetilde{z} \widetilde{x}+\widetilde{p})^{1-\sigma} \\
\widetilde{p}((1-\theta) \widetilde{z} \widetilde{x}-\widetilde{p})^{-\sigma} & =\beta \Gamma_{z_{h}, z_{l}}(\theta \widetilde{x}+1)^{1-\sigma}+\beta \Gamma_{z_{h}, z_{h}}(\theta \widetilde{z} \widetilde{x}+\widetilde{p})^{1-\sigma}
\end{aligned}
$$

Our goal is to solve for $\widetilde{p}$ as a function of $\widetilde{z}$. However, except for the special case $\sigma=1$, this system of equations cannot be solved in closed form. So instead we will linearize these equations and look for an approximate solution for relative prices as a linear function of relative productivity. We proceed as follows:

1. Take first-order Taylor-series approximations to these two first-order conditions around the nonstochastic steady state values for $\widetilde{p}, \widetilde{z}$, and $\widetilde{x}$, which we denote $P, Z$, and $X$ (where $Z=P=1)$. This gives a system of two equations in three first-order terms $(\widetilde{x}-X)$, $(\widetilde{z}-Z)$, and $(\widetilde{p}-P)$ :

$$
\left(\begin{array}{lll}
A_{11} & A_{12} & A_{13} \\
A_{21} & A_{22} & A_{23}
\end{array}\right)\left(\begin{array}{c}
(\widetilde{x}-X) \\
(\widetilde{z}-Z) \\
(\widetilde{p}-P)
\end{array}\right)=\left(\begin{array}{l}
0 \\
0
\end{array}\right)
$$

where

$$
\begin{aligned}
A_{11}= & -\sigma((1-\theta) X-1)^{-\sigma-1}(1-\theta)- \\
& \left((1-\sigma) \beta \Gamma_{z_{l}, z_{l}}(\theta X+1)^{-\sigma} \theta+(1-\sigma) \beta \Gamma_{z_{l}, z_{h}}(\theta X+1)^{-\sigma} \theta\right) \\
A_{12}= & -(1-\sigma) \beta \Gamma_{z_{l}, z_{h}}(\theta X+1)^{-\sigma} \theta X \\
A_{13}= & -(1-\sigma) \beta \Gamma_{z_{l}, z_{h}}(\theta X+1)^{-\sigma} \\
A_{21}= & -\sigma((1-\theta) X-1)^{-\sigma-1}(1-\theta)- \\
& \quad\left((1-\sigma) \beta \Gamma_{z_{h}, z_{l}}(\theta X+1)^{-\sigma} \theta+(1-\sigma) \beta \Gamma_{z_{h}, z_{h}}(\theta X+1)^{-\sigma} \theta\right) \\
A_{22}= & -\sigma((1-\theta) X-1)^{-\sigma-1}(1-\theta) X-(1-\sigma) \beta \Gamma_{z_{h}, z_{h}}(\theta X+1)^{-\sigma} \theta X \\
A_{23}= & \sigma((1-\theta) X-1)^{-\sigma-1}+((1-\theta) X-P)^{-\sigma}-(1-\sigma) \beta \Gamma_{z_{H}, z_{H}}(\theta X+1)^{-\sigma .} .
\end{aligned}
$$


2. Use the first equation in $A-18$ to solve for $(\widetilde{x}-X)$ as a linear function of $(\widetilde{z}-Z)$ and $(\widetilde{p}-P)$ :

$$
(\widetilde{x}-X)=-\frac{A_{12}}{A_{11}}(\widetilde{z}-Z)-\frac{A_{13}}{A_{11}}(\widetilde{p}-P) .
$$

Then substitute this solution into the second equation in (A-18), and solve for $(\widetilde{p}-P)$ as a function of $(\widetilde{z}-Z)$ :

$$
\begin{aligned}
(\widetilde{p}-P) & =-\frac{A_{21}}{A_{23}}(\widetilde{x}-X)-\frac{A_{22}}{A_{23}}(\widetilde{z}-Z) \\
& =-\frac{A_{21}}{A_{23}}\left(-\frac{A_{12}}{A_{11}}(\widetilde{z}-Z)-\frac{A_{13}}{A_{11}}(\widetilde{p}-P)\right)-\frac{A_{22}}{A_{23}}(\widetilde{z}-Z) .
\end{aligned}
$$

Thus,

$$
\xi^{2 p} \approx \frac{\widetilde{p}-P}{\widetilde{z}-Z}=\frac{A_{21} A_{12}-A_{22} A_{11}}{A_{23} A_{11}-A_{21} A_{13}} .
$$

3. Now assume productivity shocks are iid, so that $\Gamma_{z_{1}, z_{h}}=\Gamma_{z_{h}, z_{h}}=\Gamma_{z_{h}}$ and $\Gamma_{z_{1}, z_{l}}=\Gamma_{z_{h}, z_{l}}=$ $1-\Gamma_{z_{h}}$. Under this iid assumption, $A_{11}=A_{21}$ and thus

$$
\xi^{2 p} \approx \frac{A_{21} A_{12}-A_{22} A_{21}}{A_{23} A_{11}-A_{21} A_{13}}=\frac{A_{12}-A_{22}}{A_{23}-A_{13}}=X \frac{\sigma(1-\theta)}{((X-X \theta-1)+\sigma)}
$$

Recall that $X$ is the inverse of the steady state stock price, so we can equivalently write this elasticity in terms of the steady state gross interest rate $R$, where $R=\theta X+1$ :

$$
\xi^{2 p} \approx \frac{\sigma(1-\theta)}{1-\theta \frac{(R-\sigma)}{(R-1)}}
$$

This is the expression given in the text. Note that for $\sigma=1, \xi^{2 p}=1$.

4. We want to show that $1<\xi^{2 p}<\xi^{R A}$ for $\sigma>1$. First, note that in any equilibrium, a positive stock price implies $R>1$. Then

$$
\frac{1}{\xi^{2 p}}=\frac{1-\theta \frac{(R-\sigma)}{(R-1)}}{\sigma(1-\theta)}=\frac{1}{\sigma}\left(1+\frac{(\sigma-1) \frac{\theta}{R-1}}{(1-\theta)}\right)>\frac{1}{\sigma}=\frac{1}{\xi^{R A}} .
$$

Thus, $\xi^{2 p}<\xi^{R A}$. 
Given that $\xi^{2 p}=1$ when $\sigma=1$, showing that $\xi^{2 p}$ is strictly increasing in $\sigma$ is sufficient to prove that $\xi^{2 p}>1$ :

$$
\frac{\partial}{\partial \sigma}\left(\frac{\sigma(1-\theta)}{1-\theta \frac{(R-\sigma)}{(R-1)}}\right)=(\theta-1)(R-1) \frac{R \theta-R+1}{(R-R \theta+\theta \sigma-1)^{2}}
$$

It follows that $\xi^{2 p}$ is strictly increasing in $\sigma$ if and only if $R>\frac{1}{1-\theta}$. But in any equilibrium, positive consumption for the young requires exactly this condition:

$$
(1-\theta)-\frac{\theta}{R-1}>0 \Leftrightarrow R>\frac{1}{1-\theta}
$$

We conclude that $\xi^{2 p}>1$.

5. In the special case in which $\theta$ is such that $R=\frac{1}{\beta}$, the expression for $\xi^{2 p}$ simplifies further. The steady state value for $R$ is an endogenous variable and has to satisfy the steady state version of the intertemporal first-order condition, where the steady state stock price is $\theta /(R-1)$ :

$$
\frac{\theta}{R-1}\left((1-\theta)-\frac{\theta}{R-1}\right)^{-\sigma}=\beta\left(\theta+\frac{\theta}{R-1}\right)^{-\sigma}\left(\theta+\frac{\theta}{R-1}\right) .
$$

When $\beta=\frac{1}{R}$, equation (A-20) can be solved in closed form to give $R=\frac{1}{1-2 \theta}$. Thus, we have $R=\frac{1}{\beta}=\frac{1}{1-2 \theta}$, which implies $\theta=\frac{1}{2}(1-\beta)$. Substituting $R=\frac{1}{\beta}$ and $\theta=\frac{1}{2}(1-\beta)$ into equation (A-19) gives

$$
\xi^{2 p} \approx \frac{\sigma(1-\theta)}{1-\theta \frac{(R-\sigma)}{(R-1)}}=\frac{\sigma(\beta+1)}{\sigma \beta+1}
$$

which is the expression for this special case given in footnote 16 .

\section{F Proof of Proposition 2: Economy with Housing}

We begin by describing the decision problem in the model with housing. In a series of steps, we will then show that this problem is isomorphic to the decision problem in the model without housing.

Let $y_{i}(z, A, a)$ and $\lambda_{i}^{e}(z, A, a), \lambda_{i}^{h}(z, A, a)$ denote the optimal household policy functions for total savings and for the fraction of savings invested in equity and housing. Let $c_{i}(z, A, a), s_{i}(z, A, a)$, and $a_{i}^{\prime}\left(z, A, a, z^{\prime}\right)$ denote the policy functions for nondurable consumption, housing consumption, 
and for shares of next period wealth. Let $p^{c}(z, A), p^{h}(z, A), p(z, A), q(z, A)$, and $r(z, A)$ denote, respectively, the price of the nondurable consumption good, the price of housing, the price of stocks, the price of bonds, and the rental rate for housing, all relative to the composite good $x$. The dynamic programming problem of the household reads as

$$
\begin{aligned}
v_{i}(z, A, a)=\max _{c, y, \lambda^{e}, \lambda^{h}, a^{\prime}}\left\{u(c, s)+\beta_{i+1} \sum_{z^{\prime} \in Z} \Gamma_{z, z^{\prime}} v_{i+1}\left(z^{\prime}, A^{\prime}, a^{\prime}\right)\right\} \text { s.t. } \\
p^{c}(z, A) c+y+r(z, A) s=\varepsilon_{i}(z) w(z)+W(z, A) a \\
a^{\prime}=\frac{\left(\lambda^{e} \frac{\left[p\left(z^{\prime}, A^{\prime}\right)+d\left(z^{\prime}\right)\right]}{p(z, A)}+\lambda^{h} \frac{\left[p^{h}\left(z^{\prime}, A^{\prime}\right)+r\left(z^{\prime}, A^{\prime}\right)\right]}{p^{h}(z, A)}+\left(1-\lambda^{e}-\lambda^{h}\right) \frac{1}{q(z, A)}\right) y}{W\left(z^{\prime}, A^{\prime}\right)} \quad(\mathrm{A}-22) \\
A^{\prime}=G\left(z, A, z^{\prime}\right) .
\end{aligned}
$$

The aggregate value of start-of-period wealth in the model with housing is the value of aggregate payments to asset holders in the period $d(z)+r(z, A)+B$, plus the ex-dividend value of equity and housing $p(z, A)+p^{h}(z, A)$. Thus,

$$
W\left(z^{\prime}, A^{\prime}\right)=p\left(z^{\prime}, A^{\prime}\right)+d\left(z^{\prime}\right)+p^{h}\left(z^{\prime}, A^{\prime}\right)+r\left(z^{\prime}, A^{\prime}\right)+B
$$

A recursive competitive equilibrium can be defined as in the baseline model.

1. RESUlt ON RENTS: The agent's first-order condition with respect to the consumption of housing services implies

$$
s_{i}\left(z, A, A_{i}\right)=\frac{(1-v)}{v r(z, A)} c_{i}\left(z, A, A_{i}\right) p^{c}(z, A) .
$$

Summing across age-groups,

$$
\sum_{i=1}^{I} s_{i}\left(z, A, A_{i}\right)=\frac{(1-v) p^{c}(z, A)}{v r(z, A)} \sum_{i=1}^{I} c_{i}\left(z, A, A_{i}\right)
$$

Imposing market clearing gives

$$
r(z, A)=\frac{(1-v)}{v} p^{c}(z, A) z .
$$


Let $e$ denote total expenditure in units of the composite good:

$$
e_{i}\left(z, A, A_{i}\right)=p_{c}(z, A) c_{i}\left(z, A, A_{i}\right)+r(z, A) s_{i}\left(z, A, A_{i}\right) .
$$

Substituting in A-25 gives

$$
e_{i}\left(z, A, A_{i}\right)=\frac{1}{v} p_{c}(z, A) c_{i}\left(z, A, A_{i}\right) .
$$

Define aggregate consumption/output as

$$
X(z, A)=\sum_{i} x_{i}\left(z, A, A_{i}\right)
$$

In equilibrium

$$
\begin{aligned}
x_{i}\left(z, A, A_{i}\right) & =c_{i}\left(z, A, A_{i}\right)^{v}\left(\frac{(1-v)}{v r(z, A)} c_{i}\left(z, A, A_{i}\right) p^{c}(z, A)\right)^{1-v} \\
& =c_{i}\left(z, A, A_{i}\right) z^{v-1}
\end{aligned}
$$

so aggregate composite consumption (aggregate output) is

$$
\begin{aligned}
X(z, A) & =\sum_{i} x_{i}\left(z, A, A_{i}\right) \\
& =z^{v-1} \sum_{i} c_{i}\left(z, A, A_{i}\right) \\
& =z^{v} .
\end{aligned}
$$

Solve for $p^{c}(z, A)$ by setting the value of aggregate composite consumption equal to aggregate expenditure (recall $p^{\times}(z, A)$ is normalized to one):

$$
\begin{aligned}
z^{v} & =\sum_{i} e_{i}\left(z, A, A_{i}\right) \\
& =\frac{1}{v} p_{c}(z, A) z .
\end{aligned}
$$

Thus,

$$
p^{c}(z, A)=v z^{v-1} .
$$


It follows that

$$
r(z, A)=\frac{(1-v)}{v} z p^{c}(z, A)=(1-v) z^{v}
$$

2. Result on House Prices: Recall that the numeraire here is the composite consumption good. Thus, dividends are given by

$$
\begin{aligned}
d(z, A) & =p^{c}(z, A) \theta z-B+q(z, A) B \\
& =v \theta z^{v}-B+q(z, A) B .
\end{aligned}
$$

where the second line follows from equation (A-29). Consider the following two assets: a claim to aggregate capital income (unlevered equity) and housing. The respective returns to the two assets are

$$
\begin{aligned}
\frac{p\left(z^{\prime}, A^{\prime}\right)+d\left(z^{\prime}, A^{\prime}\right)+B}{p^{u}(z, A)} & =\frac{p^{u}\left(z^{\prime}, A^{\prime}\right)+v \theta\left(z^{\prime}\right)^{v}}{p^{u}(z, A)} \\
\frac{p^{h}\left(z^{\prime}, A^{\prime}\right)+r\left(z^{\prime}, A^{\prime}\right)}{p^{h}(z . A)} & =\frac{p^{h}\left(z^{\prime}, A^{\prime}\right)+(1-v)\left(z^{\prime}\right)^{v}}{p^{h}(z . A)} .
\end{aligned}
$$

Note that the income streams associated with these two assets are in fixed proportions. It follows immediately that

$$
p^{h}(z . A)=\frac{(1-v)}{v \theta} p^{u}(z, A)
$$

3. Result on Portfolio Choice: Given that the return to housing is equal to the return to unlevered equity, we can write the law of motion for individual wealth as

$$
\begin{aligned}
a^{\prime} W\left(z^{\prime}, A^{\prime}\right) & =\left(\lambda^{e} \frac{\left[p\left(z^{\prime}, A^{\prime}\right)+d\left(z^{\prime}\right)\right]}{p(z, A)}+\lambda^{h} \frac{\left[p\left(z^{\prime}, A^{\prime}\right)+d\left(z^{\prime}\right)+B\right]}{p(z, A)+q(z, A) B}+\left(1-\lambda^{e}-\lambda^{h}\right) \frac{1}{q(z, A)}\right) y \\
& =\left(\left(\lambda^{e}+\frac{\lambda^{h} p(z, A)}{p(z, A)+q(z, A) B}\right) \frac{\left[p\left(z^{\prime}, A^{\prime}\right)+d\left(z^{\prime}\right)\right]}{p(z, A)}+\left(\left(1-\lambda^{e}-\lambda^{h}\right)+\frac{\lambda^{h} q(z, A) B}{p(z, A)+q(z, A)}\right.\right. \\
& =\left(\tilde{\lambda} \frac{\left[p\left(z^{\prime}, A^{\prime}\right)+d\left(z^{\prime}\right)\right]}{p(z, A)}+(1-\tilde{\lambda}) \frac{1}{q(z, A)}\right) y
\end{aligned}
$$

where

$$
\widetilde{\lambda}=\lambda^{e}+\frac{\lambda^{h} p(z, A)}{p(z, A)+q(z, A) B} .
$$


Note that (i) there is no reference to house prices or rents in this law of motion, and (ii) there is only one meaningful portfolio choice for agents, given that the return to housing is a linear combination of the returns to equity debt.

4. Expression for Aggregate Wealth: Aggregate wealth can be written as

$$
\begin{aligned}
W(z, A) & =p(z, A)+d(z)+p^{h}(z, A)+r(z, A)+B \\
& =p(z, A)+q(z, A) B+p^{h}(z, A)+v \theta z^{v}+(1-v) z^{v} \\
& =p(z, A)+q(z, A) B+\frac{(1-v)}{v \theta}(p(z, A)+q(z, A) B)+(v \theta+1-v) z^{v} .
\end{aligned}
$$

Define

$$
\begin{aligned}
\tilde{p}(z, A) & =\left(1+\frac{(1-v)}{v \theta}\right) p(z, A) \\
\tilde{B} & =\left(1+\frac{(1-v)}{v \theta}\right) B \\
\tilde{d}(z, A) & =\left(1+\frac{(1-v)}{v \theta}\right) v \theta z^{v}-\tilde{B}+q(z, A) \tilde{B} .
\end{aligned}
$$

In terms of this notation, aggregate wealth is given by

$$
W(z, A)=\tilde{p}(z, A)+q(z, A) \tilde{B}+\left(1+\frac{(1-v)}{v \theta}\right) v \theta z^{v} .
$$

5. Final Household Problem: We can now write the agent's problem without any reference to housing as

$$
v_{i}(z, A, a)=\max _{c, y, \widetilde{\lambda}, a^{\prime}}\left\{\frac{x^{1-\gamma}}{1-\gamma}+\beta_{i+1} \sum_{z^{\prime} \in Z} \Gamma_{z, z^{\prime}} v_{i+1}\left(z^{\prime}, A^{\prime}, a^{\prime}\right)\right\}
$$

subject to

$$
\begin{aligned}
& x+y=\varepsilon_{i}(z)(1-\theta) v z^{v}+W(z, A) a \\
& a^{\prime}=\frac{\left(\tilde{\lambda} \frac{\left[\tilde{p}\left(z^{\prime}, A^{\prime}\right)+\left(1+\frac{(1-v)}{v \theta}\right) v \theta\left(z^{\prime}\right)^{v}-\tilde{B}+q\left(z^{\prime}, A^{\prime}\right) \tilde{B}\right]}{\tilde{p}(z, A)}+(1-\tilde{\lambda}) \frac{1}{q(z, A)}\right) y}{W\left(z^{\prime}, A^{\prime}\right)},
\end{aligned}
$$

taking as given laws of motion for $z$ and $A$, and where $W\left(z^{\prime}, A^{\prime}\right)$ is given by $A-30$. It is 
clear that this model is identical to the model without housing defined in the text, as long as parameter values in the model without housing are the following functions of parameters in the model with housing, where the latter are now denoted with superscript $H$ :

$$
\begin{aligned}
1-\theta & =\left(1-\theta^{H}\right) v^{H} \\
z & =\left(z^{H}\right)^{v} \\
B & =\left(1+\frac{\left(1-v^{H}\right)}{v^{H} \theta^{H}}\right) B^{H} .
\end{aligned}
$$

\begin{tabular}{|c|c|c|c|c|c|c|c|c|c|c|c|c|}
\hline \multirow[b]{2}{*}{ PRICE SERIES USED } & \multicolumn{4}{|c|}{2008} & \multicolumn{4}{|c|}{2009} & \multicolumn{4}{|c|}{2010} \\
\hline & Q1 & Q2 & Q3 & Q4 & Q1 & Q2 & Q3 & Q4 & Q1 & Q2 & Q3 & Q4 \\
\hline Stocks (Wilshire 5000) & -12.4 & -14.2 & -22.0 & -40.3 & -46.9 & -38.4 & -28.6 & -24.7 & -20.5 & -29.7 & -22.1 & -13.5 \\
\hline Res. Real Estate (Case-Shiller) & -13.0 & -14.9 & -17.8 & -23.9 & -29.5 & -27.3 & -24.9 & -25.8 & -27.9 & -24.5 & -25.9 & -28.8 \\
\hline Noncorp. Bus. (FoF) & -4.2 & -8.0 & -10.6 & -17.6 & -22.2 & -25.0 & -25.4 & -27.9 & -26.5 & -25.0 & -26.0 & -25.5 \\
\hline Nonres. Property (Moody's) & -0.2 & -9.6 & -7.1 & -14.3 & -20.9 & -33.9 & -41.5 & -39.3 & -40.6 & -39.9 & -41.3 & -40.6 \\
\hline Household Net Worth & -10.4 & -12.7 & -16.7 & -26.2 & -31.7 & -29.0 & -25.2 & -24.7 & -24.3 & -25.3 & -23.8 & -22.5 \\
\hline ALTERNATIVE SERIES & & & & & & & & & & & & \\
\hline Stocks (FoF)* & -9.9 & -13.1 & -22.8 & -39.3 & -47.7 & -38.3 & -27.8 & -25.4 & -21.6 & -31.4 & -22.6 & -12.8 \\
\hline Real Estate (FoF) ${ }^{* *}$ & -9.1 & -13.2 & -16.8 & -21.8 & -26.3 & -26.2 & -25.6 & -25.7 & -25.0 & -24.6 & -27.2 & -28.2 \\
\hline Real Estate (OFHEO) ${ }^{* * *}$ & -5.3 & -5.8 & -9.0 & -12.6 & -12.1 & -10.7 & -12.1 & -14.3 & -14.6 & -12.9 & -15.5 & -17.2 \\
\hline
\end{tabular}

\section{G Additional Tables}

Table A-4: Price Declines Relative to 2007:2 by Risky Asset Class

*The Flow of Funds reports price changes for directly held corporate equities: this series aligns closely with the Wilshire 5000 index.

**The Flow of Funds also reports a price series for residential real estate, based on the Loan Performance Index from First American Corelogic. This series closely tracks the Case-Shiller series. *** The house price series published by OFHEO (based on data from Fannie Mae and Freddie Mac) shows significantly smaller declines in house values.

Table A-5: Wealth-Based Welfare Gain from Recession

\begin{tabular}{l|cccc}
\hline \hline & \multicolumn{4}{|c}{ Economy } \\
\hline Cohort & End Asym & Ex Asym & End Sym & Ex Sym \\
\hline $20-29$ & $-2.98 \%$ & $-2.64 \%$ & $-0.63 \%$ & $-0.91 \%$ \\
$30-39$ & $-4.78 \%$ & $-5.73 \%$ & $-5.40 \%$ & $-4.66 \%$ \\
$40-49$ & $-6.70 \%$ & $-4.11 \%$ & $-7.24 \%$ & $-4.36 \%$ \\
$50-59$ & $-10.87 \%$ & $-9.04 \%$ & $-11.29 \%$ & $-8.19 \%$ \\
$60-69$ & $-14.47 \%$ & $-12.37 \%$ & $-14.76 \%$ & $-15.21 \%$ \\
$70+$ & $-12.34 \%$ & $-14.69 \%$ & $-12.46 \%$ & $-16.53 \%$ \\
\hline \hline
\end{tabular}

